HERP,

QL

666 IE UNIVERSITY OF KANSAS

- L223 IUSEUM OF NATURAL HISTORY

W2

1991

\title{
Altitudinal Ecology of Agama tuberculata Gray in the Western Himalayas
}

\author{
Robert C. Waltner
}





\title{
The University of Kansas \\ Museum of Natural History
}

Miscellaneous Publication No. 83

20 February 1991

\section{Altitudinal Ecology of Agama tuberculata Gray in the Western Himalayas}

\author{
ROBERT C. WALTNER \\ Taipei American School \\ 800 Chung Shan North Road Section 6, Shihlan District 11135 \\ Taipei, Taiwan, Republic of China
}

Museum of Natural History

Dyche HaLl

THE UnIVERSITY of Kansas

LaWrence, Kansas 


\section{MISCELLANEOUS PUBLICATIONS}

Editors: Robert M. Mengel and Richard F. Johnston

Managing Editor: Joseph T. Collins

Design and Typesetting: Kate A. Shaw and Joseph T. Collins

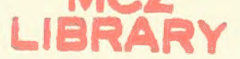

\section{MAR 131991 \\ HARVARD \\ UNIVERSITY}

Miscellaneous Publication No. 83

Pp. 1-74; 38 figures; 24 tables

Published 20 February 1991

ISBN: 0-89338-036-9

(C) 1991 by Museum of Natural History

Dyche Hall

The University of Kansas

LAWRENCE, Kansas 66045-2454, USA 


\section{CONTENTS}

INTRODUCTION AND BACKGROUND

ACKNOWLEDGMENTS

LOCATION AND DESCRIPTION OF STUDY AREAS

Soils

Climate

Vegetation

METHODS

MORPHOLOGY

Description of the Species

Maximum Size

Proportions and Sexual Dimorphism

GROWTH

Comparison of the Two Altitudes

FOOD HABITS

Qualitative Considerations

Quantitative Considerations

DAILY AND SEASONAL ACTIVITY

Comparison of the Two Altitudes

TEMPERATURE.

Comparison of the Two Altitudes

REPRODUCTION

Comparison of the Two Altitudes and Discussion

DISPLAY BEHAVIOR

Categories Used in Analysis

HOME RANGE AND TERRITORY

Movement and Behavior

Size of Territory and Home Range

Biomass

Estimate of Numbers

Survivorship

Reproductive and Life History Strategy 



\section{INTRODUCTION AND BACKGROUND}

The common rock lizard (Agama tuberculata) is one of the most abundant lizards of the western Himalayas. Its brilliant colors, moderate size, and territorial activities make it a conspicuous species. It was first reported in the literature 150 years ago (Hardwicke and Gray, 1827). Subsequent references to it generally have been limited to morphological descriptions (Duda, 1962, 1965a, 1965b; Das and Duda, 1964; Raina and Duda, 1967; Duda and Kaul, 1976) and brief notes of its habits (Stoliczka, 1872; Boulenger, 1890; Dodsworth, 1913; Minton, 1966). A few studies have cited aspects of its ecology (Bhatnagar, 1967, 1968; Koul and Duda, 1977).

The agamids are a large and diverse family of Old World lizards exhibiting parallels in adaptive types to many of the New World iguanids. The range of Agama includes Africa, southeastern Europe, and southwestern Asia (Smith, 1935). Except for A. minor; the genus is restricted to the northern and northwestern region of the Indian subcontinent. These northern and northwestern species fall into two groups (Smith, 1935; Minton, 1966): 1) medium-sized, ground-dwelling species with a small, deeply recessed tympanum, short toes, caudal scales not forming whorls, and enlarged dorsal scales irregularly scattered or lacking, and 2) larger-sized, rock-inhabiting, montane species with a large, superficial tympanum, long toes, caudal scales in whorls, and enlarged, dorsal scales in longitudinal or oblique rows. Agama tuberculata, belonging to the latter group, is largely confined to the western Himalayas (Fig. 1). Altitudinally, it ranges from the base of the Himalayas (690 m near Dehra Dun) to $4650 \mathrm{~m}$ (Gunther, 1860). Few reptiles have a greater altitudinal distribution.

Reports consistently mention A. tuberculata as being found in rocky areas (Gunther, 1860; Dodsworth, 1913; Parshad, 1914) and my own experience confirms this habitat preference. I have seen it on buildings with cracks in the walls and under the eaves or spaces between slate slabs on roofs providing the same type of refuges as are found among loose rocks. Gruber (1981) states that A. tuberculata is replaced by A. himalayana in the drier parts of the northern Himalayas in Kashmir and Ladakh. My observations suggest that the apparent preference of $A$. tuberculata for a riparian habitat (Bhatnagar, 1967) at low altitude is due to the abundance of cracks and fissures in the exposed rocks bordering streams. The lizards retire into these cracks during their period of semi-inactivity in winter.

The topic of altitudinal comparisons was prompted by studies of Ray (1960) and Lindsey (1966) who found latitudinal trends in body size among poikilotherm vertebrates, by McCoy and Hoddenbach (1966) who reported on geographic variation in the reproductive cycle of the female in the lizard Cnemidophorus tigris, and by Pianka (1970) who compared the ecology of C. tigris in various geographic locations. At the time my project was initiated, I was aware of only two European herpetological studies which had dealt specifically with altitudinal trends: on the frog Rana temporaria (Kozlowska, 1971) and the lacertid lizard Lacerta muralis (Saint Girons and Duguy, 1970). This study encompassed comparisons of morphology, growth, food habits, daily and seasonal activity, temperature, display behavior, home range, territory, and biomass and numbers between high and low altitude populations. Subsequent to my field work, a number of altitudinal studies have been reported, including studies on Sceloporus occidentalis (Goldberg, 1974; Jameson and Allison. 1976; Jameson et al., 1980), S. jarrovi (Ballinger, 1979; Ballinger and Ballinger, 1979; Ruby and Dunham, 1984), Anolis cybotes (Hertz and Huey, 1981), A. roquet and A. gundlachi (Hertz, 1981), Barisia imbricata (Guillette and Casas-Andreu, 1987), Liolaemus sp. (Fuentes and Jaksic, 1979), Cnemidophorus inornatus (Stevens, 1983), C.tigris (Goldberg, 1976), and Lacerta vipipara (Heulin, 1985). 


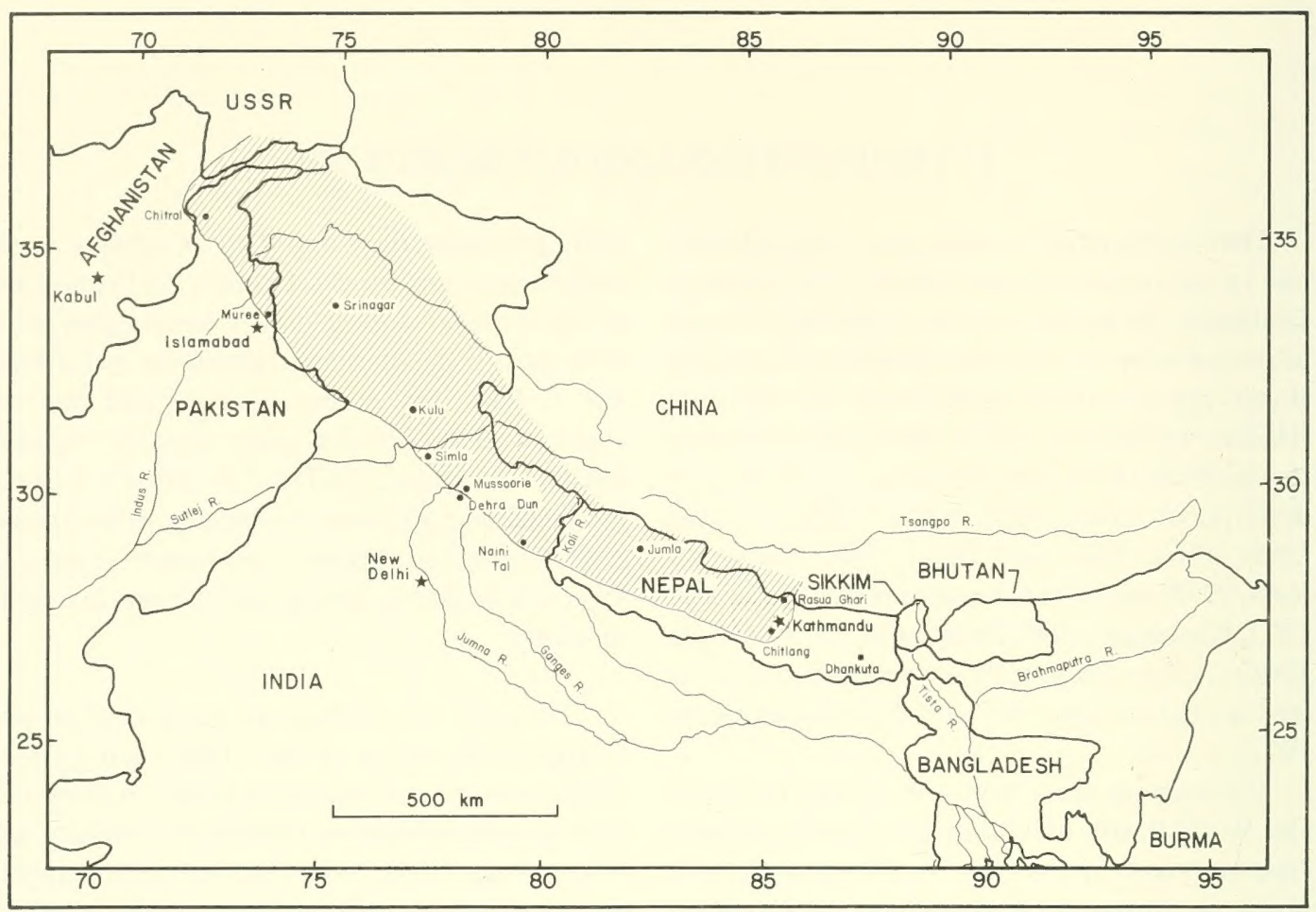

Fig. 1. Map showing study sites at Mussoorie and Dehra Dun in relationship to geographic range of Agama tuberculata.

\section{ACKNOWLEDGMENTS}

Many people assisted in the location and capture of lizards: R. K. Bhatnagar, R. N. Misra, David Fiol, Beer Singh, Nirmal Sherring, Scott Bunce, Fali Kapadia, Gordon Claassen, S. A. Hussain and Pat Louis. Superintendent Robert Alter allowed me to room and board at Woodstock School, Mussoorie where teachers (particularly Vic Reimer) and students were helpful. Austin Taylor and R. K. Bhatnagar's brother-in-law provided a base of operations in Dehra Dun.

I thank Henry S. Fitch for encouraging me and making helpful suggestions during all phases of this study and for carefully criticizing the manuscript. I am grateful to Robert S. Hoffman, Dwight
R. Platt, Linda Trueb, and Harriet Hill for suggestions and comments regarding the manuscript and text figures. Gunther Schlager and Norman A. Slade advised me on statistical procedures, however, any errors or misinterpretations are my responsibility. I thank Philip S. Humphrey, Director, Museum of Natural History, The University of Kansas, for access to funds for part of the field work. Dan Bergen and Paul McConaughy helped with photographic matters.

Finally, I thank my wife Barbara for bearing our parental responsibilities while I was in India and as a constant source of encouragement and perseverance. 


\section{LOCATION AND DESCRIPTION OF STUDY AREAS}

The study areas were located in and near Mussoorie and Dehra Dun in the northern portion of the state of Uttar Pradesh, India (Figs. 1, 2). Mussoorie lies at an elevation of $2215 \mathrm{~m}\left(30^{\circ} 19^{\prime} \mathrm{N}\right.$ and $\left.78^{\circ} 05^{\prime} \mathrm{E}\right)$ on the southern exposure of the Mahabarat range (Krishnan, 1960; Gupta, 1967) of the Kumaon Himalayas (Wadia, 1953). The town is known as "the queen of the hill stations" and is situated on a ridge which gives a view of the great Himalayas to the north as well as the Dun Valley, Siwalik range, and Gangetic plain to the south. Dehra Dun is situated in the middle of the Dun Valley of the Siwalik range at an elevation of 680 $\mathrm{m}\left(30^{\circ} 19^{\prime} \mathrm{N}\right.$ and $\left.78^{\circ} 02^{\prime} \mathrm{E}\right)$ approximately $16 \mathrm{~km}$ to the south (about $30 \mathrm{~km}$ by road) of Mussoorie. New Delhi is approximately $200 \mathrm{~km}$ to the southwest of Dehra Dun.

The high altitude study area $(2165 \mathrm{~m})$ was situated $1 \mathrm{~km}$ east and $1 \mathrm{~km}$ north of Dhanaulti which in turn is on the Mussoorie-Tehri motor road $16 \mathrm{~km}$ east and $3 \mathrm{~km}$ south of Mussoorie. The study area was bisected by a little-traveled road which joined the Mussoorie-Tehri road $1 \mathrm{~km}$ southeast of Dhanaulti. The southwest-facing slope of the mountain was an open woodland of Quercus incana and Pinus roxburghii disturbed by grazing, grass cutting, and lopping of trees and shrubs. Lizards were most abundant along the road because of the numerous crevices provided by the unmortared rocks.

The low altitude study area $(690 \mathrm{~m})$ was immediately north of Keserwala along the west bank of the Song River $7 \mathrm{~km}$ east and $2 \mathrm{~km}$ north of Dehra Dun. The sal forest bordering the river was severely disturbed by humans. Rock exposures along the base of the hill had many crevices which provided roosting sites and refuges for A. tuberculata. Extending from the hill out into the valley were a number of breakwaters which protected the irrigation tunnel from erosion damage by the river during the monsoons. Except during winter, $A$. tuberculata were also found along these breakwaters. The lizards did not normally venture out more than $20 \mathrm{~m}$ into the flat valley or up the hillside.
Lizards at both sites were conditioned to human activity and could be approached to within a few meters.

\section{SoILS}

The soils of the Himalayas are more or less immature and thereby differ basically from most of the soils of the Indian peninsula (Champion and Seth, 1968). The most common soils are of the brown forest type. Other types include podsols and gleys (Puri, 1960).

Around Mussoorie, the soils are principally of two types - one on limestone and the other on quartzite and shale. On the limestone areas, a fairly deep loamy soil with good amounts of humus is found in the valleys in contrast to a thin soil with little or no humus on ridges or spurs. On quartzite and shale, the soil is thin and poor, but if the $\mathrm{C}$ horizon is sufficiently broken up, a good growth of trees is possible (Gupta, 1967).

In the Dun Valley, Dakshini (1965) reports that the ridges and slopes have a dry, gravelly soil with a $\mathrm{pH}$ of 5.0-5.6. Soils along stream beds are low in nitrogen and phosphorous. During the hot season, large amounts of dissolved calcium salts in the water may be deposited in thick layers (Gupta, 1967).

\section{Climate}

The year in the western Himalayas may be divided into four seasons. The monsoons (late June-late September) have moderate to high temperature with abundant rain and high humidity. The sky is sunny during autumn (late September-November) and the air dry as the monsoons retreat. Winter (December-February) is cool, with some rain or snow, and moderate humidity. The hot season (March-mid-June) has occasional thunder and hailstorms, but is generally hot and dry. Visibility may be impaired by dust blowing from the south (Dudgeon and Kenoyer, 1925). 


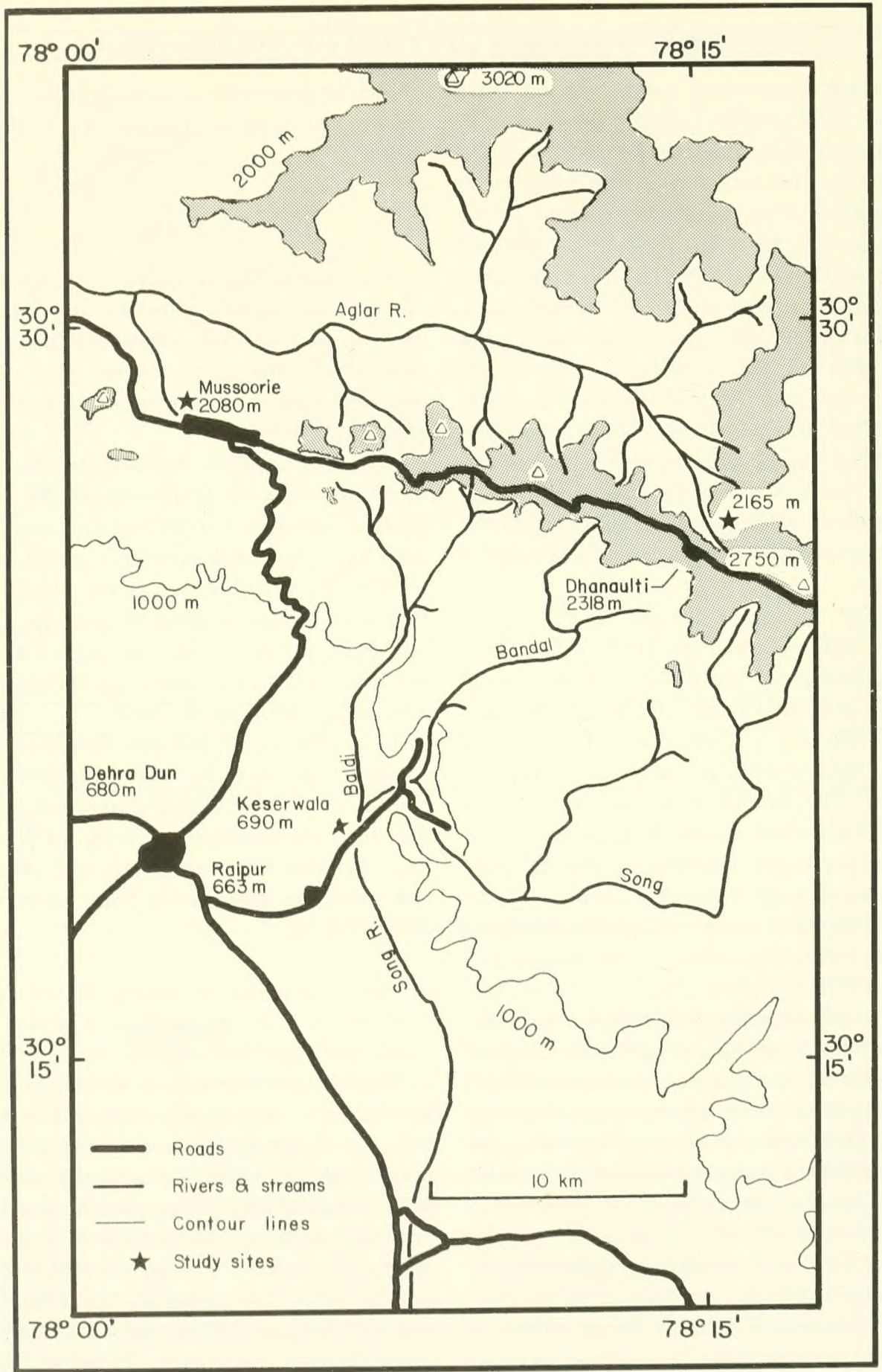

Fig. 2. Map of the Dehra Dun-Mussoorie area traced from U.S. Army topographic map series U502 NH 44-5. Lizards at high altitude were studied primarily near Dhanaulti and around Mussoorie. Lizards at low altitude were studied primarily at Keserwala on the north edge of the Dun Valley. 
The southwest monsoons are responsible for the unequal distribution of rainfall during the year with up to $90 \%$ of the annual precipitation occurring between June and September. Altitude influences the amount of precipitation an area receives. The line of greatest rainfall in the Himalayas lies at $1270 \mathrm{~m}$. Dehra Dun, at $680 \mathrm{~m}$, receives $2160 \mathrm{~mm}$ of annual precipitation. Rajpur, $10 \mathrm{~km}$ to the north at $970 \mathrm{~m}$. receives $3029 \mathrm{~mm}$. Mussoorie, $6 \mathrm{~km}$ to the north of Rajpur at $2115 \mathrm{~m}$, receives $2225 \mathrm{~mm}$ (Gupta, 1967). The mean annual temperature at Dehra Dun is $21.5^{\circ} \mathrm{C}$ and at Mussoorie, $13.7^{\circ} \mathrm{C}$.

\section{VegeTATION}

The vegetation of the Himalayas has been described by a number of investigators (e.g., Schweinfurth, 195\%; Puri, 1960; Legris, 1963; Champion and Seth, 1968). In mountainous areas. insolation, temperature, degree and direction of slope, geology, stratigraphy, soil, and adjacent topography contribute to the distinctively zoned nature of the vegetation (Fig. 3). The forests of the western Himalayas are broadly divided into dry or moist tropical forests, montane subtropical forests, montane temperate forests, sub-alpine forests, and alpine scrub (Champion and Seth, 1968). My low altitude study area was situated in moist tropical Bhabar-dun sal forest. The high altitude site was towards the upper limits of Himalayan moisttemperate Ban oak (Quercus incana) forest.

Sal (Shorearohusta) forests need a fairly mature soil (Champion and Seth, 1968). A short deciduous period of only $5-15$ days at the beginning of the hot season is typical of its semi-evergreen habit. The dense canopy reduces the growth of second story species and its shrubby undergrowth is mostly semi-evergreen.

The climax vegetation of the Himalayan moist temperate forests in the central portions of the west Himalayas is evergreen oak (Champion and Seth. 1968). The forests occur mainly on gneisses and schists and the soil is frequently loam. The canopy of Ban oak (the lowest level of the temperate forests) may be closed about $50 \mathrm{~m}$ up but on southern exposures the cover may be quite incomplete. Its chief associates are Rhododendron arboreum and Lyonia ovalifolia.

Dudgeon and Kenoyer (1925) stated that man interferes with the natural vegetation in the western Himalayas by cutting, by grazing cattle, sheep and goats, and by fire. I resided at Mussoorie from 1966-1969. Upon my return in 1973, the forests surrounding the area had been greatly decimated by severe lopping except on private property. Trees such as $Q$. incana have considerable capacity for coppicing but can hardly survive the intense lopping to which they are being subjected.

\section{METHODS}

Field studies on A. tuberculata were conducted from 15 March-26 June and 13 September-11 December 1973, 19 March, and from 28 May-5 August 1974. Data were obtained by mark and recapture, collection, and direct observation of free-ranging individuals. Of 77 individuals observed 858 times at the high altitude study area, 60 were marked and observed 796 times. Of 82 individuals observed 991 times at the low altitude study area, 72 were marked and observed 959 times. Additional data were obtained from 158 lizards collected at high altitude and 83 at low altitude. These latter specimens, collected and retained for detailed external and internal examination, were not taken from the same sites in which ongoing studies of populations were being conducted.
Noosing was found to be the most effective method of live capture. The following were recorded: snout-vent length, tail length, length of regenerated portion of tail, if any, general color pattern, degree to which preanal and belly scales were enlarged and/or thickened, abnormal physical characteristics, weight, whether or not obviously gravid, cloacal temperature, and type of activity at time of capture. Each lizard was permanently marked by a unique toe clipping combination. No more than one toe per foot was clipped with a maximum of three toes clipped per individual. Individuals were also marked for ready field identification by placing two daubs of enamel paint on the head. Daubs of paint on the lower jaw aided in identification of lizards peering down 


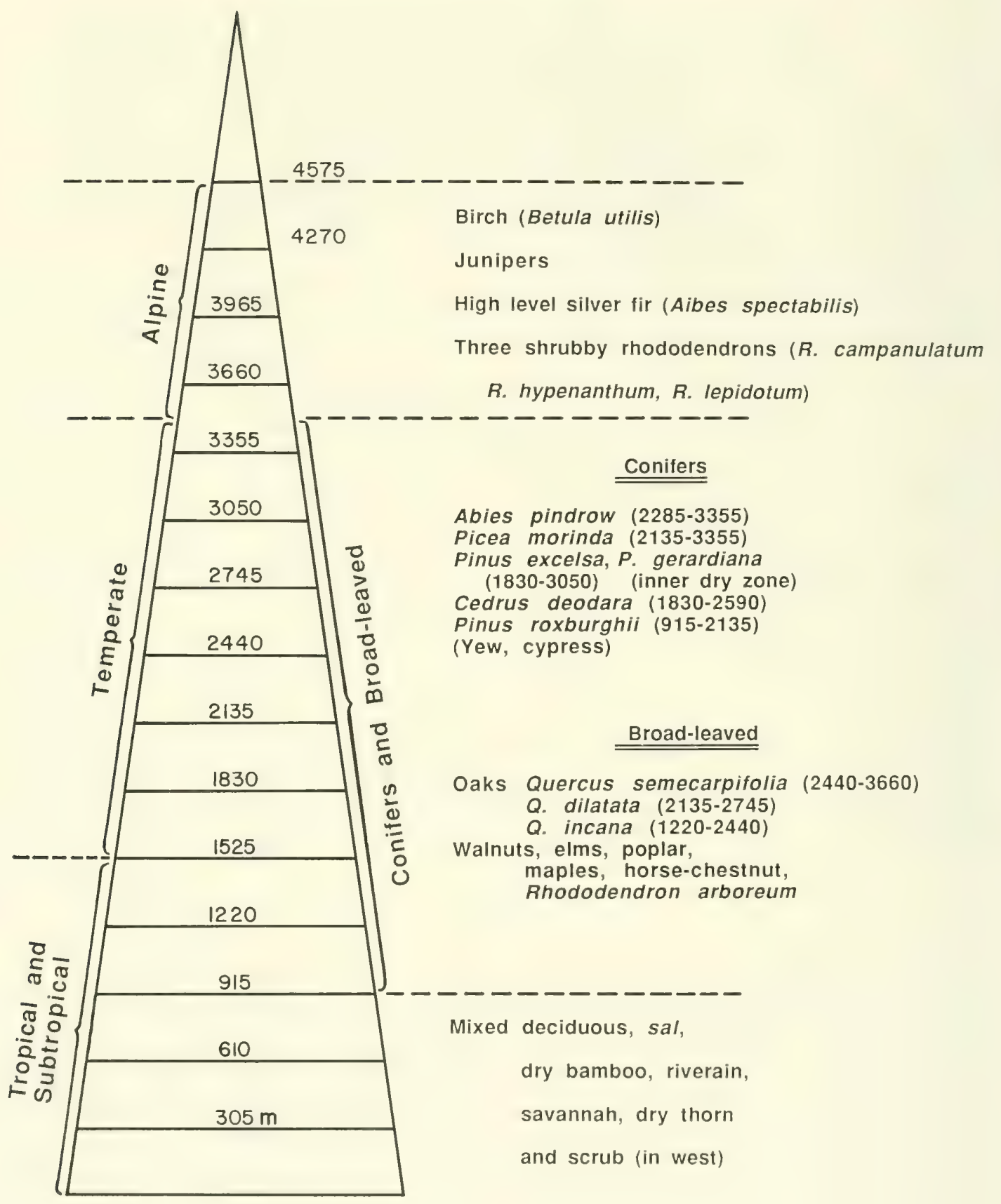

Fig. 3. Vegetation zones in the western Himalayas (from Puri, 1960).

from rocks or crevices above me. Binoculars $(7 \times 35$ wide field) also aided in identifying individuals. Prior to release, each lizard was photographed from a dorsal and ventral view with color trans- parency and/or black and white film.

The pattern of markings on the gular area and chest are unique for each individual and it was possible to identify a lizard from year to year on the 

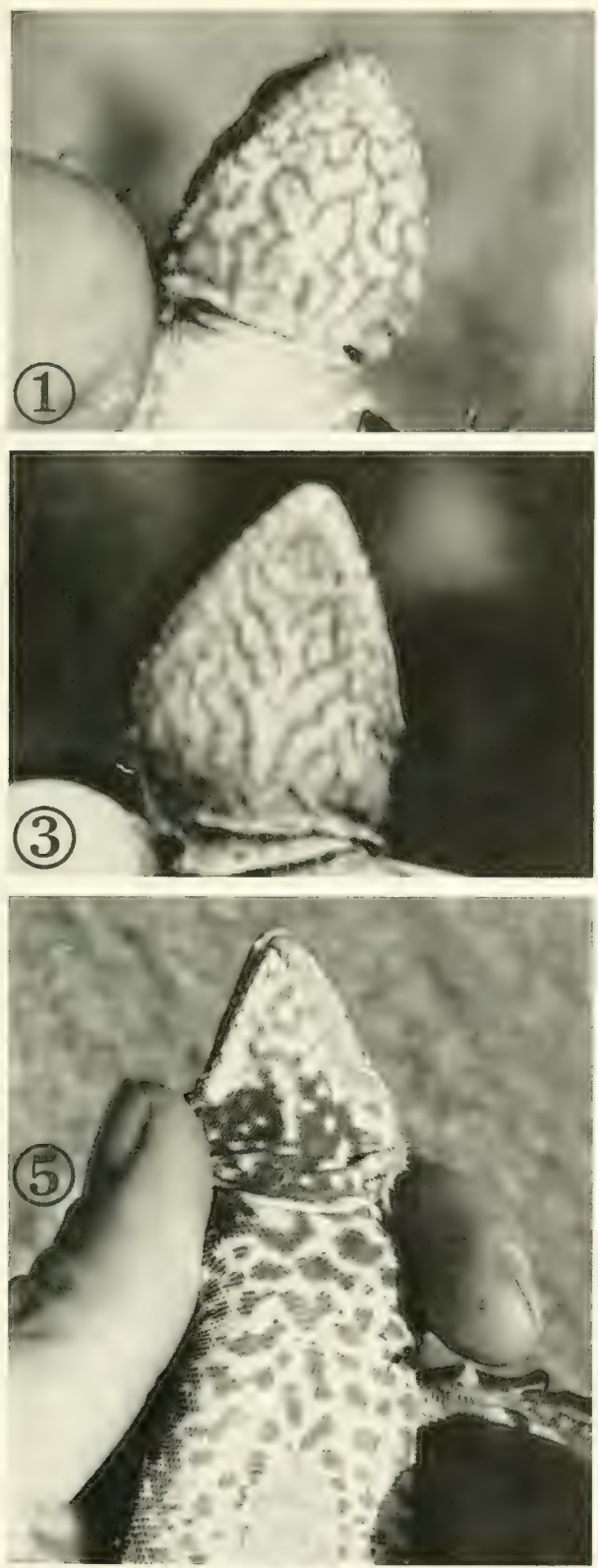
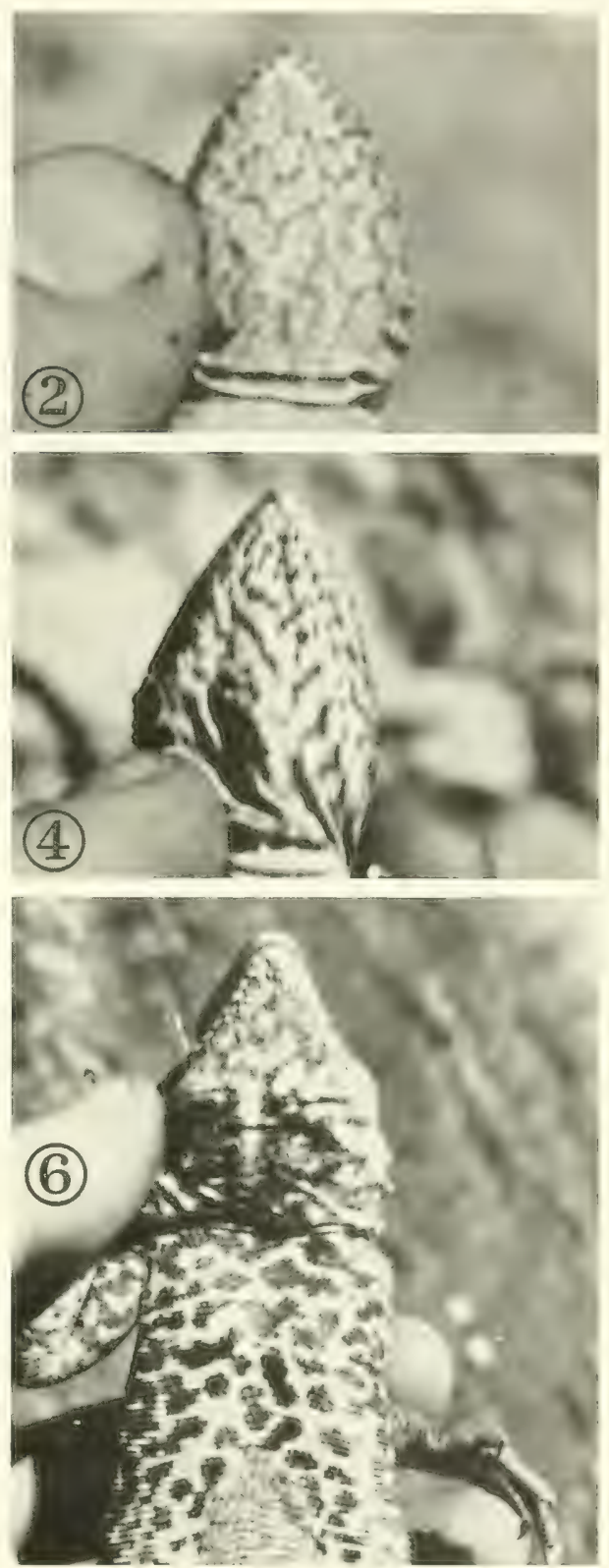

Fig. 4. Photographs of recaptured A. tuberculata showing constancy of gular and chest markings. 1. 2. Hatchling captured 29 November $1973(\mathrm{SVL}=48 \mathrm{~mm}$ ) and recaptured 29 May 1974 (SVL=65 mm); 3. 4. Juvenile captured 19 September 1973 (SVL=74 mm) and recaptured 30 May 1974 (SVL=93 mm); 5. 6. Adult male captured 23 April $1973(\mathrm{SVL}=115 \mathrm{~mm})$ and recaptured 4 June $1974(\mathrm{SVL}=127 \mathrm{~mm})$.

basis of its markings (Fig. 4). Identification was verified by toe clippings. The gular markings tend to fuse together in adult males but the pattern of chest blotches remains the same. Harris (1964) likewise was able to use gular patterns to identify individual Agama agama in Nigeria.

Challenge displays were filmed. Displays were elicited by presenting tethered individuals to freeranging individuals. The film was analyzed frameby-frame using a modified Bell and Howell projec- 
tor. Movement between successive frames was plotted by projecting the film onto graph paper.

Most individuals preserved for later study were collected with a 177 calibre air rifle. Hatchlings could be approached close enough to be momentarily stunned by a jet of air from the unloaded air rifle. Besides external measurements, cloacal temperature, and gut contents, the collected lizards also provided information on reproduction. At the end of the study, as many individuals as possible were collected from the live-study areas in order to confirm their identification and to obtain further information on their rate of growth and food habits. Procedures for statistical analysis of the data follow Sokal and Rohlf (1969) except for comparisons of slopes and elevations of regression lines which were according to Brownlee (1960). Significance of statistical tests at the 0.05 level is indicated by one asterisk (*), at the 0.01 level by two asterisks (**), and at the 0.001 level by three asterisks (***). Means are usually given with \pm one standard error.

\section{MORPHOLOGY}

\section{Description of the Species}

Adult rock lizards are colorful (Fig. 5). Males have a gray head with black edging on lips and around eyes; the throat is marked with a broken network of black blotches with a few rust-colored specks in occasional individuals. The body is black with numerous small cream or yellowish specks on a dark slate background, these specks becoming orangish on the flanks. The dorsal aspect of the limbs and basal half of the tail blue; distal half of the tail black. The cream-colored ventral surface may have an orange wash-particularly on the chest. Numerous large black and/or blue blotches on the chest become fewer and smaller on the belly which may be unmarked. Chest blotches may have a central blue area and the extent of the markings on the chest varies considerably, merging together in those with greater pigmentation. A patch of thickened scales is found on the belly and pre-anal area.

In dorsal view, adult females (Fig. 6) are similar to adult males but usually their heads are not as gray or blue. Ventrally, the differences are more obvious; the gular area is not as extensively marked with black and the chest and belly have fewer and smaller black blotches. The cream-colored chest may have a slight orange wash. Belly and pre-anal callosities are lacking.

Ontogenetic changes occur in the coloration and pattern of markings. Dorsally, hatchlings are brownish with small, scattered dark markings (Fig. 7). There is a row of larger V-shaped or transversely linear blotches on either side of the mid-line and scattered cream-colored specks. The gular area has an irregular network of dark markings. The cream-colored chest and belly are unmarked. Small juveniles have similar cryptic markings and may have dark specks on the chest. In large juveniles, the dark markings become less distinct as light-colored specks become more prominent in alternating rows running laterally from the dorsal midline. These light bars may persist in subadults and even in gravid females up to $115 \mathrm{~mm}$ snout-vent length (SVL). However, in some juveniles and subadults dorsal markings are almost lacking.

\section{Maximum Size}

Agama tuberculata is the largest of the three rock lizards which occur in Kashmir and the western Himalayas. Smith (1935) lists its measurements as: SVL $140 \mathrm{~mm}$ and tail length to $250 \mathrm{~mm}$. Maximum sizes recorded during this study were SVL $140 \mathrm{~mm}$, tail length $259 \mathrm{~mm}$, and weight $94.2 \mathrm{~g}$.

There were no significant differences in samesex comparisons of SVL between altitudes (Table 1: $P>0.4$ for males; $P>0.1$ for females). However. at both altitudes, males were significantly larger than females $\left(t=5.283^{* * *}, \mathrm{df}=148\right.$ for montane: $t=4.356 \%$, df $=9.3$ for low land $)$. My findings are in contrast to Stevens (1983) who found high elevation populations of Cnemidophorus inornatus to have a larger adult body size than lower elevation populations. 

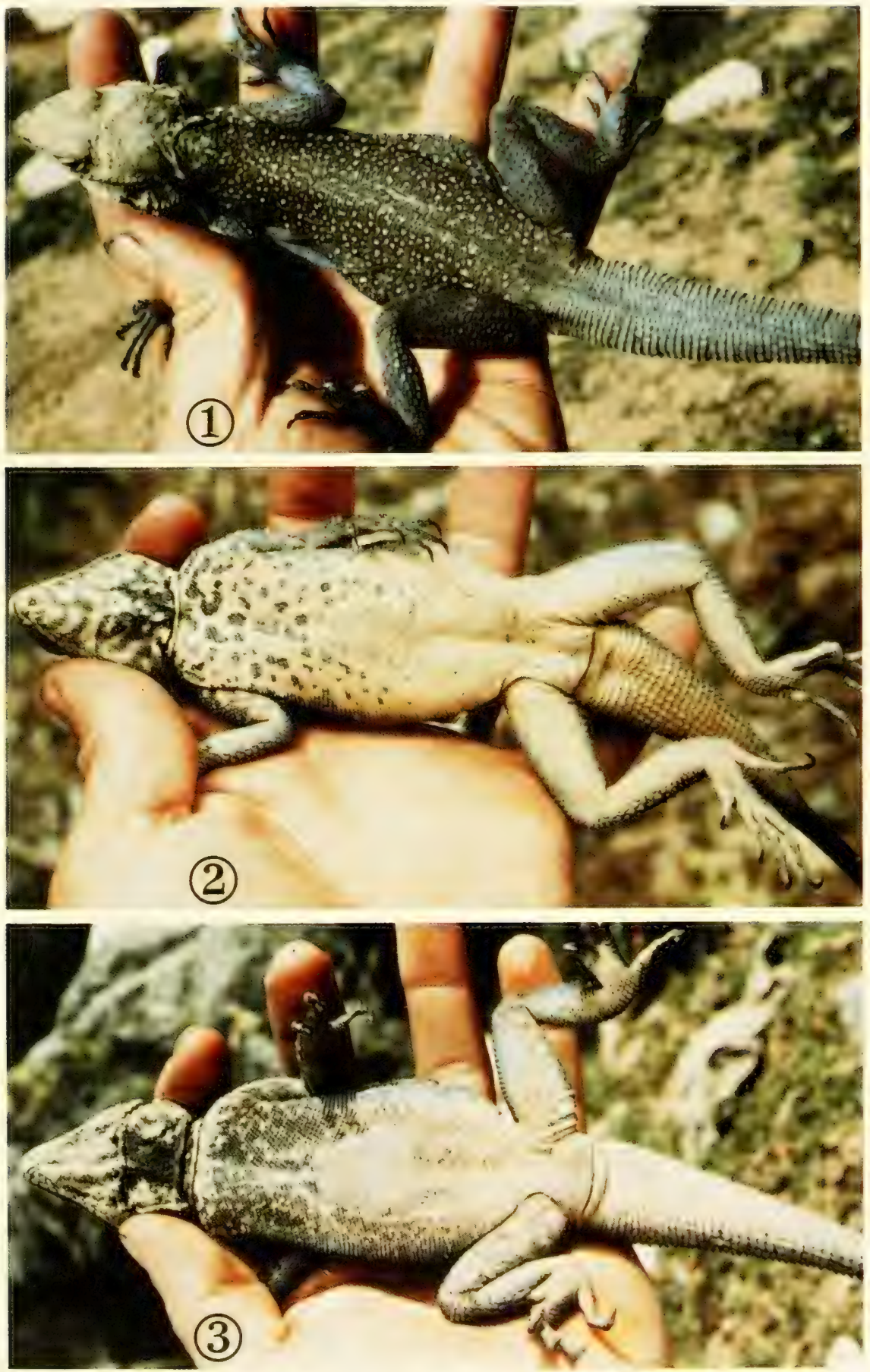

Fig. 5. Adult male A, tuberculata. 1. Dorsal view 2. Ventral view (note pre-anal and belly callosities) 3. Ventral view (note increased pigmentation compared to $\mathrm{B}$ ). 

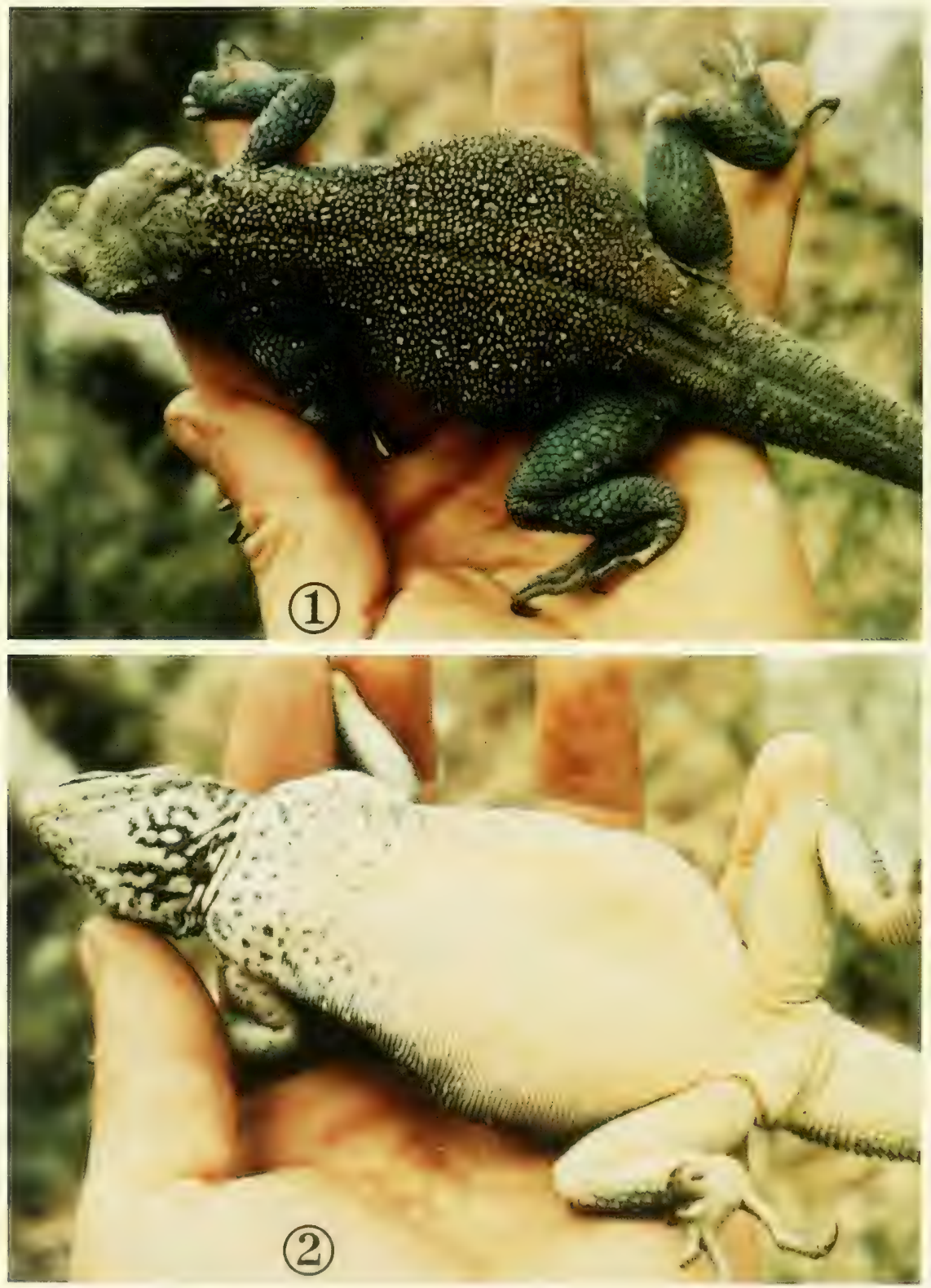

Fig. 6. Adult female A. tuberculata. 1. Dorsal view 2. Ventral view (note lack of belly callosity and fewer markings on chest as compared to adult males). 

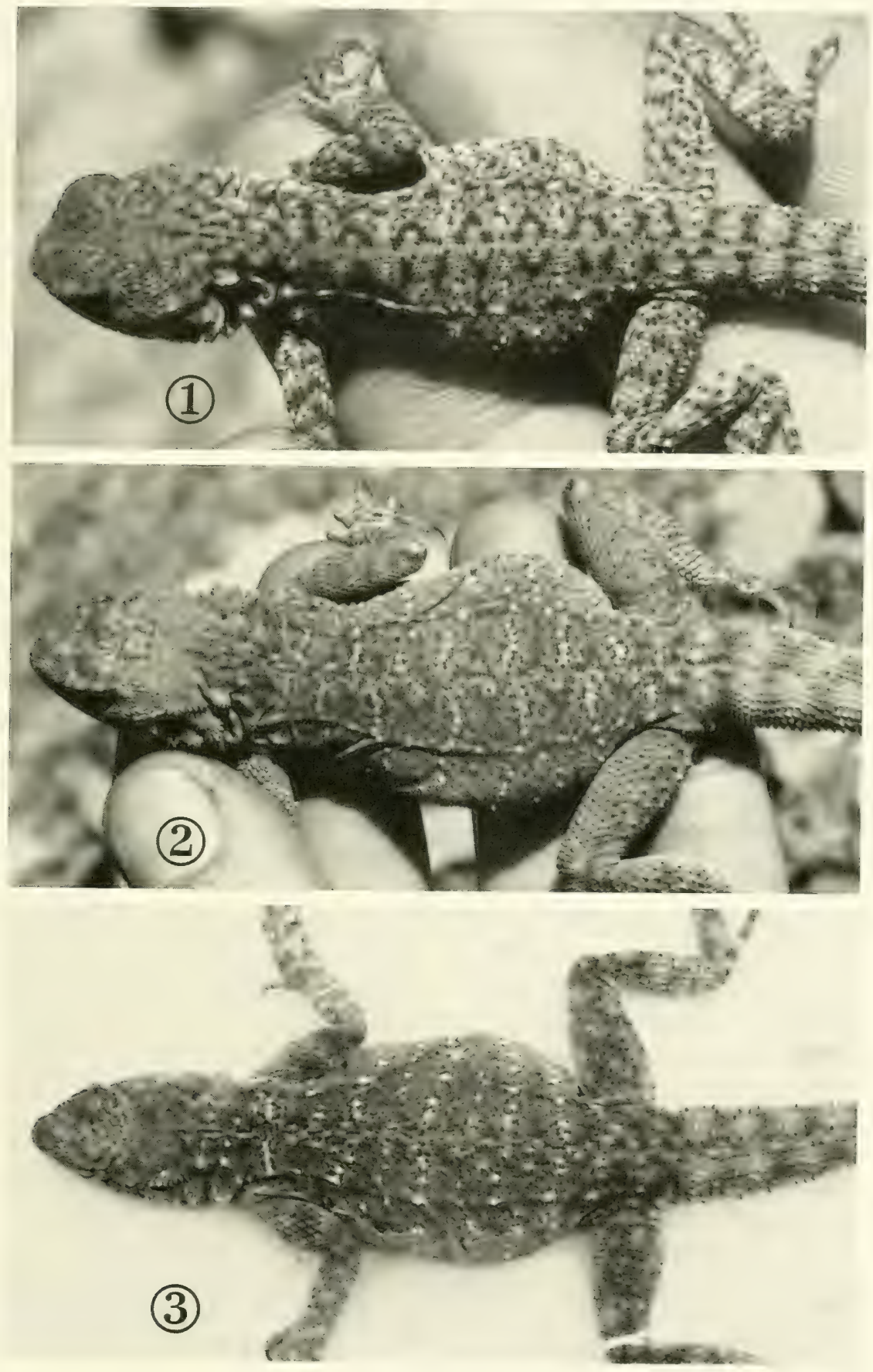

Fig. 7. Changes in the markings of A. tuberculata. 1. Hatchling ( $\mathrm{SVL}=44 \mathrm{~mm}) 2$. Juvenile ( $\mathrm{SVL}=77 \mathrm{~mm})$ 3. Young adult female (SVL=102 mm). 
Table 1. Snout-vent lengths of adult high and low altitude $A$. tuberculata. ( )=sample size.

$\bar{X} \pm \mathrm{s}_{\mathrm{F}} \quad$ range

\section{High altitude}

$\sigma \geq 100 \mathrm{~mm}$ SVL $\quad 121.7 \quad 1.2(61) \quad 100-140$

$q \geq 96 \mathrm{~mm}$ SVL $\quad 113.9 \quad 0.9(89) \quad 97-138$

\section{Low altitude}

$\sigma \geq 100 \mathrm{~mm}$ SVL $\quad 120.1 \quad 1.7(35) \quad 100-133$

Q $\geq 96 \mathrm{~mm} \mathrm{SVL} \quad 111.8 \quad 1.1(60) \quad 96-131$

\section{Proportions and Sexual Dimorphism}

As the lizards grow, the ratio between the SVL and tail length changes (Figs. 8,9). Comparison of the slopes of the regression lines (immatures to adult males or females) indicate a non-significant decrease in the ratio as high altitude individuals mature (Table 2). Sometime prior to reaching adult size, the lizard's tail seems to reduce briefly its relative growth rate and then increases it again. This might account for the fact that slopes between adult females and immatures do not differ significantly although a comparison of elevations of the lines shows significant difference. Also, the immature group was heterogeneous including both sexes with possibly different growth patterns. At high altitude, the ratio between SVL and tail length is the same for adult males and females (the slope of the line is not significantly different). The tail increases at the same rate compared to the SVL for both sexes, yet the elevation of the two lines is significantly different. The same trend is evident at low altitude but data were too few to test for significance. For immatures at low altitude, the rate at which the tail increases compared to the SVL is significantly faster than at high altitude, resulting in adult lizards from low altitude having proportionately longer tails than their high altitude counterparts. Even though the rate at which the tail increases is not significantly different for low altitude adult females compared to high altitude females, the elevation of the lines is significantly different. Low altitude adult females have tails as long as high altitude adult males of comparable SVL.
The relationship between SVL and weight is the same regardless of sex or age at a given altitude (Fig. 10, Table 2). However, males and immatures from high altitude are significantly heavier than their low altitude counterparts of comparable SVL. As females with oviducal eggs weigh more than nongravid females of the same SVL, only nongravid females or those with ovarian follicles $<10 \mathrm{~mm}$ diameter in the months of April, May, and September were used in this analysis.

Head length was measured from the anterior edge of the tympanum to the tip of the snout. Male rock lizards have significantly longer heads than females of comparable SVL (Fig. 11, Table 2). However, there is no difference in the ratio between high and low altitude within either sex. The rate at which the SVL increases as head length increases is the same regardless of sex or altitude.

Sexual dimorphism is also apparent at both altitudes in the ratio of head length to head width (Fig. 12, Table 2). At high altitude, the ratio for small-headed males and females is the same but the rate at which head width increases as head length increases is significantly different so that largeheaded males have appreciably wider heads than females of a comparable head length. The same trends are present in low altitude populations.

The fourth toe on the hind foot is the longest toe and is significantly longer in males than females (Fig. 13, Table 2). Moreover, lizards at low altitude have significantly longer toes than lizards of the same sex at high altitude. There are no significant differences in the rate of change between SVL and toe length regardless of sex or altitude.

Length of toes in these rock-climbing lizards presumably is related to their facility at clambering up cliffs and into crevices. In spite of their longer toes, the low altitude lizards did not appear to live out in the open more than the high altitude lizards or to be able to climb over rocks more readily.

The increased bulk at high altitude may be related to heat balance. Body temperature in the preferred activity range could be maintained more easily and for a longer period by a bulkier lizard. A less bulky lizard at low altitude could dissipate heat more readily at mid-day when ambient temperatures exceed the level necessary to maintain the preferred body temperature. 


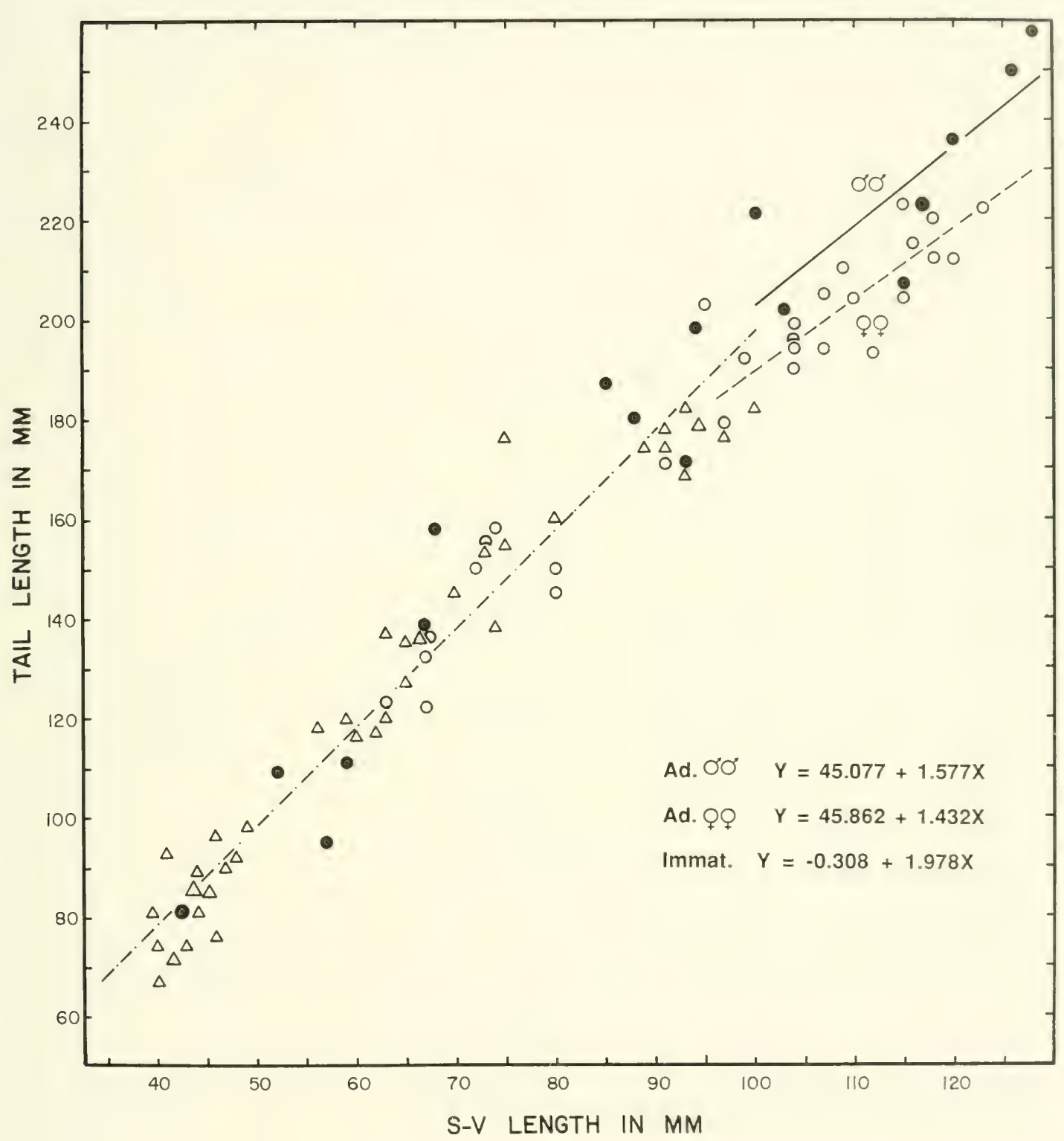

Fig. 8. Relationship between tail length and SVL of high altitude A. tuberculata. Large symbols represent three records, medium symbols two records, and small symbols a single record. Triangles represent immatures, open circles females, and closed circles males. 


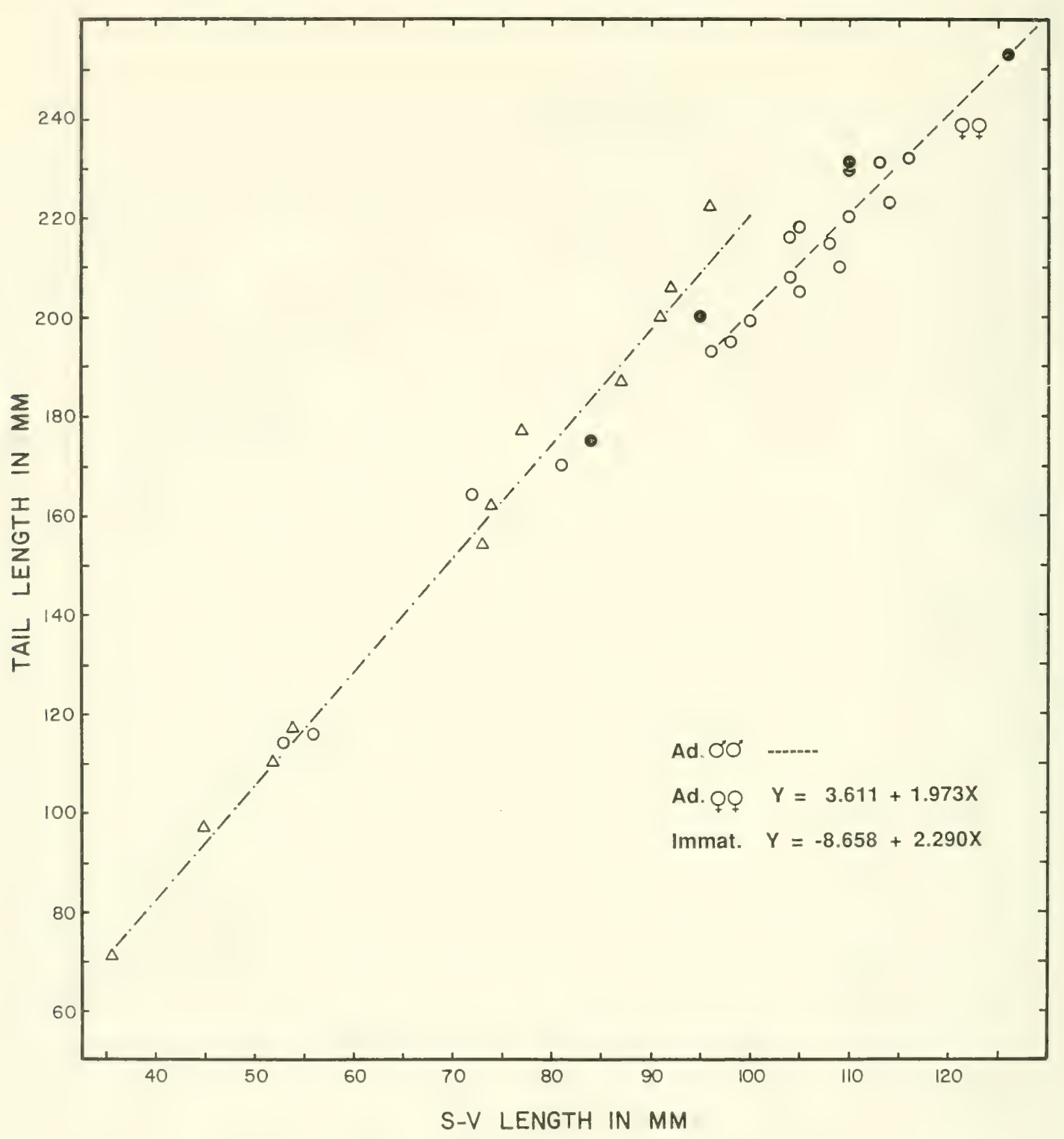

Fig. 9. Relationship between tail length and SVL of low altitude A. tuberculata. Only two adult males were found with complete tails. Symbols as in Fig. 8.

\section{GROWTH}

Snout-vent measurements were used to study growth. Grow th rates were calculated from records of recaptured individuals of various age classes and regression lines were plotted for different agesex classes. Records for 1973-1974 were combined. Individuals of undetermined sex were not used in regression computations.

High altitude.- Sizes and sexes of lizards obtained at high altitude are shown in Figs. 14 and 15. Recapture records and size groupings were used in dividing age categories but the dividing line between each age class is approximate. The growth 
Table 2. Comparison of body proportions of $A$. tuberculat $a$. Ad. =adult, $a=$ elevation of regression line; $b=$ slope of regression line; $b=$ slope of common regression line; $\mathrm{s}_{b}=$ standard error of common regression line. 'insufficient sample size; ${ }^{2}$ invalid since $b_{1} \neq b_{2} ;()=$ sample size.

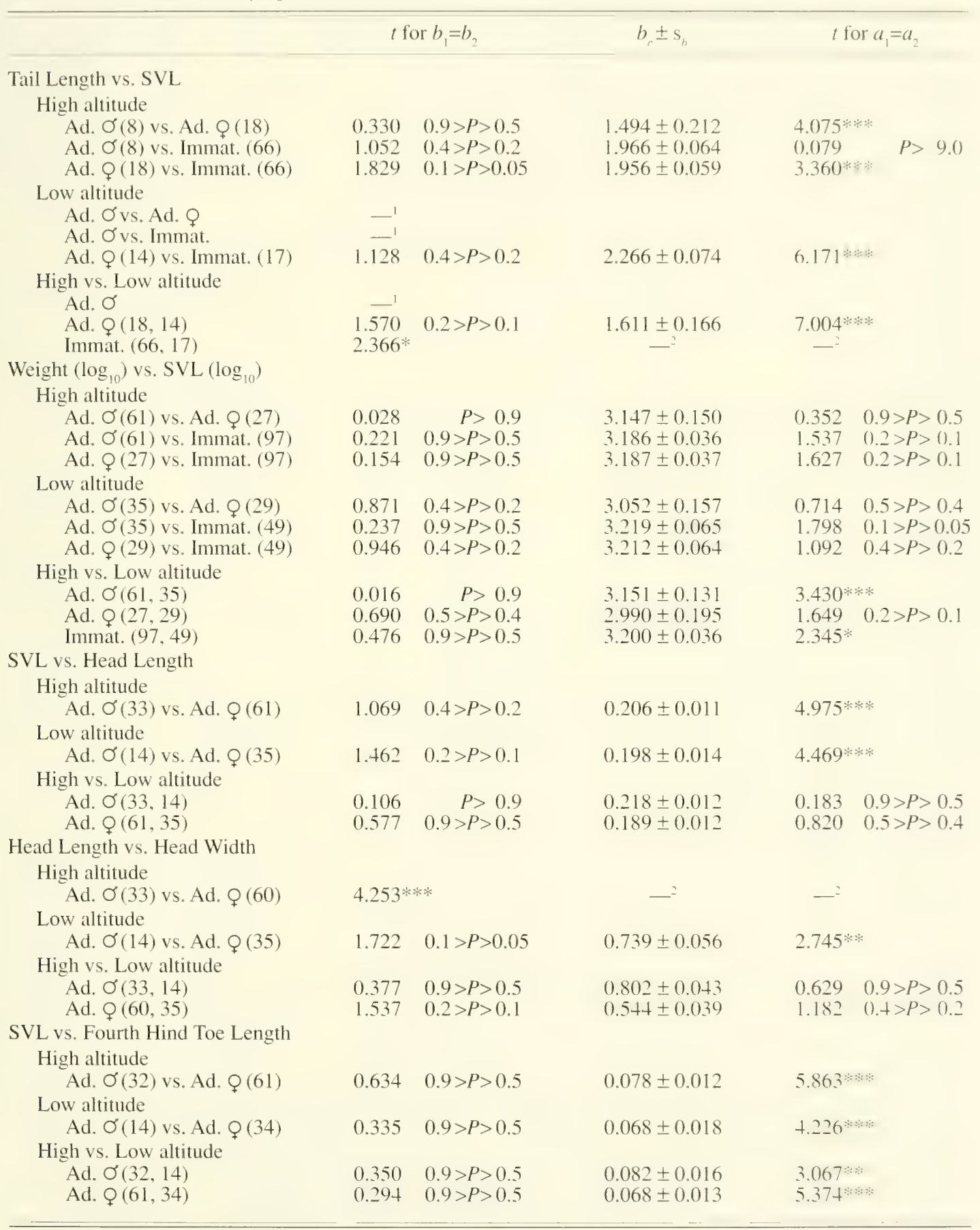



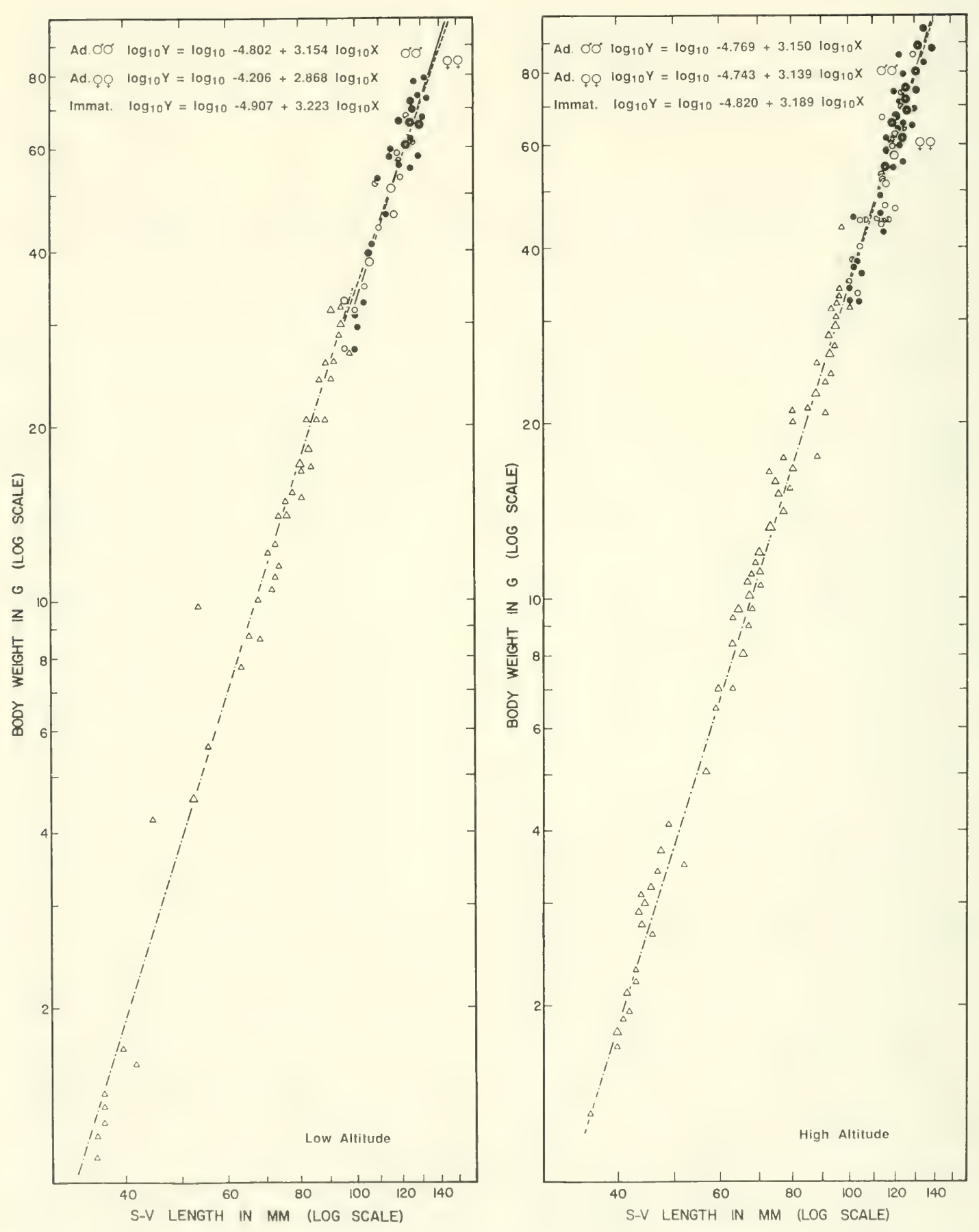

Fig. 10. Relationship between weight and SVL of high altitude and low altitude A. tuberculata. Symbols as in lị̈. S. 


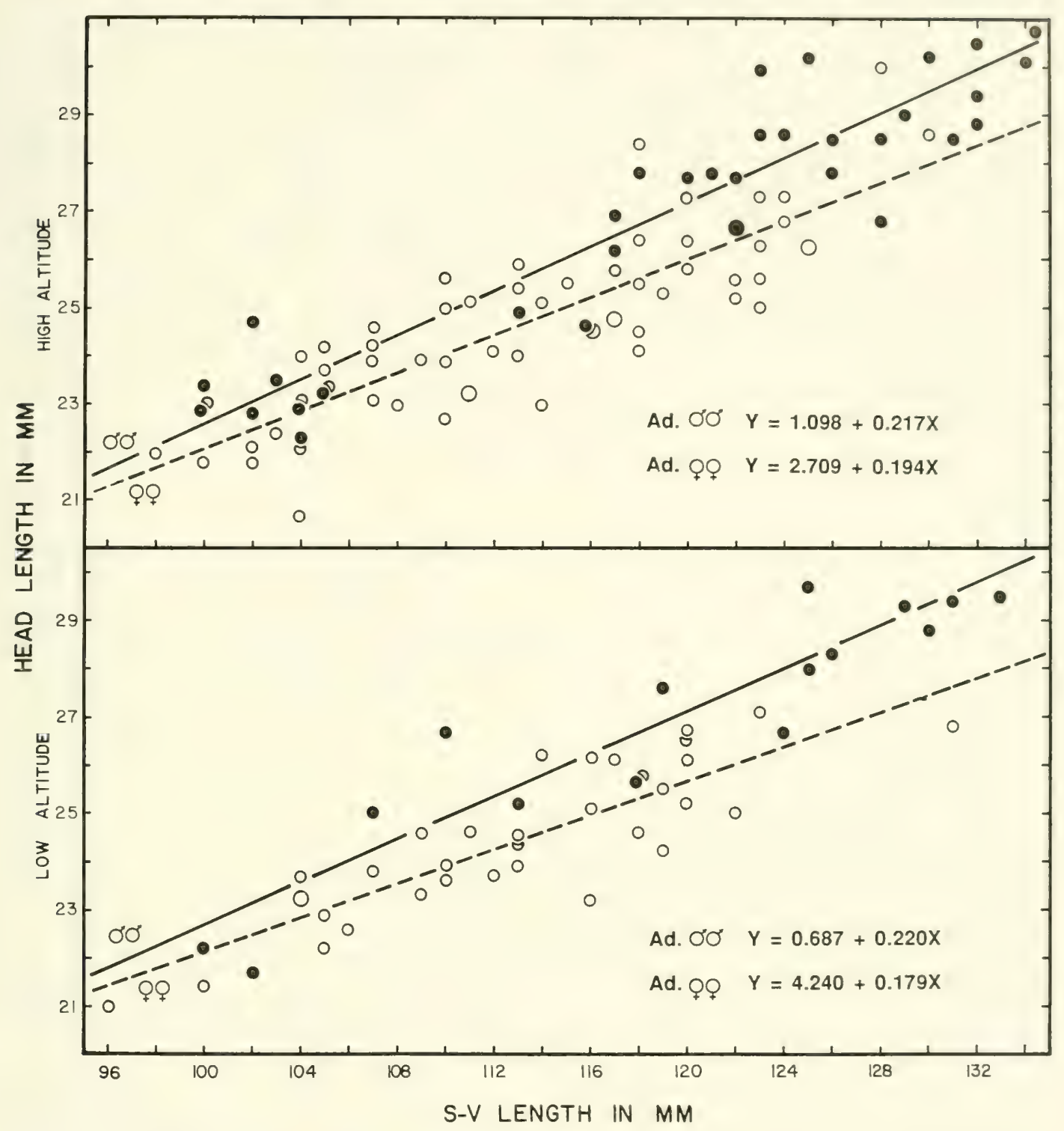

Fig. 11. Relationship between head length and SVL of high altitude and low altitude A. tuherculata. Large symbols show two records, small symbols one record. Closed circles represent males, open circles females.

rate tends to decrease with increasing age. There is extensive overlap between yearly age classes more than 2 years old. Normally, most rapid growth occurs in the hatchling category. Size of hatchlings in November indicates many eggs hatch aftermid-October; inclusion of these individuals would cause the regression line to be steeper that illustrated for hatchlings.
Growth records of recaptured lizards are presented in Table 3. Considerable variation in the growth rates between individuals is apparent. Several juveniles made no growth during the monsoon rainy period (July). In the section on body temperature, data are presented showing slightly lower mean body temperature for lizards in 


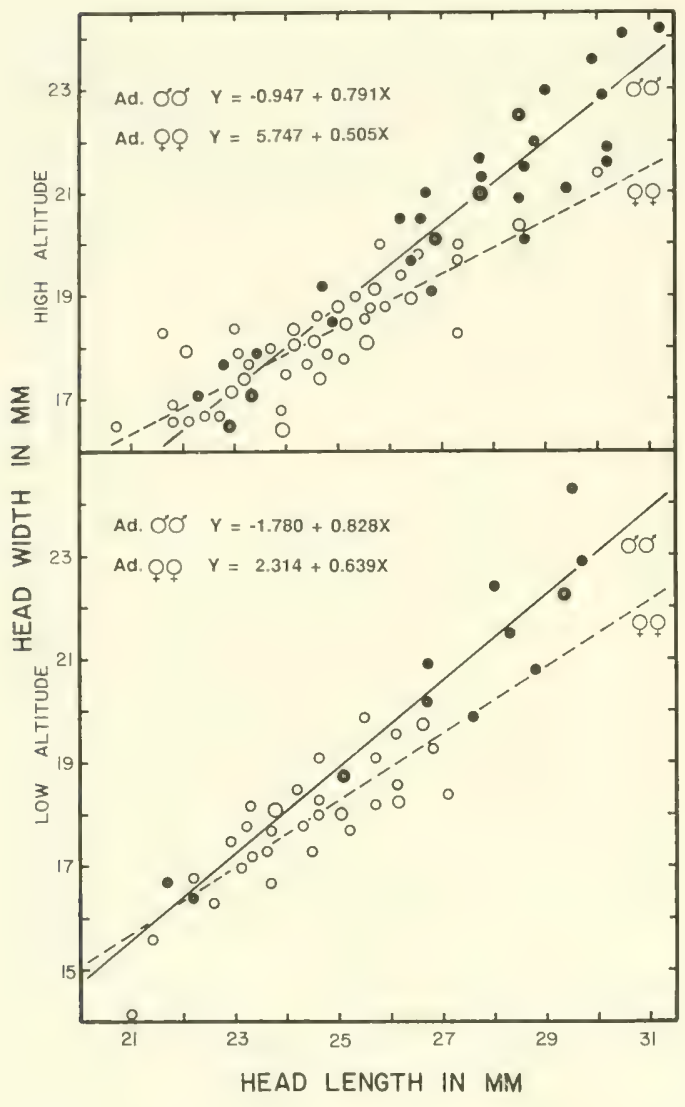

Fig. 12. Relationship between head width and head length of high altitude and low altitude $A$. tuberculata. Large symbols show three records, medium symbols two records, and small symbols one record. Closed circles represent males, open circles females.

the monsoons with more time spent basking compared to the hot season and autumn. During the monsoons, some lizards may not be able to capture sufficient food to maintain their growth rate and/or the lower body temperature may in itself reduce the rate of growth during the monsoons. Also, the period between captures for these individuals was short and handling and marking may retard subsequent growth as Fitch found in rattlesnakes in California (1949) and in various species of Costa Rican lizards (1973).

The rate of growth (comparison of $b$ for regression lines) is not significantly different between the sexes for juveniles or subadults; there- fore a common regression coefficient for all individuals in each age category has been computed (Table 4). Despite lack of significant differences in the rate of growth between sexes in their first and second seasons, the elevation of the regression lines is almost significantly different $(t=1.815$; $\mathrm{df}=34 ; 0.1>P>0.05$ ) in the second season. 1 suspect that the slope of the regression line for the first season in Figs. 14 and 15 is steeper than depicted. By the time males reach sexual maturity at an age of 20-24 months they are larger than females of the same age and the difference becomes even greater in the third year at which time females are channeling their energy into reproduction rather than growth. Females probably do not lay their first clutch until their third season (30-32 months) even though they reach reproductive size in their second year (20-24 months).

Low altitude.- Sizes and sexes of lizards obtained at low altitude are presented in Figs. 16 and 17. Growth rate, as calculated by the regression line, is less for hatchlings than juveniles - the reason being that hatching is spread out over several months thereby reducing the slope of the line. Considerable variation is evident (Table 5).

The rate of growth is not significantly different between males and females in juvenile and subadult classes (Table 4); however, males tend to grow a little faster than females. Males reach reproductive size at an age of 16-18 months but probably do not contribute much to reproductive activities for at least one more year until they secure territories of their own. Some females may reproduce at an age of 16-18 months, but most probably do not produce eggs until the following year.

Female rainbow lizards (Agama agama) in Nigeria reach sexual maturity at an earlier age than do A. tuberculata at low altitude. Harris (1964) found that approximately 14 months normally were required for female A. agama to reach breeding size (90 mm SVL) but 18 months may elapse before reproduction occurred if the lizard hatched at the end of a reproductive season. At the same age, $A$. agama males are 15-20 mm longer (SVL) and nearing sexual maturity but probably do not acquire territories (a prerequisite for mating) until they are about 2 years old. More rapid growth of A. agama is due, in part, to southern Nigeria having a mean annual temperature $4.8^{\circ} \mathrm{C}$ higher than Dehra Dun. 


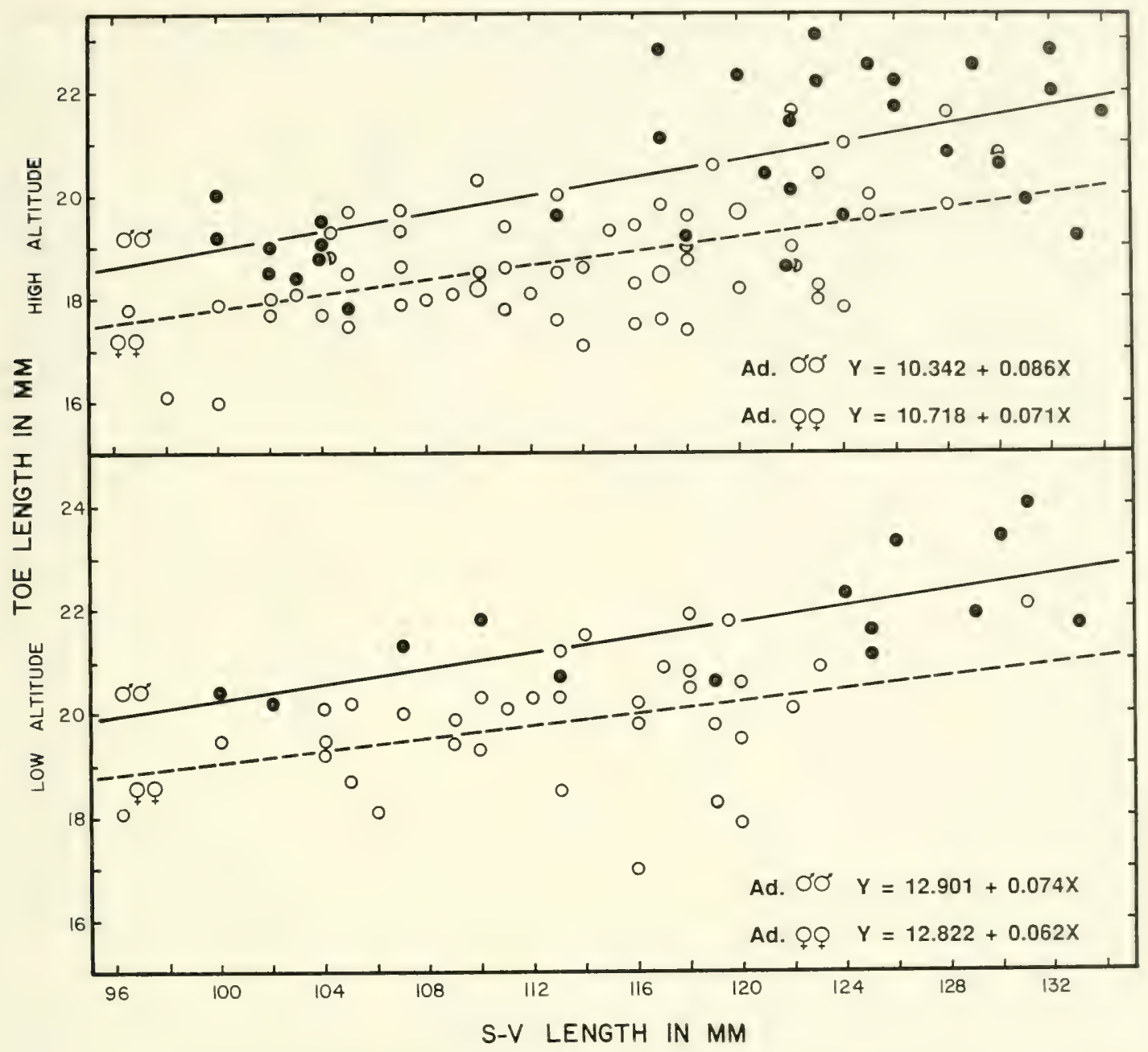

Fig. 13. Relationship between fourth hind toe length and SVL of high altitude and low altitude A. tuhe'rulata. Large symbols show two records, small symbols one record. Closed circles represent males, open circles females.

\section{Comparison of the Two Altitudes}

There are no significant differences in growth rates of lizards of comparable age-sex categories at high and low altitudes (Table 4). Heliothermic behavior enables $A$. tuberculata to grow at the same rate at different altitudes. However, the elevation of the regression lines is significantly higher for juveniles and subadults at low altitude. Lizards living at low altitude have a longer growing season and thus are able to reach sexual maturity approximately a year earlier than those living at $2165 \mathrm{~m}$.
Similarly, high altitude populations of Lacerta vivipara in France take 2 years to mature compared to only 1 year for low altitude populations (Huelin, 1985). Ballinger (1979) found Sceloportus jarrovi to mature in 5 months at $1675 \mathrm{~m}$ and in 15 months at $2542 \mathrm{~m}$. In his study comparing Colorado and Texas populations of Uta stansburiana, Tinkle (1967) found that the former grew at the same rate as the latter but took longer to reach sexual maturity because they hatched later in the summer and had a shorter growing season. 


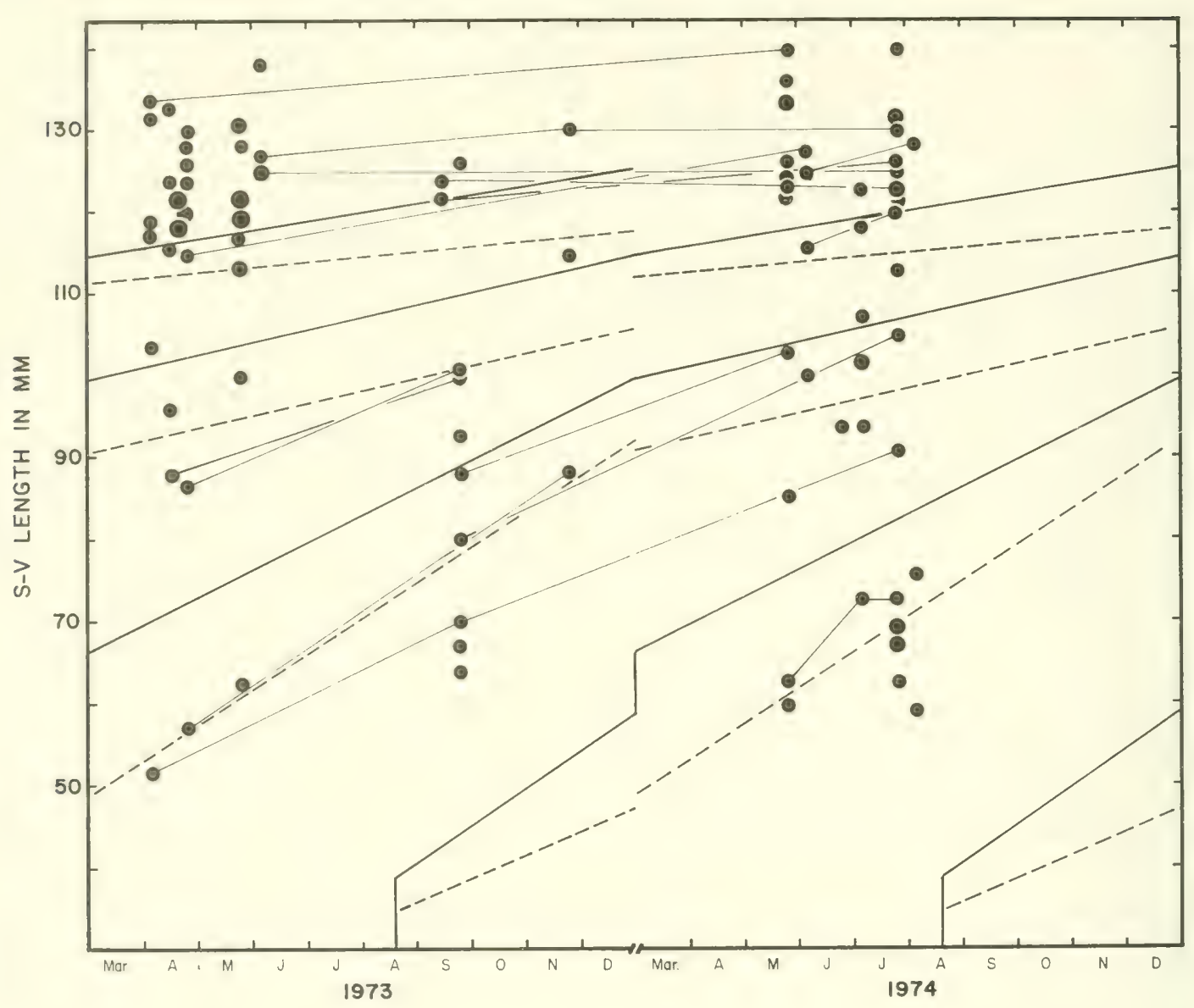

Fig. 14. Growth records for male high altitude A. tuberculata. Heavy lines separate age classes. Narrow lines connect individual recapture records. Regression lines (dashed) are fitted to the combined data for both years for each age class. The hatchling regression line is for records shown in Fig. 15. Large symbols show three records, medium symbols two records, and small symbols one record.

\section{FOOD HABITS}

There are few records of the feeding habits of $A$. tuberculata. Dodsworth (1913) reported a diet "of ants, butterflies, and other ... insects" and mentioned that the lizards were frequently seen "nipping the petals off the flowers" in gardens. On the other hand, Acharji and Kripalani (1952) did not find any vegetation to be eaten by rock lizards in the Kulu and Kangra Valleys of the western Himalayas. Bhatnagar (1968) analyzed the gut contents of 162 individuals collected near Dehra Dun during 1964 and found Orthoptera, Hymenoptera, and Coleoptera to be eaten in all seasons,
Isoptera eaten mainly during the hot season, and Annelida during the monsoons. The proportions of individuals eating a particular item also changed during the year. Relatively fewer lizards ate spiders during the hot season and monsoons than during the rest of the year. Bhatnagar stated that the rock lizard deliberately includes vegetation in its diet as he observed "individuals biting and nipping petals of Dhalia and Zenias [sic]."

I analyzed the stomach contents of 221 lizards (143 from high altitude and 78 from low altitude). Contents from each individual were placed on a 


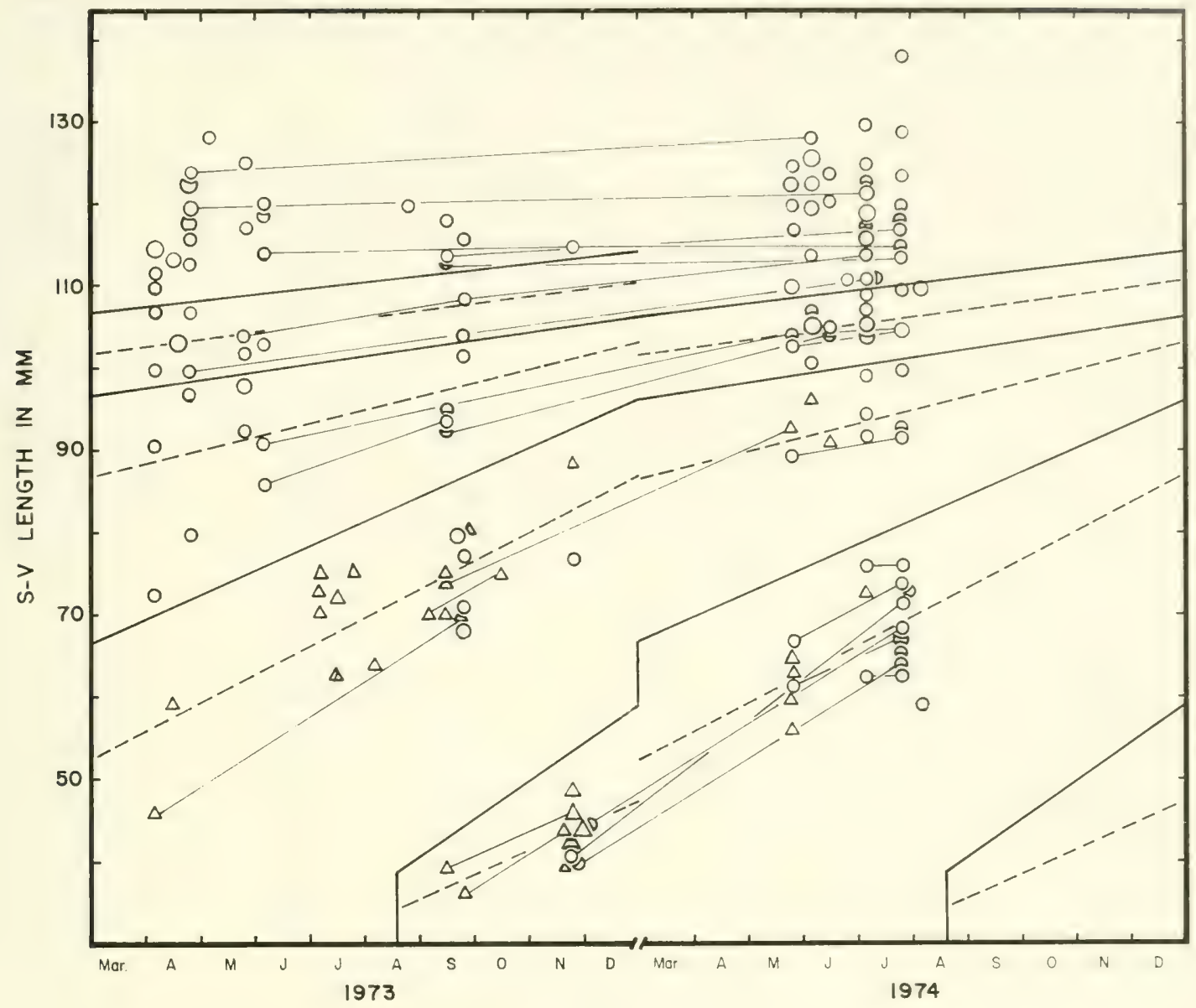

Fig. 15. Growth records for female (circles) and unsexed (triangles) high altitude A. tuberculata. Lines and symbols as in Fig. 14. Records of unsexed individuals were not used in calculating the regression lines except for hatchlings.

millimeter grid and examined through a dissecting microscope. The wet volume in $\mathrm{mm}^{3}$ for each of 23 categories was estimated (Tables 6, 7). Lizards were placed in 1 of 16 groups on the basis of their age or sex, season collected (monsoon or nonmonsoon), and altitude. No hatchlings were collected at high altitude during the monsoons; all other groups had at least six individuals.

\section{Qualitative Considerations}

The relative importance of various components of the diet of each group is shown in Figs. 18-21. Prey items not previously reported include a scor- pion and two skinks (Scincella himalayanum). Overall diet of the rock lizard shows increasing importance of the total animal component from non-monsoon to monsoon and from adult male to adult female to immature within these 2 times of year. Adult males generally eat the most vegetation but at high altitude during the non-monsoon months adult females have a comparable proportion of vegetation in their diet. Minton (1966) noted that the adults of large agamids in West Pakistan were predominantly herbivorous whereas adults of smaller species were carnivorous. Also, juveniles of the larger species were omnivorous. By contrast. Yadgarov (1974) found plant remains in only 8 of 
Table 3. Growth of recaptured high altitude A.tuberculata. Individual growth rates may be compared to the average growth rate for each category (right hand column) calculated from data in Figs. 14-15. A=SVL at 1 st and 2nd capture; $\mathbf{B}=$ number of d in interval; $\mathbf{C}=$ growth in $\mathrm{mm} / \mathrm{d} ; \mathbf{D}=$ grow th in $\mathrm{mm} / 30 \mathrm{~d} . b=$ slope of regression line; $\mathrm{s}_{b}=\mathrm{standard}$ error of regression line; ( )=sample size.

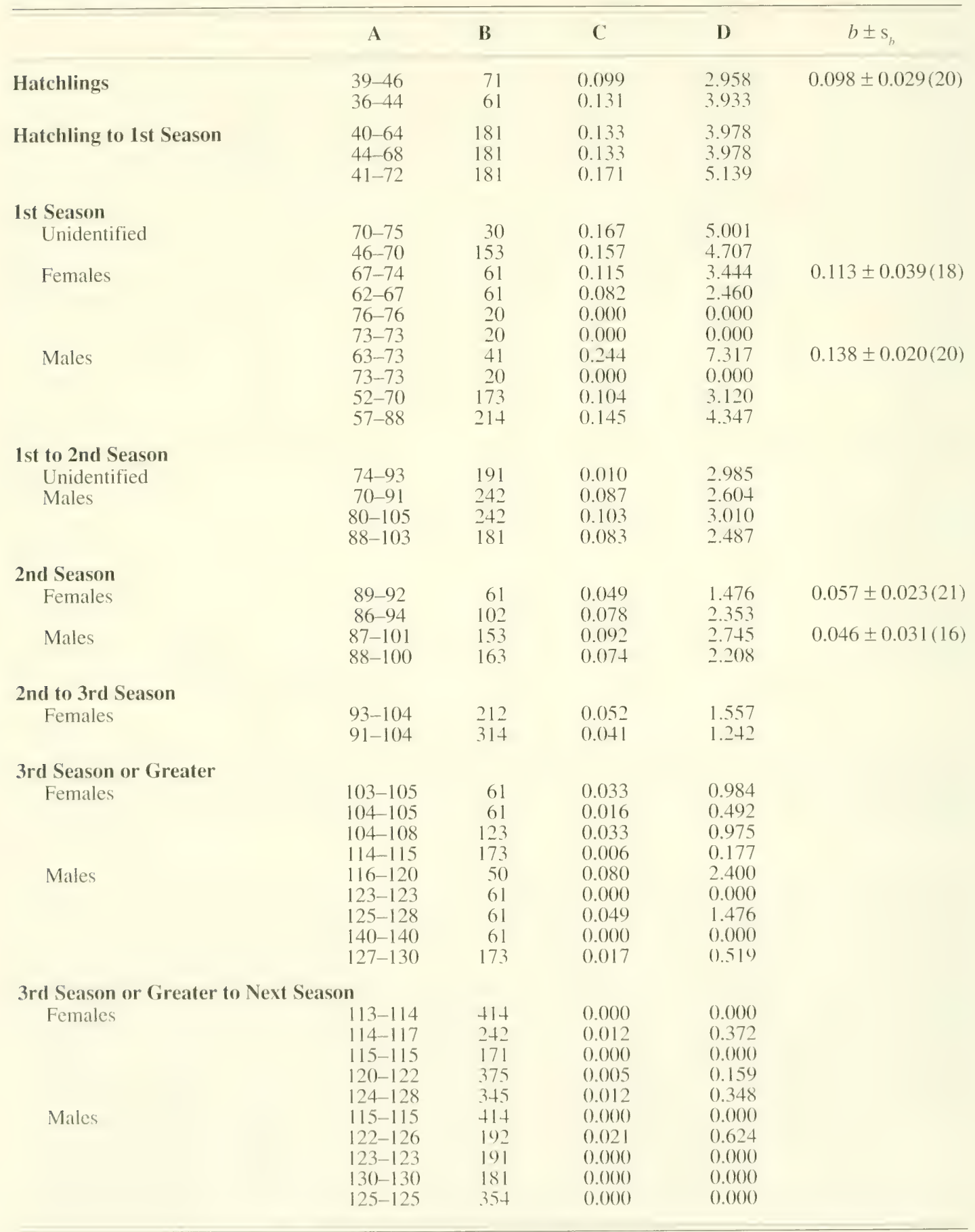


Table 4. Comparison of slope and elevation of regression lines for growth rates of high and low altitude A. tuberculata. Symbols as in Table 2 except as noted.
$t$ for $b_{1}=b_{2}(\mathrm{df})$
$b_{c} \pm \mathrm{s}_{h}$
$t$ for $a_{1}=a_{2}(\mathrm{df})$

\section{Male vs. Female}

High altitude 1st Season

High altitude 2 nd Season

0.585 (34) $\quad 0.9>P>0.5$

$0.132 \pm 0.018(38)$

0.328

(35) $0.9>P>0.5$

Low altitude 1 st Season

0.299 (33) $\quad 0.9>P>0.5$

$0.053 \pm 0.018(37)$

1.815

(34) $0.1>P>0.05$

Low altitude 2nd Season

$0.716(36) \quad 0.5>P>0.4$

$0.136 \pm 0.017(40)$

0.493

(37) $0.9>P>0.5$

$1.133(33) \quad 0.4>P>0.2$

$0.040 \pm 0.014(37)$

$2.756^{*} *(34)$

High vs. Low altitude
Hatchling
0.096 (30) $\quad P>0.9$
$0.093 \pm 0.029(34)$
1.980
(31) $0.1>P>0.05$
Female 1st Season
$\begin{array}{lll}0.729 & \text { (38) } & 0.5>P>0.4\end{array}$
$0.141 \pm 0.017(42)$
4.412 **** (39)
Female 2nd Season
1.157 (37) $\quad 0.4>P>0.2$
$0.039 \pm 0.014(41)$
$6.635 * * *(38)$
Male 1st Season
0.462 (32) $0.9>P>0.5$
$0.129 \pm 0.019(36)$
$3.150 * *$ (33)
Male 2nd Season
0.287 (29) $\quad 0.9>P>0.5$
$0.053 \pm 0.019(33)$
$4.687 * * *(30)$

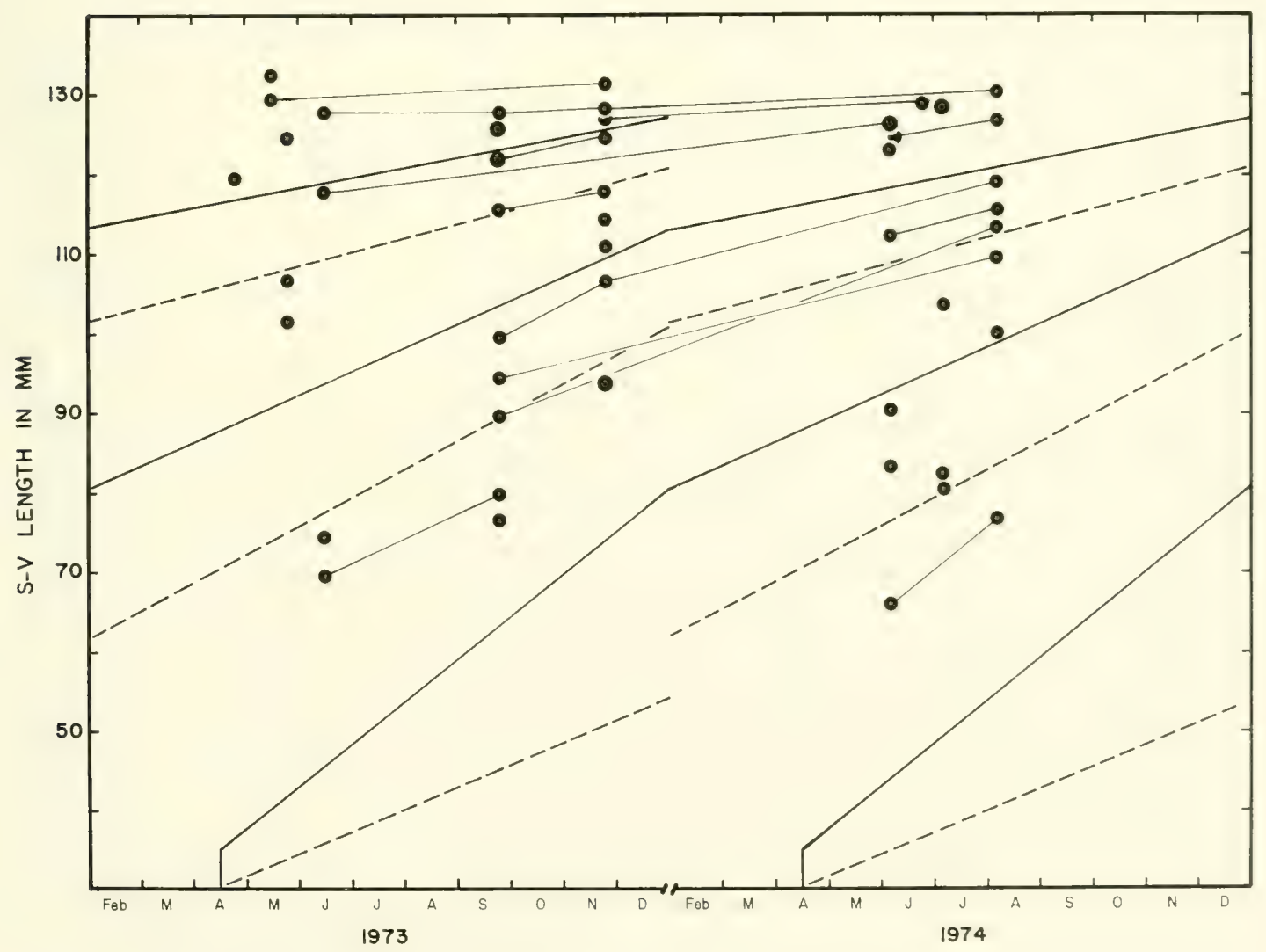

Fig. 16. Growth records for male low altitude A. tuberculata. Lines as in Fig. 14. Large symbols show two records, small symbols one record. The hatchling regression line is for records shown in Fig. 17. 


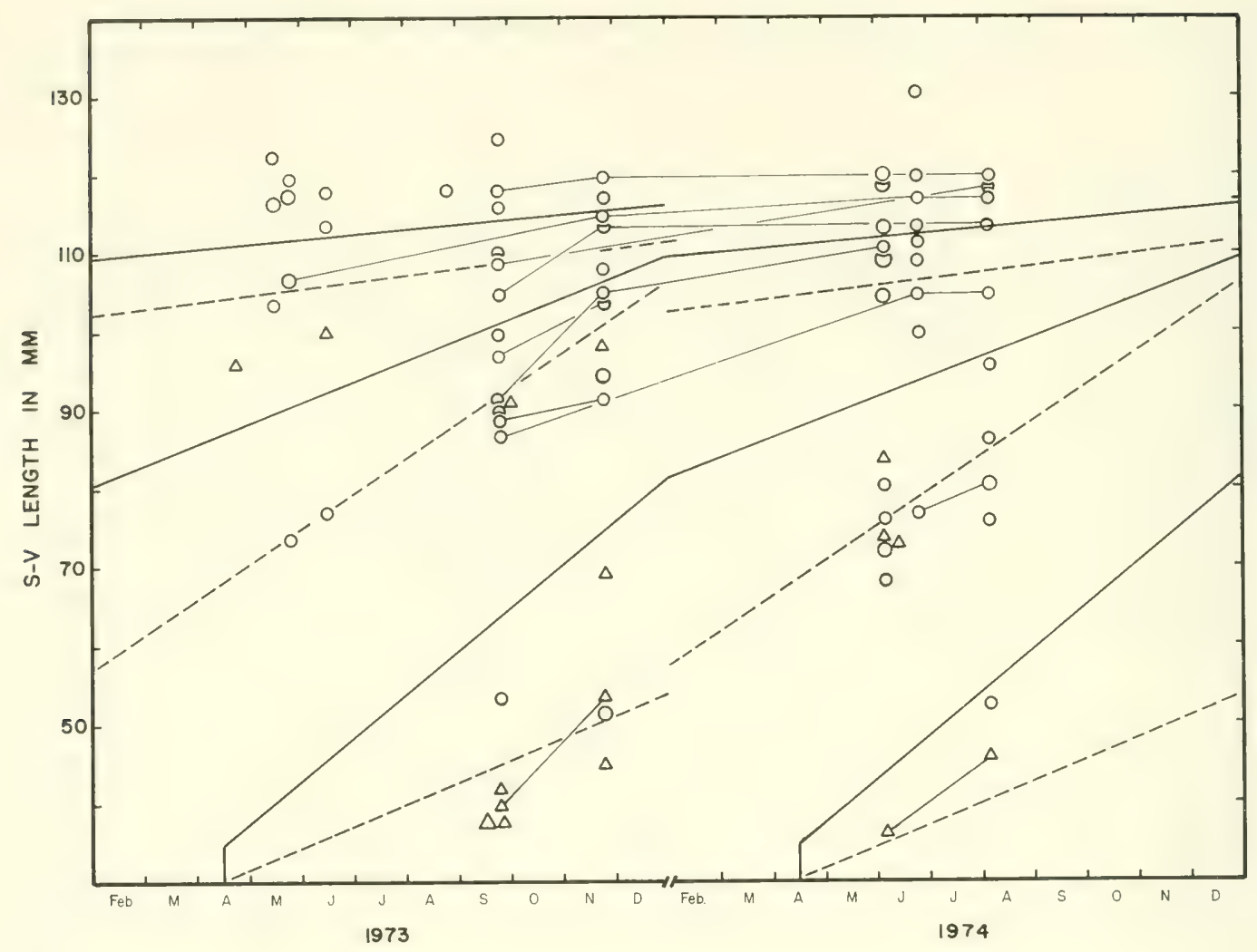

Fig. 17. Growth records for low altitude female (circles) and unsexed (triangles) A. tuberculata. Lines and symbols as in Fig. 14.

111 Agama caucasica examined in Russia. Increased herbivory among larger individuals may be possible because they have the physical strength to adequately macerate large amounts of vegetation (Sokol, 1967). Also, Pough (1973) and Troyer (1984) proposed that the higher energy requirement per body weight of small lizards is met by eating energy-rich insects, whereas adults find it difficult to catch active insects so they ingest more plant material which requires much less of an expenditure of energy to procure. Increasing herbivory with increasing age has also been found in various iguanids; for example, Péfaur and Duellman (1980) noted it in Liolaemus multiformis of the high Andes.

Increase in the animal component of the diet in the monsoons is to be expected because during that season a wide variety of insects are generally available. Also, some other taxa of invertebrates, such as millipedes and snails, are more active then. Spiders were taken in the same or smaller percent volume in the monsoons compared with other seasons. This may be a result of decreased abundance of spiders or the increased abundance of insects.

Qualitative dietary differences in addition to the animal versus plant component are also evident between age classes. Hatchlings at high altitude had a much greater proportion of spiders in their diet than did older lizards during late Novemberearly December. The greatly reduced availability of insects at this time of year may account for most of this difference. Studies of food habits in Eumeces egregius (Mount, 1963), Cnemidophorus hyperythrus beldingi (Bostic, 1966), and Sceloporus undulatus, S. magister, and Cnemidophorus tigris 
Table 5. Growth of recaptured low altitude A. tuberculata. Individual growth rates may be compared to the average growth rate for each category (right hand column) calculated from data in Figs, 16-17. A=SVL at Ist and

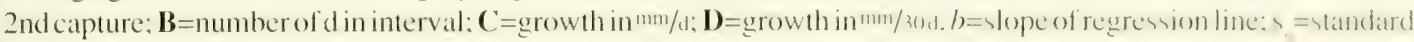
error of regression line; ( )=sample size.

\begin{tabular}{|c|c|c|c|c|c|}
\hline & A & B & C & l) & $b \pm s_{b}$ \\
\hline \multirow[t]{2}{*}{ Hatchlings } & $36-46$ & 61 & 0.164 & 4.917 & $0.091 \pm 0.050(14)$ \\
\hline & $40-54$ & 61 & 0.230 & 6.885 & \\
\hline \multicolumn{6}{|c|}{ Hatchling to 1st Season } \\
\hline Females & $52-76$ & 181 & 0.133 & 3.978 & \\
\hline \multicolumn{6}{|l|}{ 1st Season } \\
\hline Unidentified & 89-92 & 61 & 0.049 & 1.476 & \\
\hline \multirow[t]{5}{*}{ Females } & $77-92$ & 102 & 0.147 & 4.413 & $0.146 \pm 0.019(24)$ \\
\hline & $92-105$ & 61 & 0.213 & 6.393 & \\
\hline & $77-81$ & 41 & 0.098 & 2.928 & \\
\hline & $97-104$ & 61 & 0.115 & 3.444 & \\
\hline & $89-92$ & 61 & 0.049 & 1.475 & \\
\hline \multirow[t]{4}{*}{ Males } & $66-77$ & 61 & 0.180 & 5.409 & $0.120 \pm 0.034(16)$ \\
\hline & $70-80$ & 102 & 0.098 & 2.940 & \\
\hline & $75-90$ & 102 & 0.147 & 4.413 & \\
\hline & $100-107$ & 61 & 0.115 & 3.444 & \\
\hline \multicolumn{6}{|l|}{ 1st to 2nd Season } \\
\hline \multirow[t]{2}{*}{ Females } & $87-105$ & 242 & 0.074 & 2.232 & \\
\hline & $105-111$ & 161 & 0.037 & 1.119 & \\
\hline \multirow[t]{3}{*}{ Males } & $90-114$ & 283 & 0.085 & 2.544 & \\
\hline & $95-110$ & 283 & 0.053 & 1.590 & \\
\hline & $107-119$ & 222 & 0.054 & 1.623 & \\
\hline \multicolumn{6}{|l|}{ 2nd Season } \\
\hline \multirow[t]{3}{*}{ Females } & $105-105$ & 41 & 0.000 & 0.000 & $0.025 \pm 0.016(20)$ \\
\hline & $105-114$ & 61 & 0.148 & 4.425 & \\
\hline & $107-115$ & 184 & 0.044 & 1.305 & \\
\hline \multirow[t]{3}{*}{ Males } & $113-116$ & 61 & 0.049 & 1.176 & $0.057 \pm 0.025(17)$ \\
\hline & $116-118$ & 61 & 0.033 & 0.987 & \\
\hline & $123-125$ & 61 & 0.033 & 0.987 & \\
\hline \multicolumn{6}{|c|}{ 2nd to 3rd Season } \\
\hline \multirow[t]{4}{*}{ Females } & $105-111$ & 161 & 0.037 & 1.119 & \\
\hline & $109-118$ & 282 & 0.032 & 0.957 & \\
\hline & $114-114$ & 202 & 0.000 & 0.000 & \\
\hline & $115-117$ & 181 & 0.011 & 0.330 & \\
\hline Males & $118-126$ & 324 & 0.025 & $0.7+1$ & \\
\hline \multicolumn{6}{|c|}{ 3rd Season or Greater } \\
\hline \multirow[t]{4}{*}{ Males } & $125-127$ & 61 & 0.033 & 0.987 & \\
\hline & $128-128$ & 102 & 0.000 & 0.000 & \\
\hline & $128-128$ & 61 & 0.000 & 0.000 & \\
\hline & $130-132$ & 194 & 0.010 & 0.309 & \\
\hline \multicolumn{6}{|c|}{ 3rd Season or Greater to Next Season } \\
\hline \multirow[t]{2}{*}{ Males } & $127-129$ & 181 & 0.011 & 0.330 & \\
\hline & $128-131$ & 222 & 0.014 & 0.405 & \\
\hline
\end{tabular}




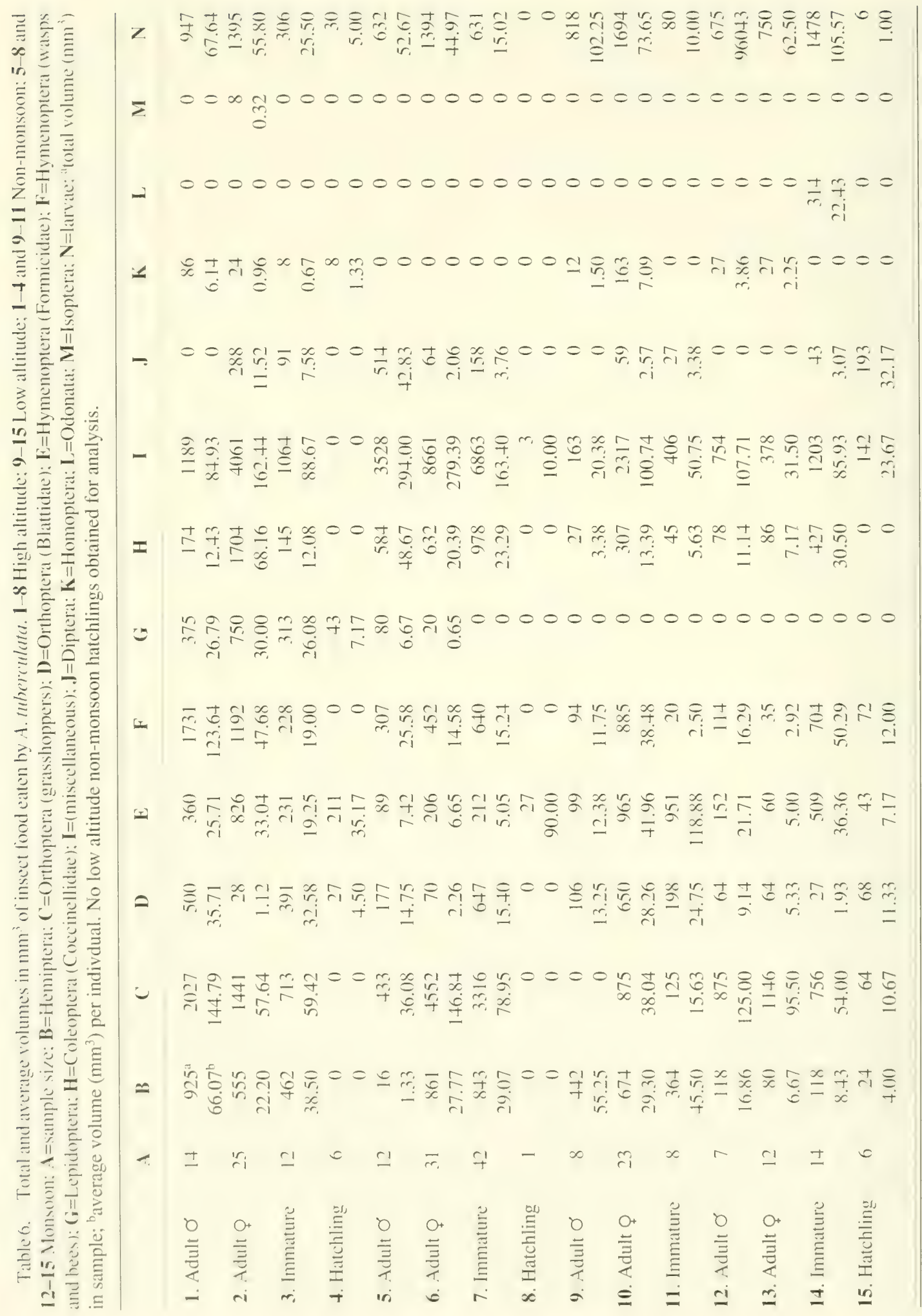




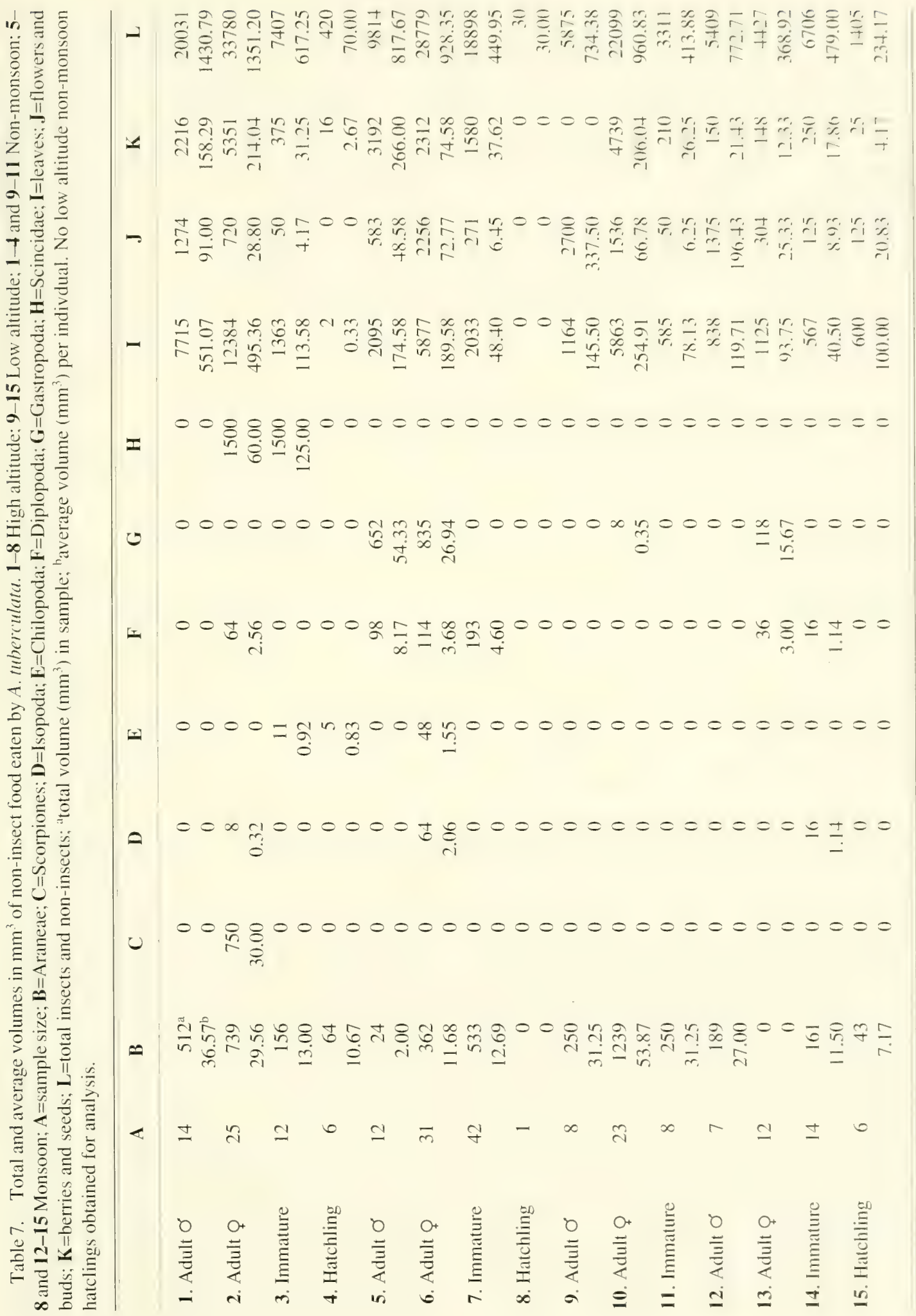




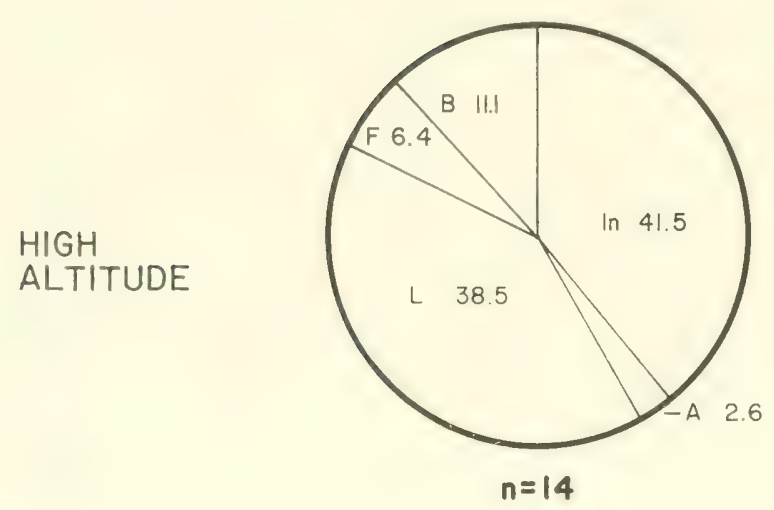

LOW
ALTITUDE

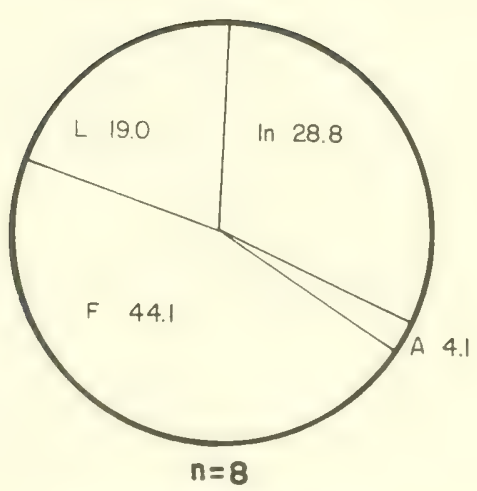

NON-MONSOON
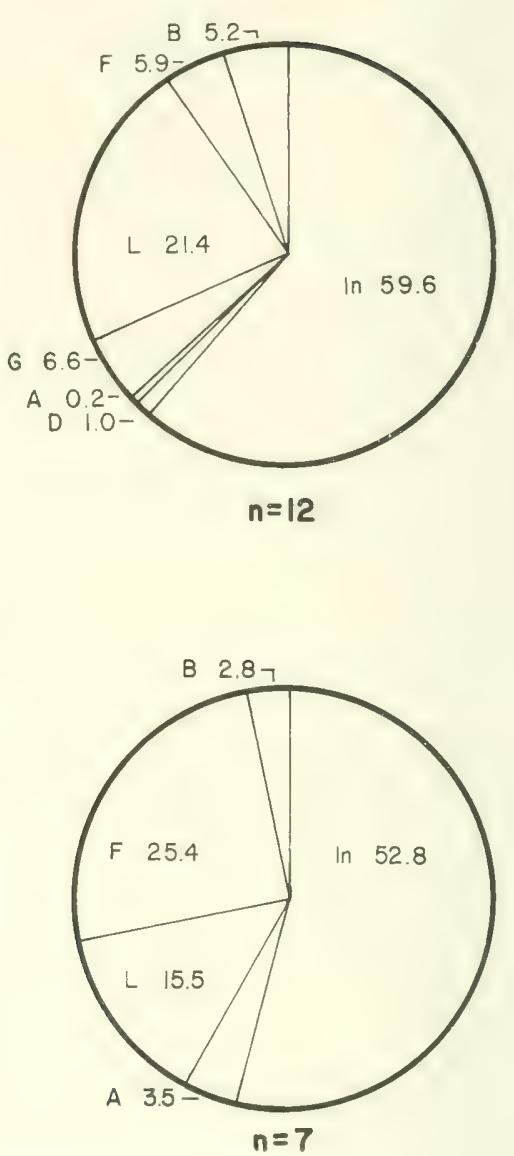

MONSOON

Fig. 18. Changing composition of the diet of adult male high and low altitude $A$. tuberculata. Sample sizes as in Tables 6-7. $\mathrm{A}=$ Aranae, $\mathrm{B}=$ berries and seeds, $\mathrm{C}=$ Chilopoda, $\mathrm{D}=\mathrm{Diplopoda}, \mathrm{F}=$ flowers and buds, $\mathrm{G}=\mathrm{Gastropoda}$, In=Insecta, Is=Isopoda, L=leaves, $\mathrm{Sc}=$ Scorpiones, $\mathrm{Sk}=$ Scincidae.

(Johnson, 1966) have not revealed differences between age classes. However, distinct dietary differences between juveniles and adults have been reported for Takydromus tachydromoides (Jackson and Telford, 1975). They found juveniles to feed equally on spiders and insects, whereas in adults the biomass of insects taken was three times that of the spiders. The difference was attributed to a possible preference by juveniles for soft-bodied prey and the almost total lack of availability of insects in late fall and early spring when adults were relatively inactive compared to juveniles. Differences in the jaw mechanism of adult and juvenile Agama bibroni have been implicated in dietary differences between age groups (CapelWilliams and Pratten, 1978) with adults eating mainly Orthoptera and juveniles mainly Hymenoptera and Formicidae. Paulissen (1987) reported that adult Cnemidophorus sexlineatus preferred grasshoppers and avoided plant arthropods whereas juveniles had a reversed preference for the same groups. Schoener (1971) predicted that food size should decrease with decreasing predator size within a species. This prediction was borne out in Takydromus tachydromoides (Jackson and Telford, 1975) and also in Agama tuberculata in the present study. Ants eaten by hatchling A. tuberculata were exclusively of the smallest species available 

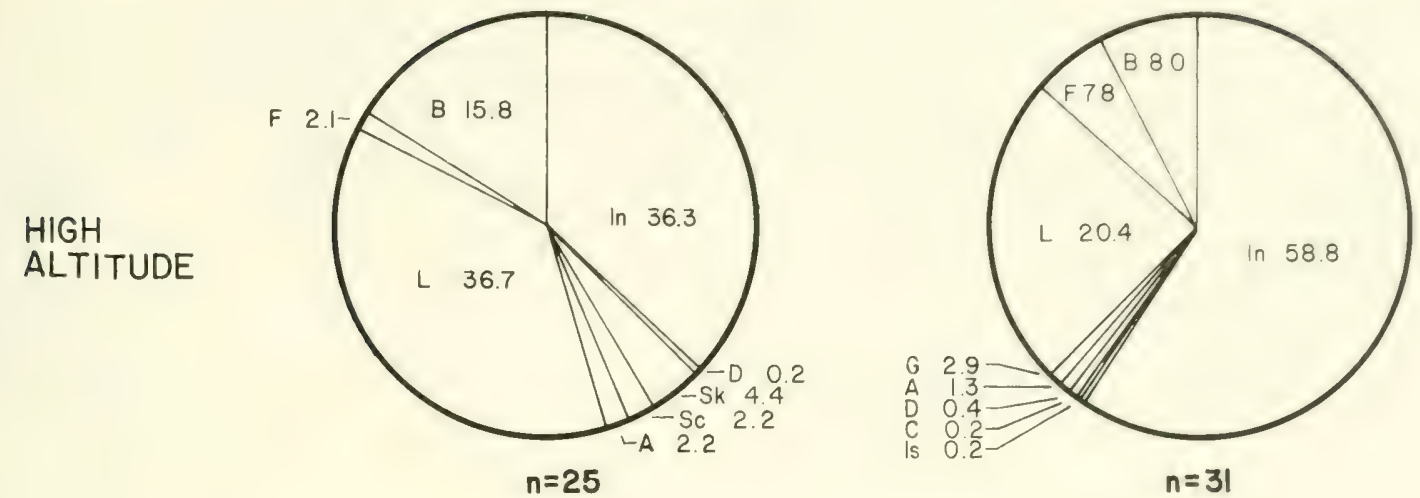

\section{LOW ALTITUDE}
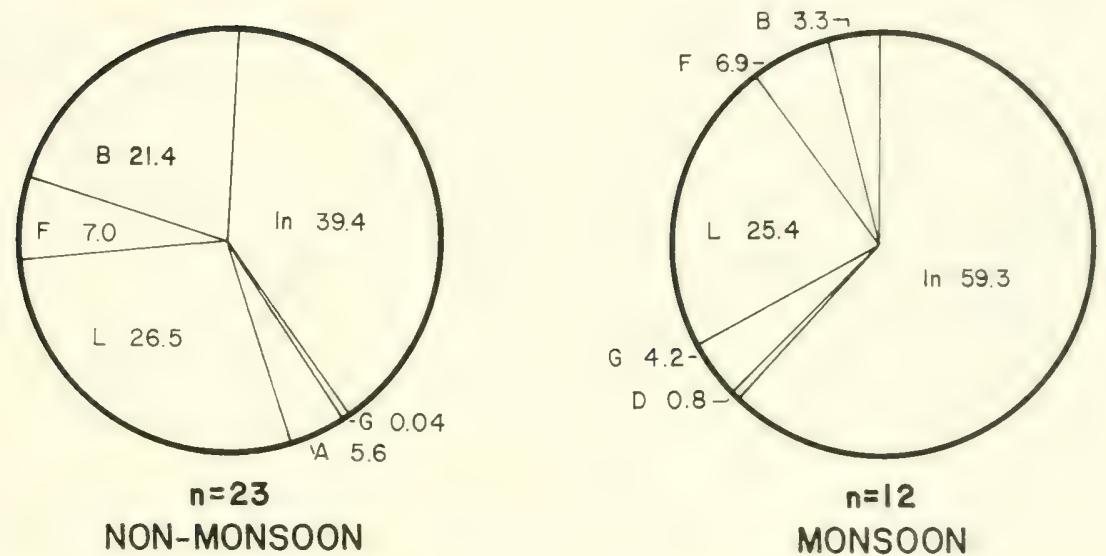

Fig. 19. Changing composition of the diet of adult female high and low altitude A. tuberculata. Sample sizes as in Tables 6-7, symbols as in Fig. 18.

whereas older lizards tended to eat ants of larger species.

The importance ( $\%$ of total volume eaten) of different orders of insects in the diet changes with the season (Tables 8, 9). Except for high altitude adult males, more grasshoppers and beetles were eaten (irrespective of altitude) during the monsoons than at other times. Lizards at low altitude ate more larvae during the monsoons. Fewer cockroaches were eaten during the monsoons than at other times. Ants are more important in the diet of hatchlings at high altitude than at low altitude whereas immatures at low altitude eat more ants than at high altitude. No Lepidoptera were recorded from the guts of lizards at low altitude: however, in my field notes I have recorded several instances of successful pursuit of butterflies by immatures. Rapidly flying insects such as Diptera were caught most frequently by immatures or hatchlings.

Comparisons by Kendall's rank correlation (Tables 10,11) reveals that the diet of adult males. adult females, and immatures have a significant positive correlation to each other within each season and altitude (except for adult males and immatures at low altitude during the non-monsoon months). Diet of hatchlings at high altitude in late fall tends to be negatively correlated with the other age groups (significantly so with high altitude adult females during the non-monsoon months) 


\section{HIGH ALTITUDE}
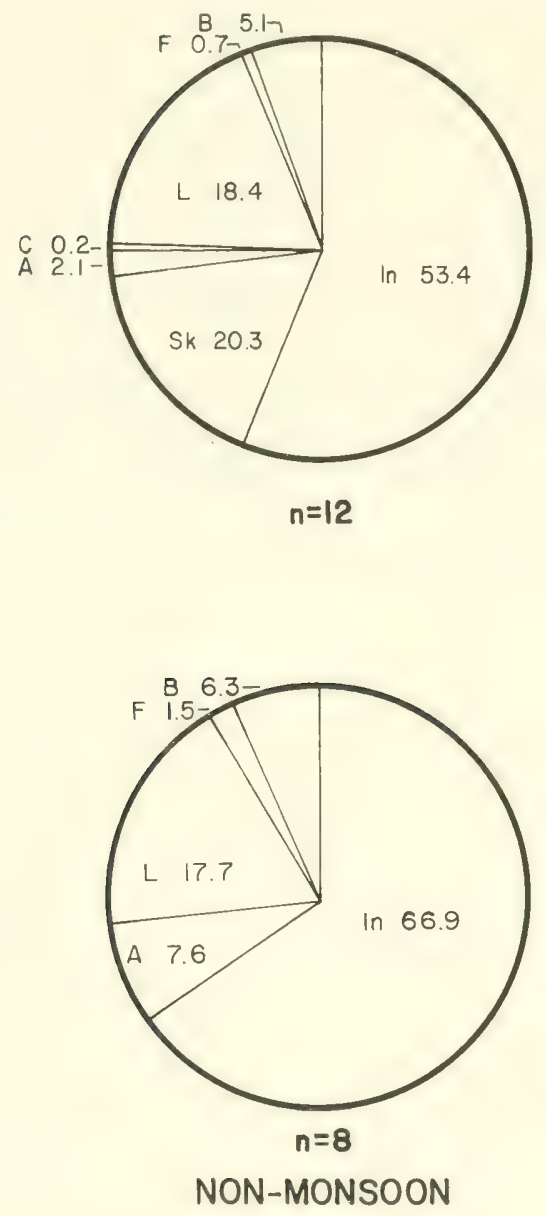
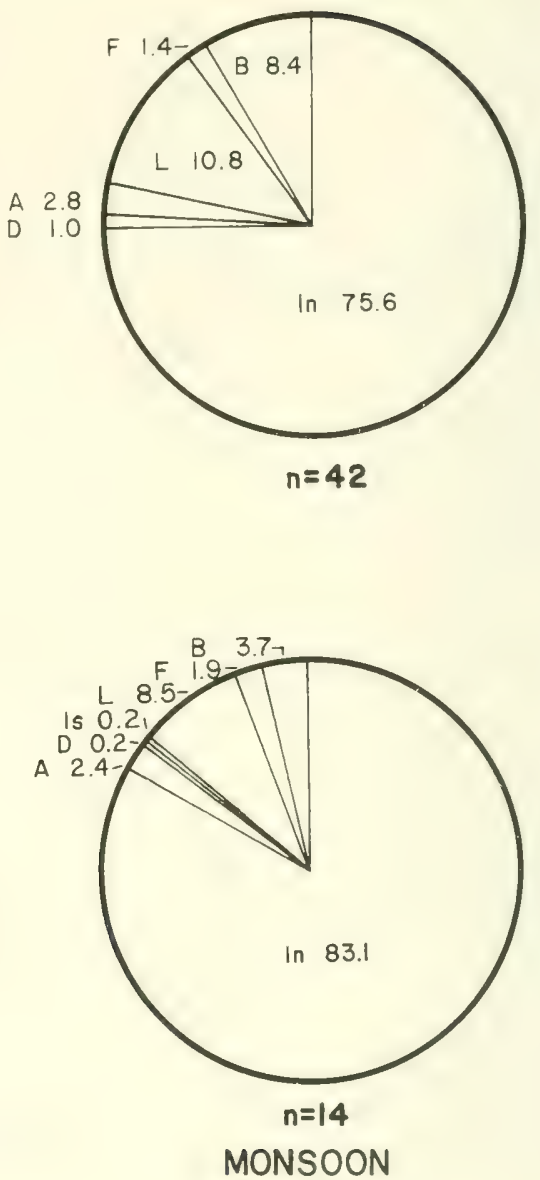

Fig. 20, Changing composition of the diet of immature high and low altitude $A$. tuberculata. Sample sizes as in Tables 6-7, symbols as in Fig. 18.

\section{Quantitative Considerations}

regardless of altitude or seasonal comparisons. Low altitude hatchlings appear earlier in the year than at high altitude and their diet during the monsoons is not significantly different from any other group. The diet of high altitude hatchlings is markedly different from other groups because ants are the most available food in late fall. The low altitude monsoon collections indicate that when hatchlings are presented with a choice of food, their diet becomes more similar (a non-significant positive correlation) to that of the other age classes.
Quantitative comparison of diet reveals that adult males of $A$. tuberculata had the least relative volume of food in their stomachs per gram body weight (Table 12), adult females ranked second, and immatures had the most. There were insufficient data to determine the relative amount of food contained by hatchlings but indications are that they ate as much or more food per gram body weight than even immatures. Jameson et al. (1980) noted a similar trend for Sceloporus occidentalis. Younger lizards consume larger amounts of food 


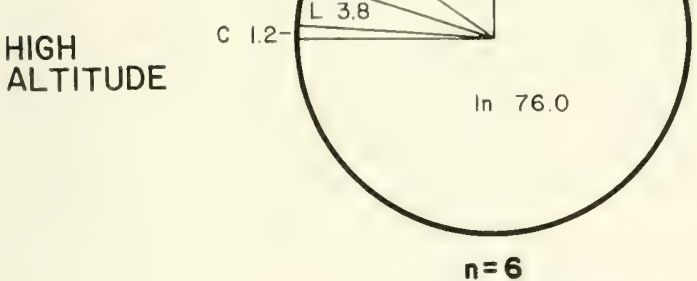

NON-MONSOON

\section{LOW} ALTITUDE

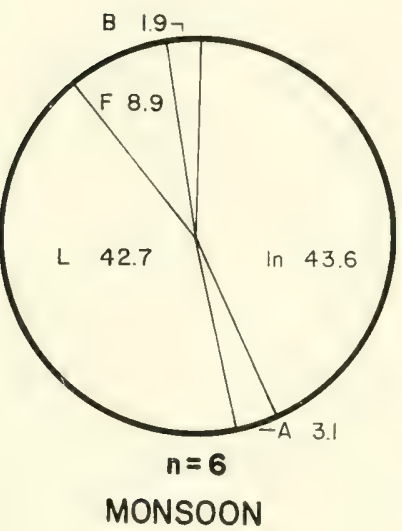

Fig. 21. Diet of hatchling high and low altitude $A$. tuberculata. Sample sizes as in Tables 6-7, symbols as in Fig. 18.

probably because they have proportionally greater energy requirements per gram of body weight than larger individuals. In the small Japanese lacertid, Takydromus tachydromoides, Jackson and Telford (1975) found juveniles to consume relatively larger amounts of food than adults and proposed that their high level of consumption would "correspond to higher energy requirements necessary for rapid growth of young lizards." Schoener and Gorman (1968) have noted similar findings for anoles in the Lesser Antilles.

The amount of food eaten by lizards at high altitude is less during the monsoons compared to the non-monsoon months. Temperatures are lower during the monsoons and lizards were observed to spend much of their time thermoregulating. At low altitude, adult males and immatures ate no less food during the monsoons. In spite of increased cloud cover, ambient temperatures were high enough that there was no need for protracted thermoregulatory activity. Low altitude adult females, however, showed a marked decrease in amount of food eaten. Ten of the 12 individuals in the sample were gravid with nearly mature oviducal eggs, but the two nongravid females also had eaten little.

\section{DAILY AND SEASONAL ACTIVITY}

Hourly censuses throughout the day for different months revealed varying degrees of activity (Figs. 22-27). Counts included all visible individuals regardless of the type of activity. Most observations were of inactive individuals; adults engaged in few prolonged periods of active foraging. Rather, they occasionally dash out from a favorite basking place or look-out point and promptly return to it or another point after each sortie. Juveniles were observed to search for food more actively than older individuals. Lizards at low altitude engaged in more active searching than those at high altitude.
High altitude.-During the hot season, lizards emerged from their crevices after 8:30 am and returned before $6: 30 \mathrm{pm}$ (Fig, 22). Adults and young emerged about the same time but the smaller individuals did not bask as long as the adults before dispersing, as also noted for Agama sanguinolenta (Berezhnoi, 1980). Lizards did not emerge from their crevices until direct sunlight was available. Due to the exposure of the study site, initiation of activity was delayed till several hours after sunrise. A secondary study area at the Polo Grounds in Mussoorie received early morning sun but was in shade by mid-afternoon; compared with the 
Table 8. Importance (\% of total volume) of various categories of insects in the diet of high altitude A. tuberculata. A, E=adult male; $\mathbf{B}, \mathbf{F}=$ adult female; $\mathbf{C}, \mathbf{G}=$ immature; $\mathbf{D}, \mathbf{H}=$ hatchling; ( )=sample size.

\begin{tabular}{|c|c|c|c|c|c|c|c|c|}
\hline & \multicolumn{4}{|c|}{ Non-monsoon } & \multicolumn{4}{|c|}{ Monsoon } \\
\hline & $\begin{array}{c}\mathbf{A} \\
(14)\end{array}$ & $\begin{array}{c}\mathbf{B} \\
(25)\end{array}$ & $\begin{array}{c}\mathrm{C} \\
(12)\end{array}$ & $\begin{array}{l}\text { D } \\
(6)\end{array}$ & $\begin{array}{c}\mathbf{E} \\
(12)\end{array}$ & $\begin{array}{c}\mathbf{F} \\
(31)\end{array}$ & $\begin{array}{c}\mathbf{G} \\
(42)\end{array}$ & $\begin{array}{l}\mathbf{H} \\
(1)\end{array}$ \\
\hline Hemiptera & 4.6 & 1.6 & 6.2 & 0.0 & 0.2 & 3.0 & 4.5 & 0.0 \\
\hline $\begin{array}{l}\text { Orthoptera } \\
\quad \text { (grasshoppers) }\end{array}$ & 10.1 & 4.3 & 9.6 & 0.0 & 4.4 & 15.8 & 17.5 & 0.0 \\
\hline $\begin{array}{l}\text { Orthoptera } \\
\quad \text { (Blattidae) }\end{array}$ & 2.5 & 0.1 & 5.3 & 6.4 & 1.8 & 0.2 & 3.4 & 0.0 \\
\hline $\begin{array}{l}\text { Hymenoptera } \\
\text { (Formicidae) }\end{array}$ & 1.8 & 2.4 & 3.1 & 50.3 & 0.9 & 0.7 & 1.1 & 90.0 \\
\hline $\begin{array}{l}\text { Hymenoptera } \\
\text { (wasps \& bees) }\end{array}$ & 8.6 & 3.5 & 3.1 & 0.0 & 3.1 & 1.6 & 3.4 & 0.0 \\
\hline Lepidoptera & 1.9 & 2.2 & 4.2 & 10.2 & 0.8 & 0.1 & 0.0 & 0.0 \\
\hline $\begin{array}{l}\text { Coleoptera } \\
\quad \text { (Coccinellidae) }\end{array}$ & 0.9 & 5.0 & 2.0 & 0.0 & 6.0 & 2.2 & 5.2 & 0.0 \\
\hline $\begin{array}{l}\text { Coleoptera } \\
\quad \text { (miscellaneous) }\end{array}$ & 5.9 & 12.0 & 14.4 & 0.0 & 36.0 & 30.2 & 36.3 & 10.0 \\
\hline Diptera & 0.0 & 0.9 & 1.2 & 0.0 & 0.0 & 0.2 & 8.4 & 0.0 \\
\hline Homoptera & 0.4 & 0.1 & 0.1 & 0.1 & 1.9 & 0.0 & 0.0 & 0.8 \\
\hline Odonata & 0.0 & 0.0 & 0.0 & 0.0 & 0.0 & 0.0 & 0.0 & 0.0 \\
\hline Isoptera & 0.0 & 0.02 & 0.0 & 0.0 & 0.0 & 0.0 & 0.0 & 0.0 \\
\hline Total larvae & 4.7 & 4.1 & 4.1 & 7.1 & 6.5 & 4.8 & 3.4 & 0.0 \\
\hline
\end{tabular}

Dhanaulti study site, the lizards were active as much as $1.5 \mathrm{~h}$ earlier but retreated into crevices up to $1.5 \mathrm{~h}$ earlier in the afternoon. As individuals basked, they occasionally snapped at hovering gnats or rapidly scratched their heads or bodies. There were intermittent flurries of activity as they jockeyed for suitable basking positions. Occasionally, adults clambered on top of each other or on subadults.

Lizards were seen in maximum numbers by 10 or $11 \mathrm{am}$. Most were seen throughout the day until late afternoon when again there was a slight rise in activity. By $6 \mathrm{pm}$ there was a sharp drop in activity and before sunset all individuals had retired to their crevices. At mid-day, even though many of the lizards were visible, most of them were in shade or facing the sun and holding their bodies high above the substrate. At this time, some adult males kept watch over their territories from sheltered places such as beneath rock overhangs.

Adults remained basking beside their crevices for extended periods before retiring for the night during May and June. They usually did not reemerge if forced to take cover during this basking period. Extensive basking of females at this time of year probably expedites maturation of their clutches.

During the monsoons (July), lizards emerged from crevices about the same time as in the dry season, but spent a longer time basking before moving to their areas of activity. In fact, if there was a heavy overcast or mist, the lizards remained beside their crevices and did not forage. Because of decreased insolation, individuals foraged throughout the day rather than retiring to shade at mid-day. 
Table 9. Importance (\% of total volume) of various categories of insects in the diet of low altitude A. tuberculata $\mathbf{A}, \mathbf{E}=$ adult male; $\mathbf{B}, \mathbf{F}=$ adult female; $\mathbf{C}, \mathbf{G}=$ immature; $\mathbf{D}, \mathbf{H}=$ hatchling; ( )=sample size.

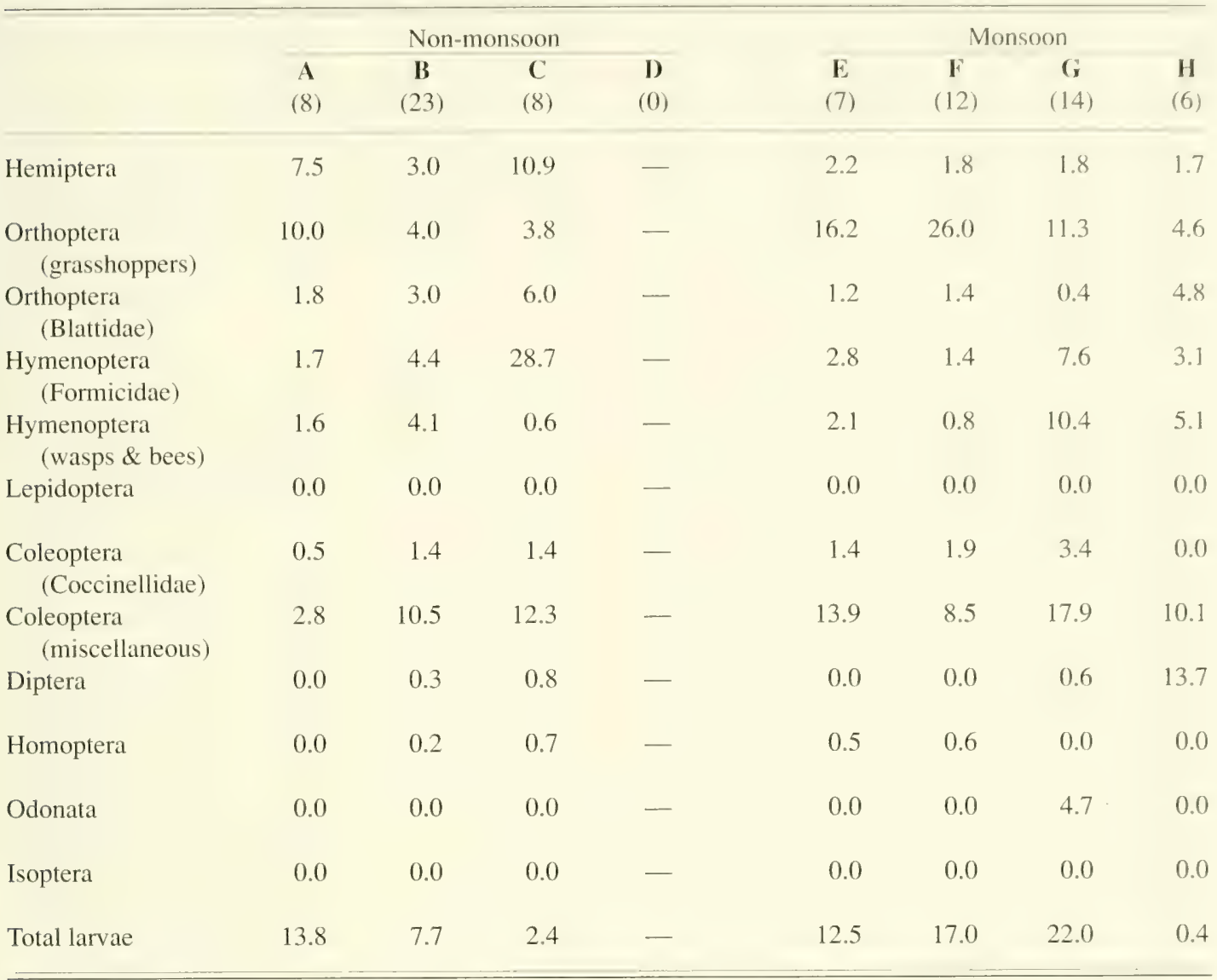

Most of the lizards were basking near their crevices by mid-afternoon and they retired for the day as much as two hours before sunset. The increased time spent basking during this season evidently served to maintain body temperature near the "preferred" level in spite of less insolation.

The early post-monsoon period (late September) is characterized by a fairly high level of lizard activity throughout the day. A sharp reduction in activity after $5: 30 \mathrm{pm}$ may be a response to the decreasing photoperiod or ambient temperatures which rapidly decrease in the late afternoon. By late November-early December, those lizards which are still active delay their emergence until late morning and retire by mid-afternoon.

From September onwards, a sharp reduction in activity is evident in all age classes except hatch- lings (Figs. 23-27). Hatchlings were the only age group that I observed foraging in late November and early December. Subadults and adults did not forage but remained close to crevices as they basked. A definite change in the physiology of the lizards had occurred, so that although adult body temperature was well within their previous activity range, foraging did not occur. Hatchlings began to emerge from their crevices within 2 minutes after there was direct sunlight in the vicinity and when air temperature might be only $15.1^{\circ} \mathrm{C}$. The smallest lizards actively foraged until retiring for the day. Larger hatchlings did some basking during midday. On 28 November the study area was in shade by $4: 07 \mathrm{pm}$ and all hatchlings were in their crevices within 3 minutes, when the air temperature was $13.5^{\circ} \mathrm{C}$. On this same day less than $1.5 \mathrm{~km}$ from the 
Table 10. Kendall's rank correlation comparing food habits of A. tuberculata of different ages and sex at high altitude for two different times of the year. Rows 1-4 Non-monsoon; 5-6 Monsoon. One monsoon hatchling and 42 monsoon immatures. ( )=sample size.

\begin{tabular}{|c|c|c|c|c|c|c|c|}
\hline & \multicolumn{3}{|c|}{ Non-monsoon } & \multicolumn{3}{|c|}{ Monsoon } & \\
\hline & Adult Q & Immature & Hatchling & Adult $\sigma$ & Adult $Q$ & Immature & \\
\hline 1. Adult $\sigma$ & $0.429 * *$ & $0.573 * *$ & -0.279 & 0.235 & $0.546^{* * *}$ & 0.527 & (14) \\
\hline 2. Adult $\bigcirc$ & & $0.440^{* * *}$ & $-0.360^{*}$ & 0.263 & $0.388 *$ & $0.443 * *$ & (25) \\
\hline 3. Immature & & & -0.353 & 0.274 & $0.391 *$ & $0.644 * * *$ & (12) \\
\hline 4. Hatchling & & & & -0.192 & -0.219 & -0.237 & (6) \\
\hline 5. Adult $\sigma$ & & & & & $0.533 * *$ & $0.366^{*}$ & (12) \\
\hline 6. Adult $q$ & & & & & & $0.660^{* * * *}$ & (31) \\
\hline
\end{tabular}

study area a subadult remained basking for only 5 minutes after lengthening late afternoon shadows engulfed its perch at 4:30 pm.

Low altitude.-Pre-monsoon activity of lizards at low altitude showed strong peaks from early to mid-morning and again in mid- to late afternoon (Fig. 22). Lizards withdrew to deep shade or into crevices at mid-day. As the study site was on the west bank of the Song River, the first rays of the rising sun shone on it. On 12 May before sun-up at an air temperature of $26.6^{\circ} \mathrm{C}$, a juvenile and two adults were at the edge of their crevices. Small lizards were the first to shift to their daytime haunts. In the evening the entire area was in shadow by 4:50 pm. The lizards slowly returned to the vicinity of their crevices and continued foraging until 5:30-6:00 pm. One adult male made occasional sorties until $6: 30 \mathrm{pm}$. Eventually all the lizards were inactive and one by one they disappeared into their crevices, the last at 7:15 pm, when the air temperature was $31.1^{\circ} \mathrm{C}$. At dusk on one occasion in June I observed an adult female and adult male clamber out onto a bush jutting from the hillside. This was the only case I observed in which lizards did not enter a crevice for the night.

During the monsoons, lizards did not become active as early in the morning as at other times and the incidence of diurnal basking in the open in-

Table 11. Kendall's rank correlation comparing food habits of A. tuberculata of different ages and sex at low and high altitude for two different times of the year. Rows 1-4 and 8-10 Non-monsoon; 5-7 and 11-13 Monsoon; 1-7 High altitude; 8 -13 Low altitude. Too few high altitude monsoon and low altitude non-monsoon hatchlings for analysis. Six low altitude monsoon hatchlings. ( )=sample size.

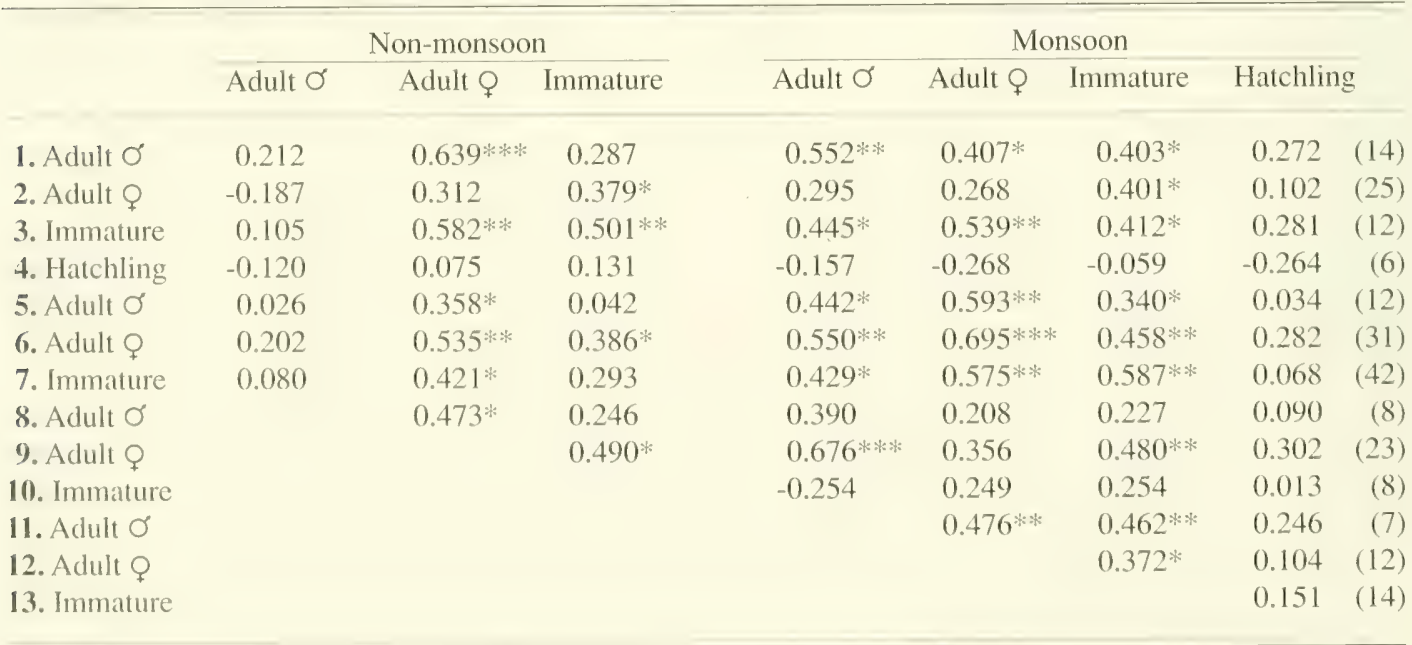


Table 12. Estimated volume of stomach contents in $\mathrm{mm}^{3} / \mathrm{g}$ body weight of $A$. tuberculata. ( )=sample size. $\mathbf{A}=$ Non-monsoon; $\mathbf{B}=$ Monsoon.

$\begin{array}{rrrr}\text { High altitude } & & \text { Low } & \text { Altitude } \\ \text { A } & \text { B } & \text { A } & \text { B }\end{array}$

\begin{tabular}{|c|c|c|c|c|}
\hline Adult $\sigma$ & $23.1(14)$ & $11.6(12)$ & $13.5(8)$ & $15.0 \quad(6)$ \\
\hline Adult $Q$ & $26.3(25)$ & $18.55(27)$ & $19.2(23)$ & $7.3(12)$ \\
\hline Immature & $33.4(12)$ & $21.2 \quad(36)$ & $32.3(8)$ & $31.2(14)$ \\
\hline Hatchling & $32.3(6)$ & $23.1 \quad$ (1) & $-(0)$ & $69.7)$ \\
\hline
\end{tabular}

creased. There was not nearly as much decrease in activity at mid-day as in the hot season (Fig. 22). The lizards also curtailed their late afternoon activity by about 1 hour, but they continued to forage even in moderately hard rain.

The post-monsoon months of September and October showed a continuing decrease in the total amount of activity time; the lizards were active throughout the day and did not seek shelter at midday as they had in the hot season.

As winter approached, an even more important change in activity took place. Lizards which had been living on the breakwater shifted to the natural crevices at the base of the hill. Only about one-half of the population remained active-the rest were packed together deep inside the crevices. The few I was able to extract were very lethargic and had body temperatures approximating ambient. Hatchlings were the only age class that were as numerous outside the crevices during the day as they had been earlier in the year (Figs. 23-27). They were also active for a longer period during the day than the older lizards. The other lizards which were active spent almost all their time basking but on occasion dashed out to seize some food item.

\section{Comparison of the Two Altitudes}

Lizards at high altitude have a shorter season of activity than at low altitude- - a condition also observed by Stevens (1983) for Cnemidophorus inornatus. In the hot season, Agama tuberculata at low altitude were active for a longer time during the day than those at high altitude, but their activity at mid-day was much more sharply reduced. Hertz (1981) also observed a bimodal activity pattern for lowland Anolis roquet as compared to a unimodal pattern for higher level populations. During the monsoon and early post-monsoon, the main difference in Agama tuberculata populations was the total amount of time they were active (longer at low altitude). Both populations sharply reduced the total amount of time they were active during early winter. The hatchlings were the most active in both groups at this time.

Hatchlings at high latitude have a rather short activity season between hatching and the onset of winter. By late November or early December they have made little growth, lack well developed fat bodies, and probably do not have sufficient energy reserves to survive a lengthy hibernation. It is not surprising that they remain active at least into early winter and probably as long as the temperatures permit. The frequency and intensity of their foraging activity indicated that food was plentiful in early December.

Somewhat the same situation applies to hatchlings at low altitude but probably is not of such critical importance because: 1) the hatchlings are larger at a given time than at high altitude, and 2) winter does not last as long.

Body temperatures of basking adults at high altitude in early winter are sufficiently high for foraging activities. They do not forage probably because they have ample fat reserves to overwinter. Fat reserves of lowland lizards are less ample than those of montane populations (see section on reproduction) which may explain why some adults and subadults at low altitude were foraging in early December.

Maximum temperatures in early December at low altitude approximated maximum temperatures in September at high altitude, yet approximately one-half the lizards at low altitude were torpid in December whereas in September the high altitude lizards were active and foraged throughout the day. A. tuberculata is a temperate species that probably invaded the Himalayas from the northwest. Its penetration into areas of lower altitudes may have occurred after eastward migration along the southern flanks of the Himalayas. If so, the period of torpor in winter even at low altitude is readily understood as a physiological response retained in the life cycle. No data were collected to determine the correlation of resource availability and winter inactivity of adults at low altitude. 

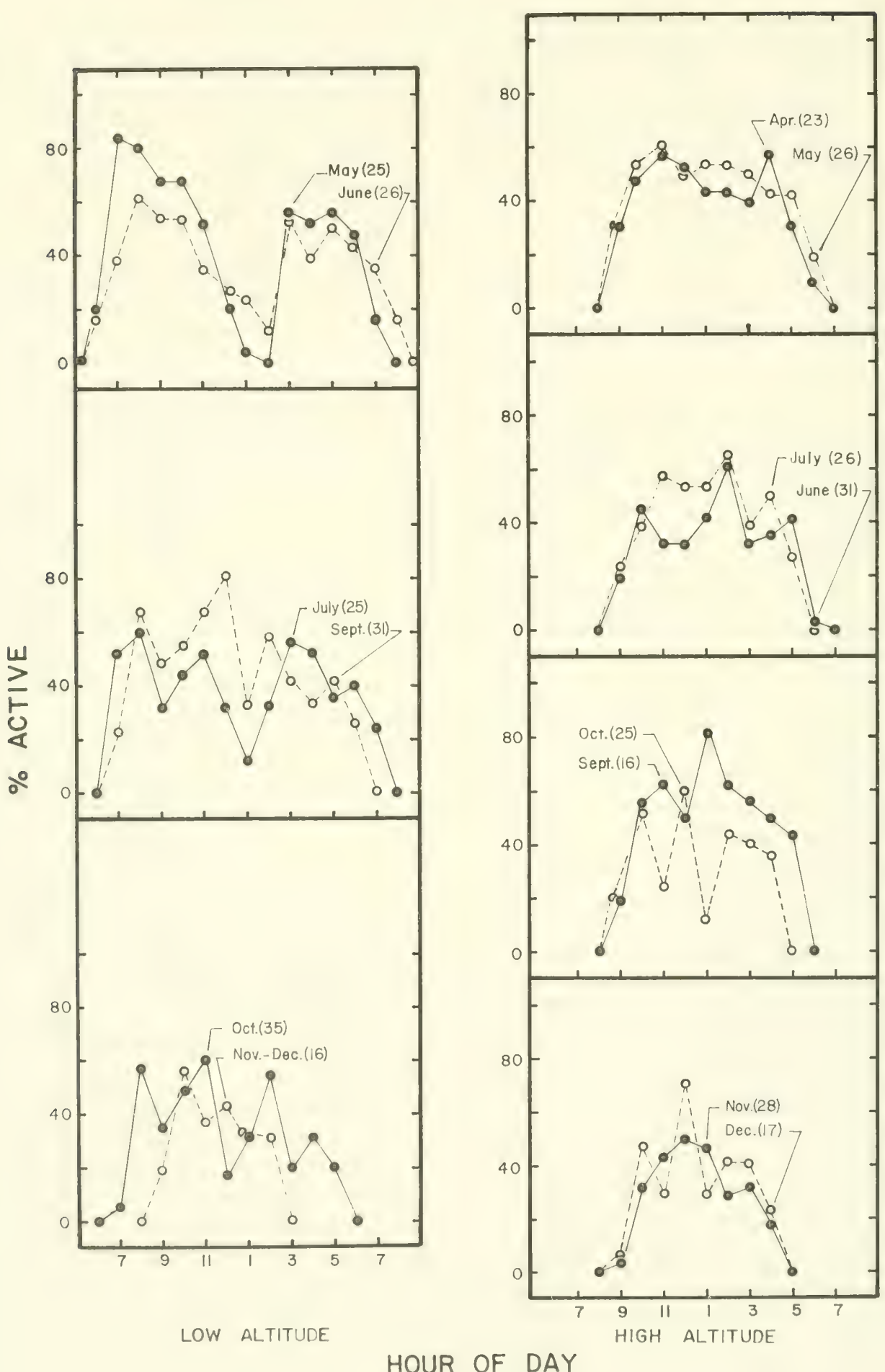

HOUR OF DAY

Fig. 22. High and low altitude A. tuberculata observed at hourly intervals. During the hot season, low altitude lizards retire into crevices at mid-day. ( )=sample size. 


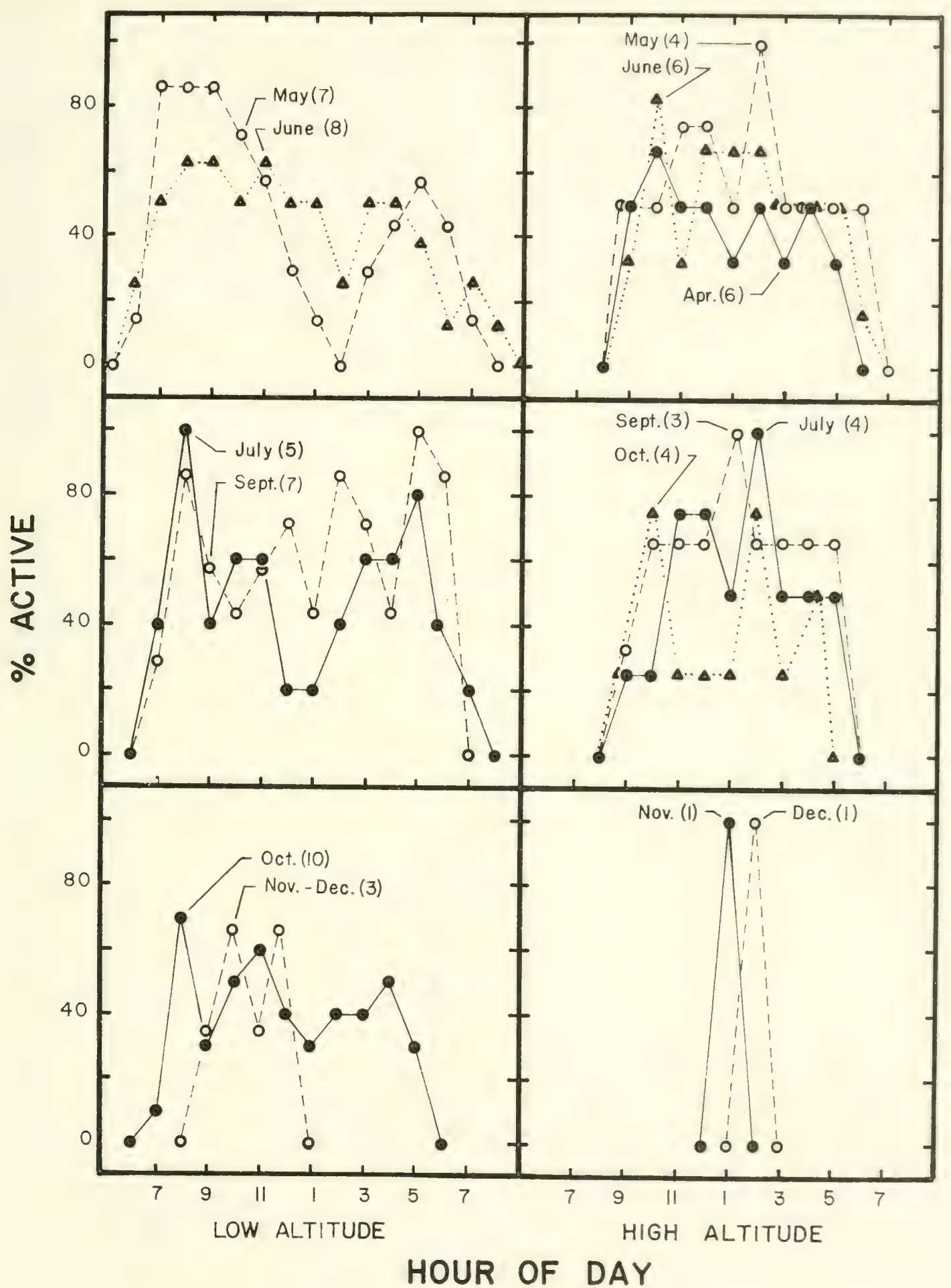

Fig. 23. Adult male high and low altitude A. tuberculata observed at hourly intervals. ( )=sample size. 


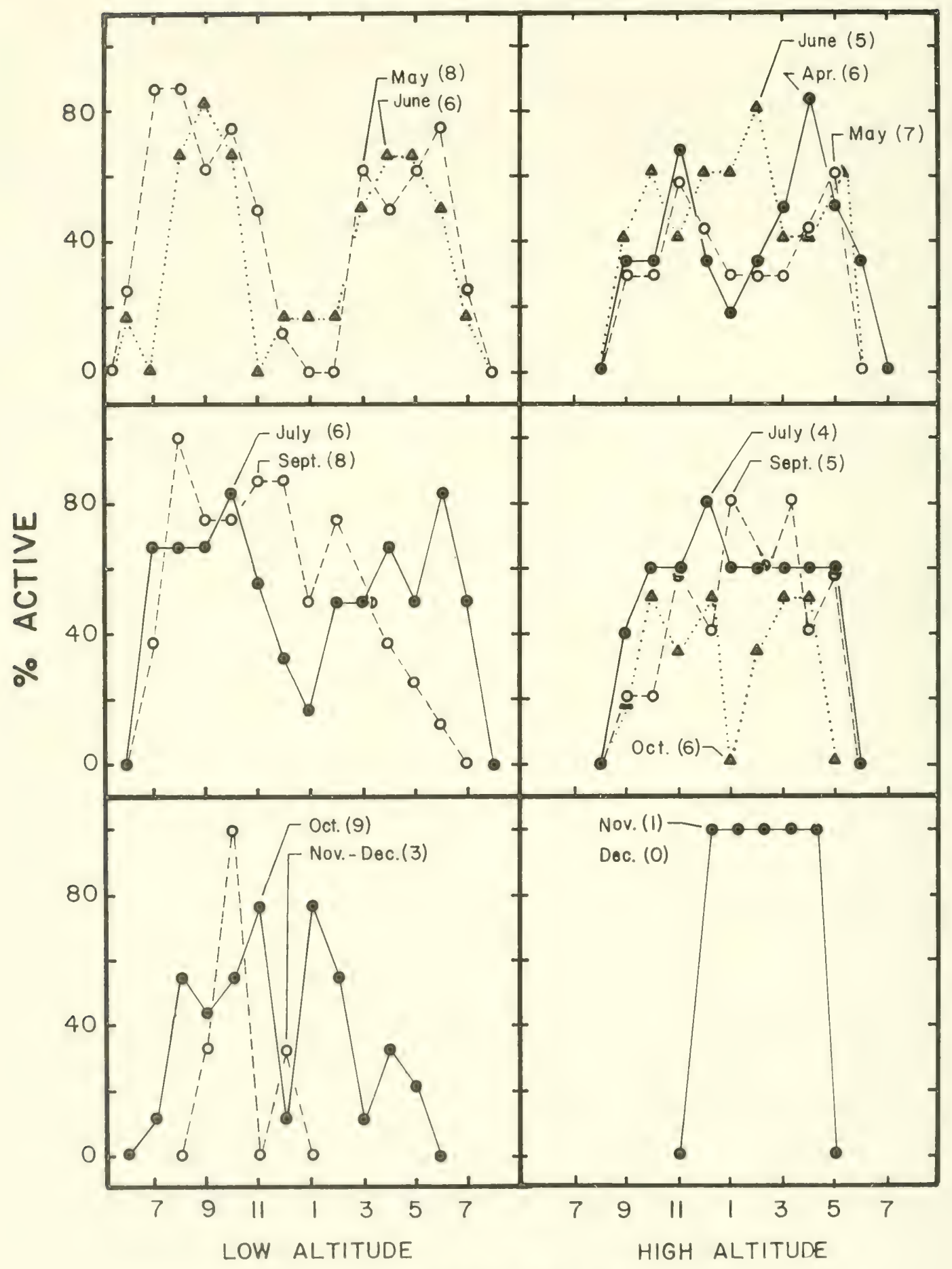

HOUR OF DAY

Fig. 24. Adult female high and low altitude $A$. tuberculata observed at hourly intervals. ( )=sample size. 


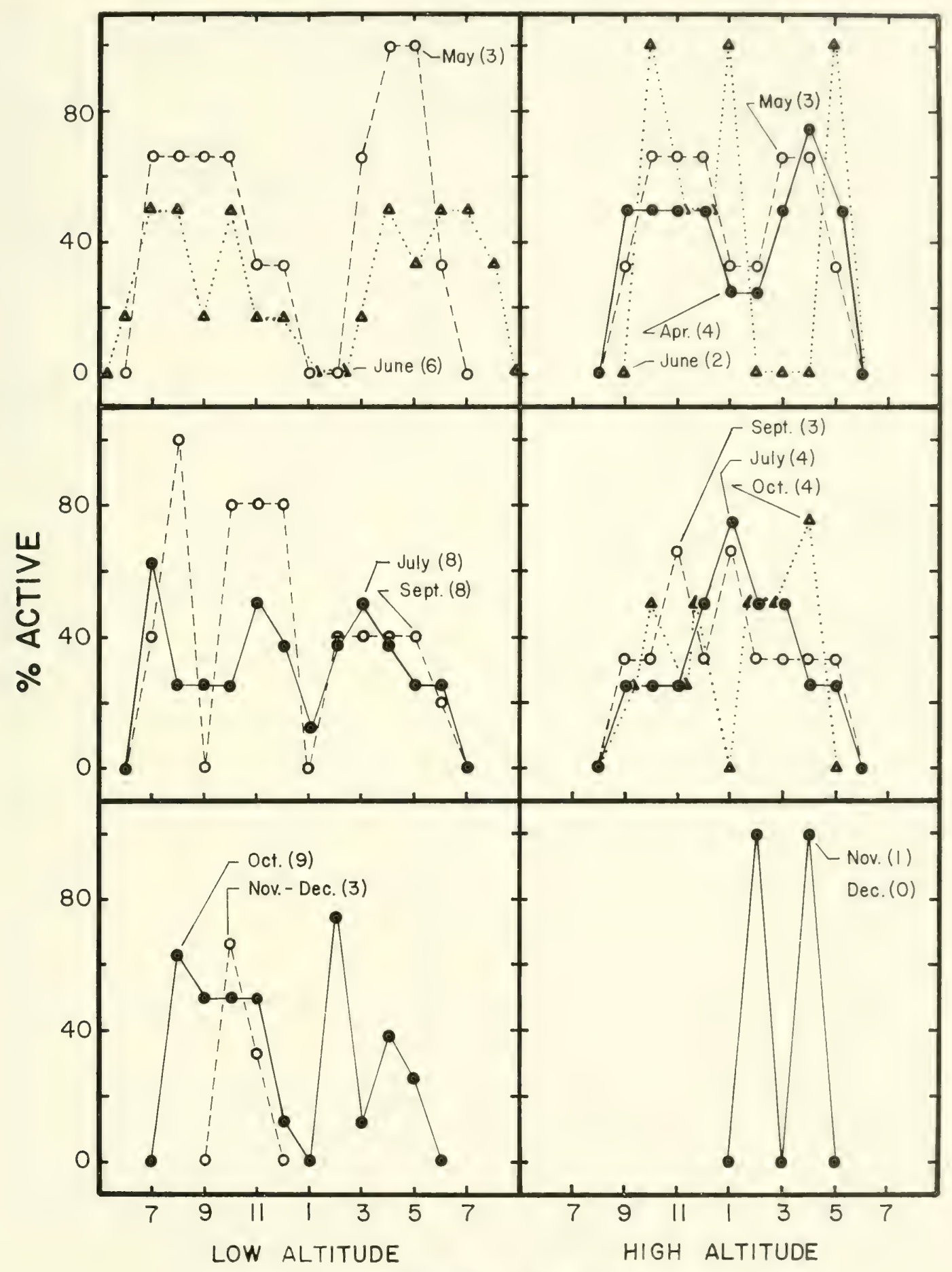

HOUR OF DAY

Fig. 25. Subadult high and low altitude A. tuberculata observed at hourly intervals. ()=sample size. 


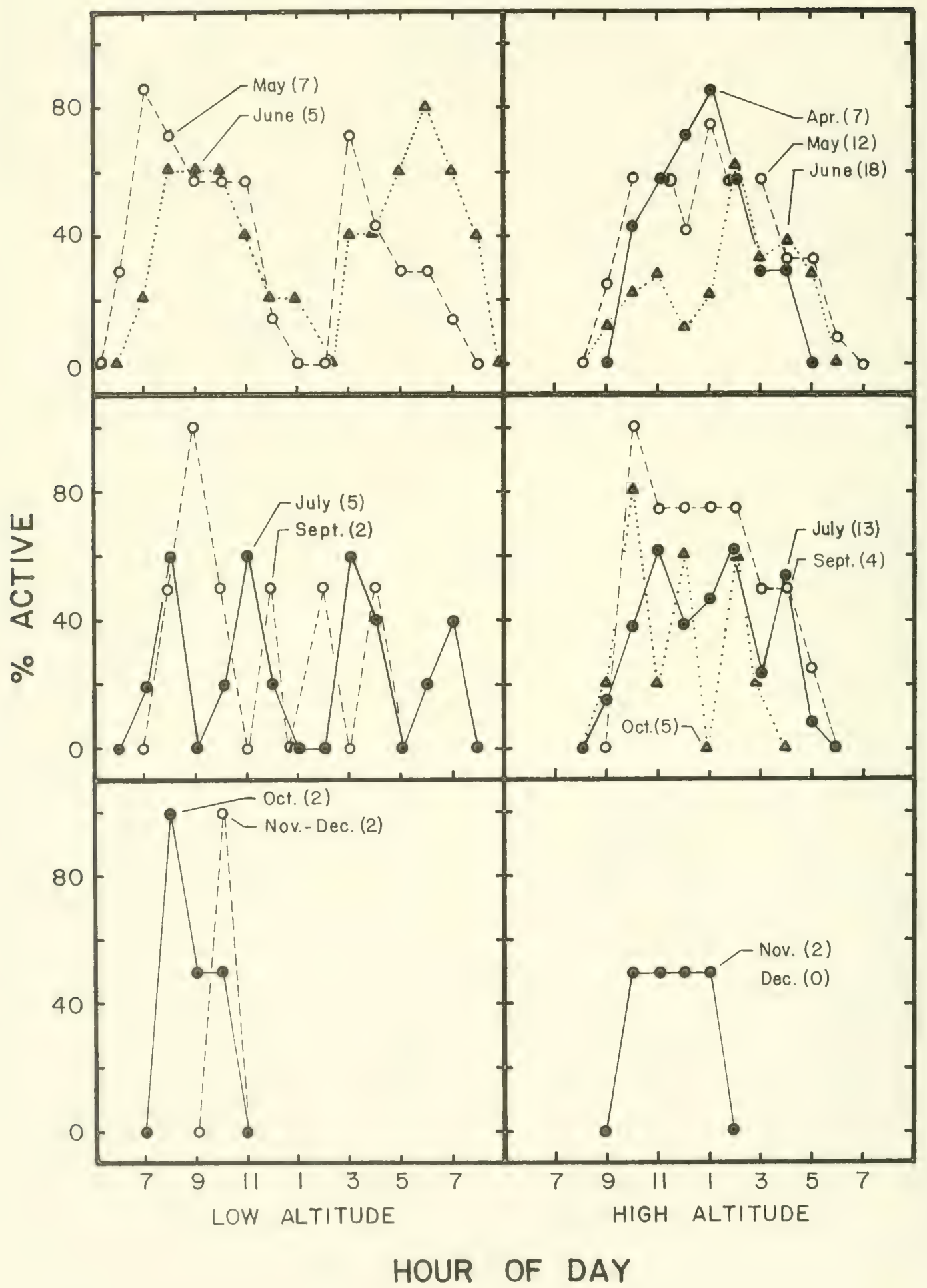

Fig. 26. Juvenile high and low altitude $A$. tuberculata observed at hourly intervals. ( )=sample size. 


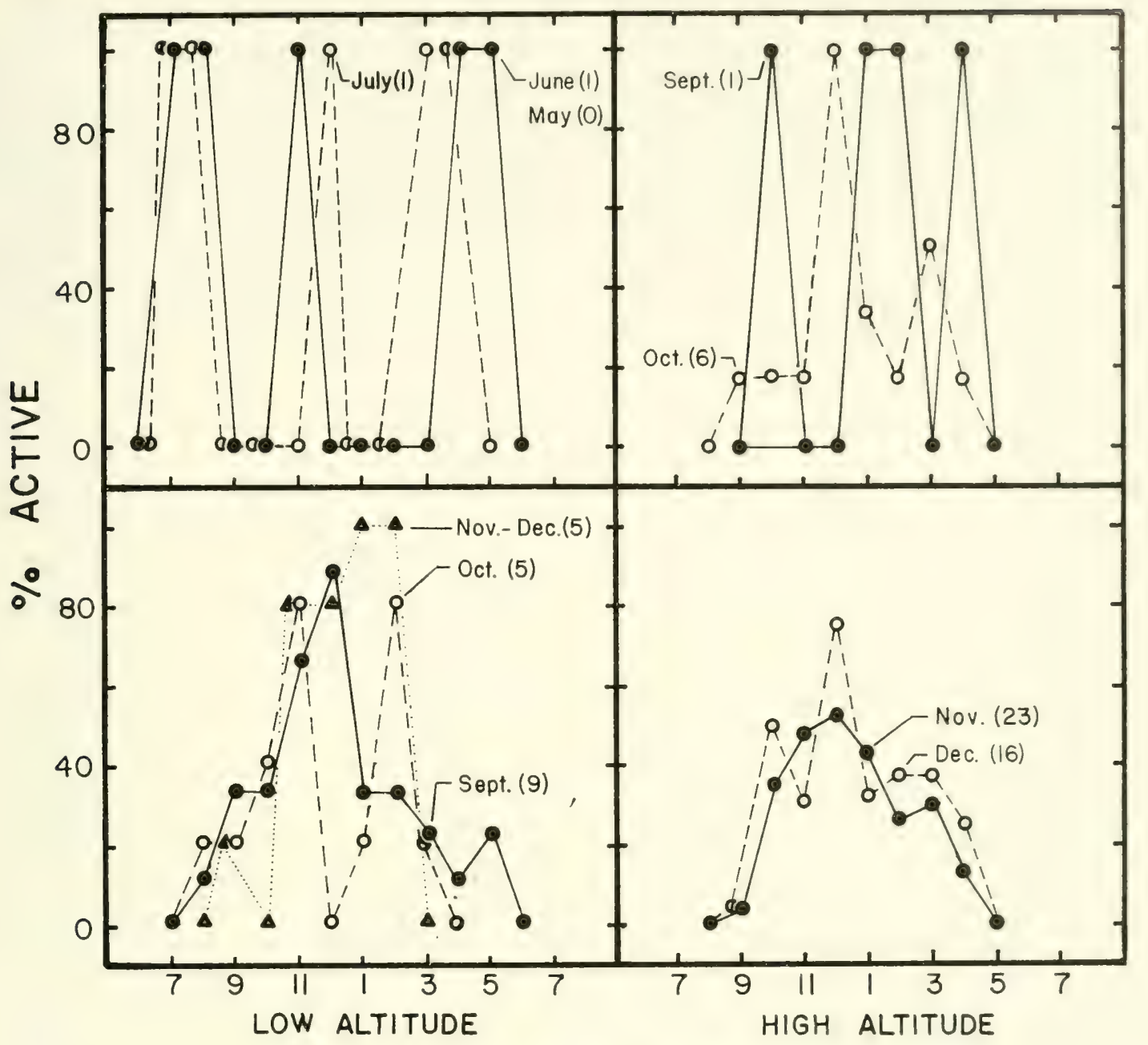

HOUR OF DAY

Fig. 27. Hatchling high and low altitude A. tuberculata observed at hourly intervals. ()=sample size.

Shifts in the distribution of daily activity with seasons have been noted previously in other lizards. Mayhew (1964) found that three species of Uma in California were active only brief́ly at midday during winter and for increasingly longer periods in spring. Finally, in the hot summer months there were separate activity periods in morning and (a shorter one) in late afternoon. For these desertdwelling species, soil and air temperatures exceed the critical level at mid-day and early afternoon. A similar pattern has been observed for Cnemidophorus tigris (Pianka, 1970), Agama caucasica (Yadgarov, 1974), and A. hispida (Huey and Pianka, 1977). In an earlier study, Pianka (1969) found that skinks of the genus Ctenotus in the Australian deserts with high mean body temperature tend to have a unimodal mid-day period of activity whereas those species with lower mean body temperature tend to have a bimodal daily pattern. 


\section{TEMPERATURE}

Cloacal temperatures of rock lizards caught in the field were measured with a Schultheis quickreading thermometer immediately after noosing or shooting. Care was taken to avoid heat transfer from my hand to the lizard's body before the reading was taken. An accompanying reading was taken of the air temperature within 1 in. of the shaded ground where the lizard had been.

High altitude.- The relationship between body temperature $\left(\mathbf{T}_{h}\right)$ and air temperature is presented for 111 lizards in Fig. 28 identifying the time of year and state of activity of each animal. The mean

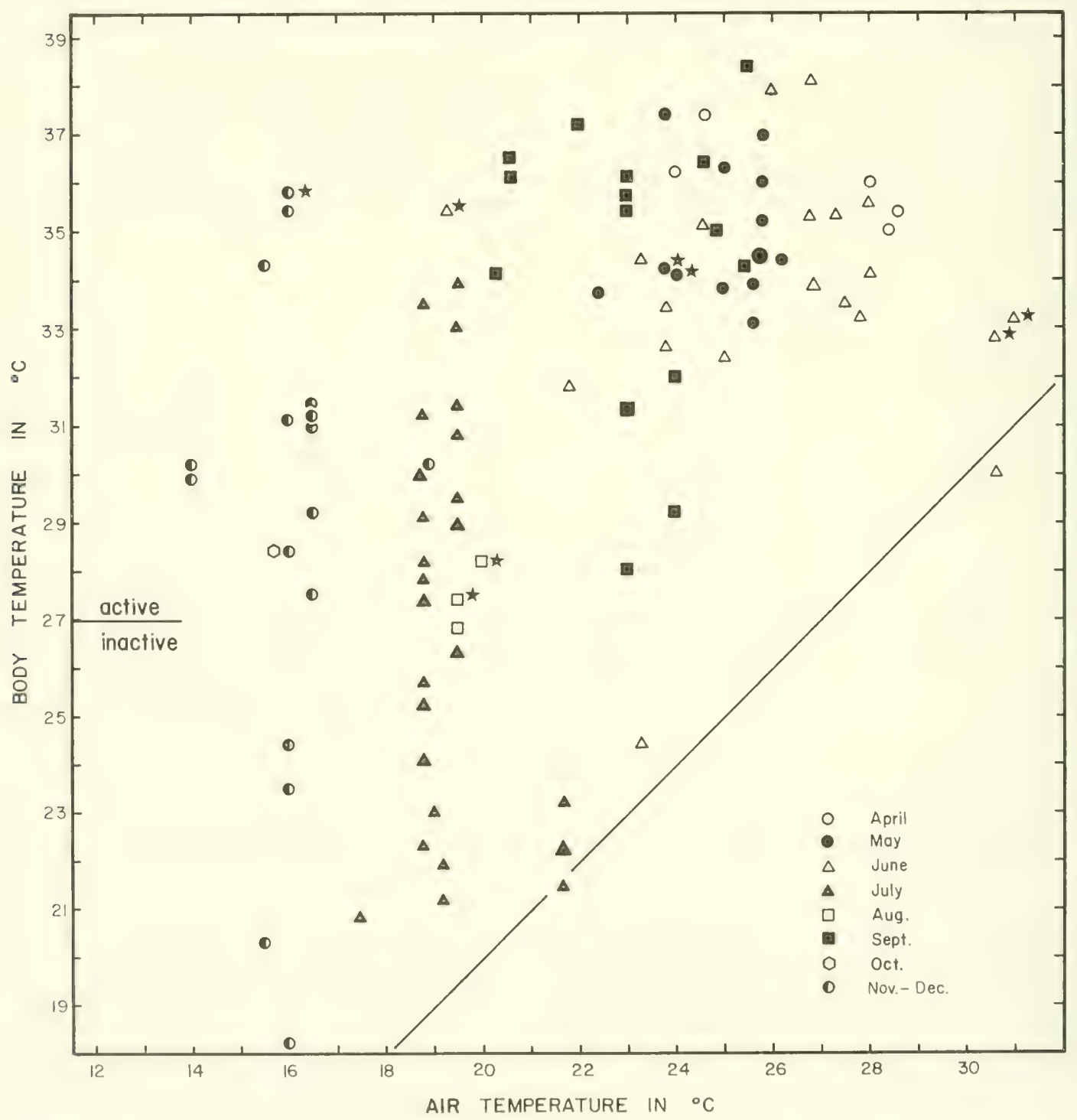

Fig. 28. Relationship between body temperature and air temperature of high altitude A. tuberculata. Individuals with a body temperature below $27.0^{\circ} \mathrm{C}$ were inactive and basking beside or just inside the entrance to crevices. A few inactive individuals with body temperature above $27.0^{\circ} \mathrm{C}$ are identified by a solid star. Large symbols show three records, medium symbols two records, small symbols one record. 
body temperature $\left(\overline{\mathrm{T}}_{h}\right)$ for the active animals $(n=79)$ was $33.1^{\circ} \mathrm{C} \pm 0.3\left(27.3-38.4^{\circ} \mathrm{C}\right)$ compared to a mode of $34^{\circ} \mathrm{C}$ (Fig. 29). Air temperatures at ground surface were in the range of $14-28.6^{\circ} \mathrm{C}$. Brattstrom (1965) defines the normal activity range as the range of temperature of active animals. Platt (1969) defined the usual activity range as that range of cloacal temperatures grouped about the mode that includes more than $75 \%$ of the measurements. At $2165 \mathrm{~m}$, the usual activity range of $A$. tuberculata was between $30-37^{\circ} \mathrm{C}$ (includes $78 \%$ of the "ac- tive" readings).

The maximum voluntary temperature ( $\left.\mathbf{T}_{\text {mox }}\right)$ may be taken as the highest body temperature recorded (Brattstrom, 1965). In the hot season $\mathbf{T}$, was $38.1^{\circ} \mathrm{C}$ and after the monsoons (in September) was $38.4^{\circ} \mathrm{C}$, whereas during the monsoons, the highest cloacal temperature was $33.9^{\circ} \mathrm{C}$. A summary of $\mathrm{T}_{h}$ and $\mathbf{T}_{\max }$ for various months is given in Table 13. An analysis of variance of $\mathrm{T}_{b}$ and $\mathbf{T}$ max for the months of April-June revealed no significant difference $(F=2.114 ; \mathrm{df}=2,31 ; 0.25>P>0.1)$. The readings for

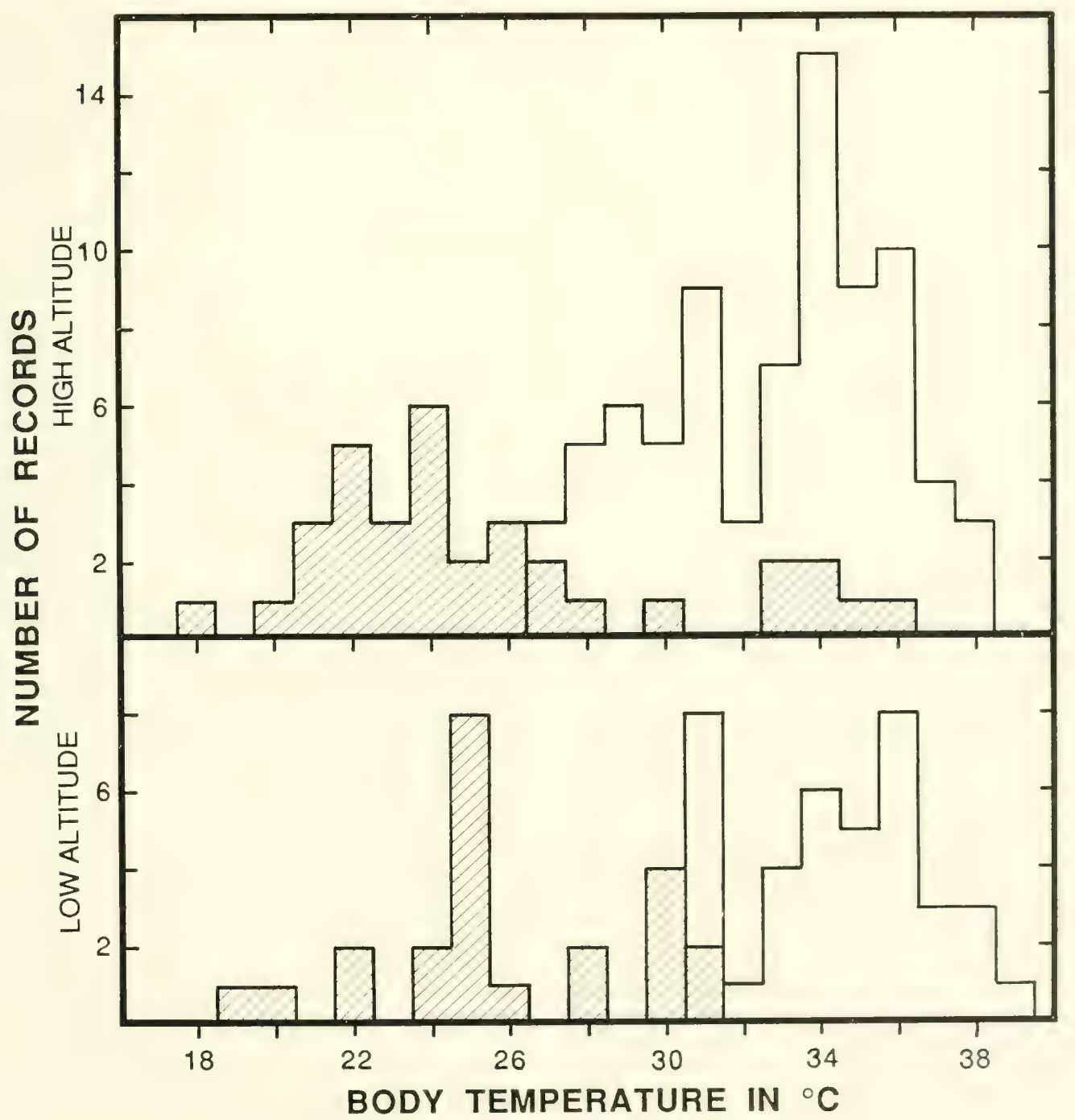

Fig. 29. Body temperature of high and low altitude A. tuberculata. Unshaded=active; shaded=basking or in crevice. 
Table 13. Mean body temperature $\left(\overline{\mathrm{T}}_{b}\right)$ in ${ }^{\circ} \mathrm{C}$ of active $A$. tuberculat $a$. ( ) $=$ sample size.

\begin{tabular}{|c|c|c|c|c|}
\hline & $\overline{\mathrm{T}}_{b} \pm \mathrm{SE}$ & & range & \\
\hline \multicolumn{5}{|l|}{ High altitude } \\
\hline April & $36.0 \pm 0.4$ & (5) & $35.0-37.4$ & \\
\hline May & $34.9 \pm 0.4$ & (13) & $33.1-37.4$ & \\
\hline June & $34.4 \pm 0.4$ & (16) & $31.8-38.1$ & \\
\hline April-June & $34.8 \pm 0.3$ & (34) & $31.8-38.1$ & \\
\hline July & $30.1 \pm 0.5$ & (16) & $27.3-33.9$ & \\
\hline September & $34.2 \pm 0.4$ & (16) & $28.0-38.4$ & \\
\hline October & 28.4 & (1 juvenile) & & \\
\hline \multirow[t]{2}{*}{ November } & $30.5 \pm 0.6$ & (11) & $27.5-35.4$ & (hatchlings) \\
\hline & 34.3 & (1 juvenile) & & \\
\hline \multicolumn{5}{|l|}{ Low altitude } \\
\hline April & 36.3 & (2) & $35.8, \quad 36.8$ & \\
\hline June & $33.9 \pm 0.7$ & (11) & $31.2-37.7$ & \\
\hline August & $33.5 \pm 1.2$ & (4) & $31.1-36.5$ & \\
\hline September & $35.1 \pm 0.7$ & (14) & $31.0-38.9$ & \\
\hline November- & $33.1 \pm 1.2$ & (3) & $31.4-34.5$ & (hatchlings) \\
\hline December & $35.8 \pm 0.5$ & (5) & $34.2-37.1$ & (adults) \\
\hline
\end{tabular}

those 3 months were grouped together and compared to July which revealed a highly significant drop in $\widetilde{\mathrm{T}}_{h}\left(t=8.986^{* * * * ;} \mathrm{df}=48\right)$. In September, the $\overline{\mathrm{T}}_{h}$ increased to pre-monsoon levels. In November, the hatchling $T_{b}$ was significantly lower than for readings taken in September $\left(t=3.588^{*} * ; \mathrm{df}=25\right)$ or April-June of adults-juveniles $(t=7.383 * * *$; $\mathrm{df}=43$ ).

The monthly mean maximum air temperature decreased steadily from June through January, yet the $\bar{T}_{b}$ of the rock lizards rose in September to premonsoon levels. In December, when no adults were active, a basking male had a cloacal temperature of $35.8^{\circ} \mathrm{C}$ showing that the body temperature can be raised to high levels by behavioral thermoregulation even when the ambient temperature is relatively low $\left(16^{\circ} \mathrm{C}\right.$ or less).

The lower $\bar{T}_{h}$ in July is presumably due to the fact that during the monsoons the persistent cloud cover and mist prevents the lizards from absorbing sufficient heat to maintain the $\overline{\mathrm{T}}_{b}$ at pre-monsoon levels. Observations showed a marked increase in the amount of time the rock lizards devoted to basking during the monsoons. In spite of their maintaining body temperatures that averaged $4.7^{\circ} \mathrm{C}$ lower than pre-monsoon levels, the lizards were still very active and vigorously pursued their prey.

The monthly differences between cloacal tem- peratures and ambient temperature are presented in Table 14. The differences of the pre-monsoon months of April-June are not significant $(F=1.176$; $\mathrm{df}=2,31 ; 0.5>P>0.25)$ from one another so were grouped together and compared with the monsoon month of July. The lizards were maintaining their body temperatures in July at a significantly higher level above ambient temperature than had the premonsoon group $\left(t=3.026^{* *} ; \mathrm{df}=48\right)$ in spite of the fact that their $\bar{T}_{b}$ in July was lower than for AprilJune. In September, the difference between the $\bar{T}_{b}$ and ambient was essentially the same as for July $(t=0.119 ; \mathrm{df}=30 ; P>0.9)$ but the $\overline{\mathrm{T}}_{h}$ for September was significantly higher than for July $\left(t=4.526^{* * *}\right.$; $\mathrm{df}=30$ ). Probably lizards are able to maintain a higher $\bar{T}_{b}$ in September than in July because of the decrease in cloud cover. There was no significant difference between the September $\overline{\mathrm{T}}_{b}$ and AprilJune $\overline{\mathrm{T}}_{b}(t=1.022 ; \mathrm{df}=50 ; 0.4>P>0.2)$ yet the corresponding mean ambient temperature dropped $2.7^{\circ} \mathrm{C}$, indicating that the lizards were spending more time basking after the monsoons than before them.

By late November, active hatchlings were maintaining a $\bar{T}_{h}$ significantly farther above air temperature than they had in September $(t=2.707 *$; $\mathrm{df}=25$ ). One active juvenile had a cloacal temperature of $12.6^{\circ} \mathrm{C}$ above ambient and the cloacal 
Table 14. Difference between mean body temperature $\left(\mathrm{T}_{h}\right)$ and air temperature $\left({ }^{\circ} \mathrm{C}\right)$ of active $A$. tuberculata. ( ) =sample size.
${ }^{\circ} \mathrm{C} \pm \mathrm{SE}$
range

\section{High altitude}

$\begin{array}{lrrr}\text { April } & 9.3 \pm 1.3 & (5) & 6.6-12.8 \\ \text { May } & 9.7 \pm 0.5 & (13) & 8.2-13.6 \\ \text { June } & 8.5 \pm 0.5 & (16) & 5.4-11.9 \\ \text { April-June } & 9.1 \pm 0.4 & (34) & 5.4-13.6 \\ \text { July } & 11.0 \pm 0.5 & (16) & 8.5-14.7 \\ \text { September } & 11.1 \pm 0.9 & (16) & 5.0-15.9 \\ \text { October } & 11.1 & (1 \text { juvenile) } & 10.0-19.4 \\ \text { November } & 14.4 \pm 0.7 & (1 \text { juvenile) } & \end{array}$

Low altitude

$\begin{array}{lrrrr}\text { April } & 2.0 & (2) & 1.3,2.7 & \\ \text { June } & 6.3 \pm 0.5 & (11) & 3.8-8.7 & \\ \text { August } & 5.2 \pm 0.9 & (4) & 3.3-7.5 & \\ \text { September } & 6.4 \pm 0.5 & (14) & 3.5-13.0 & \\ \text { June, August, and } & & & & \\ \quad \text { September } & 6.2 \pm 0.3 & (29) & 3.3-13.0 & \text { (hatchlings) } \\ \text { November- } & 10.7 \pm 1.2 & (3) & 8.2-12.0 & \text { (adults) } \\ \quad \text { December } & 14.2 \pm 1.3 & (5) & 11.6-19.1 & \end{array}$

temperature of a basking adult male was $19.8^{\circ} \mathrm{C}$ above ambient. Most adults and subadults remained deep within crevices, and those which were seen, basked close to their crevices and did not forage. Pearson (1954) recorded cloacal temperatures of Liolaemus multiformis at $4633 \mathrm{~m}$ in Peru $31^{\circ} \mathrm{C}$ above ambient.

Low altitude.-The relationship between cloacal temperature and ambient temperature for 62 lowland rock lizards is presented in Fig. 30. The $\overline{\mathrm{T}}_{b}$ for 39 active lizards was $34.6^{\circ} \mathrm{C} \pm 0.4$. The modes were $31^{\circ} \mathrm{C}$ and $36^{\circ} \mathrm{C}$ (Fig. 29). This was also the usual activity range as it included $82 \%$ of the readings. Corresponding ambient air temperatures for the entire sample ranged from $15.1^{\circ} \mathrm{C}$ to $34.5^{\circ} \mathrm{C}$. The $\mathbf{T}_{\max }$ varied from a low of $36.5^{\circ} \mathrm{C}$ in August to $38.9^{\circ} \mathrm{C}$ in September (Table 10 ). There was no significant drop in the $\overline{\mathrm{T}}_{h}$ from pre-monsoon to monsoon levels $(t=0.273 ; \mathrm{df}=13 ; 0.9>P>0.5)$. The $\overline{\mathrm{T}}_{h}$ for adults in November-December was not significantly higher than for pre-monsoon June $(t=1.987 ; \mathrm{df}=14 ; 0.1>P>0.05)$. However, there is a tendency toward a higher $\overline{\mathrm{T}}_{h}$ in winter compared to the hot season. As was the case at high altitude, lowland adults were observed to spend a great deal more time basking in winter than in the hot season or monsoons. In November, the adults had a significantly higher $\bar{T}_{h}$ than the hatchlings ( $t=2.824 *$; $\mathrm{df}=6$ ) but the sample size was small.

The difference between cloacal temperatures and ambient temperature (Table 14) for June, August, and September did not differ significantly $(F=0.727 ; \mathrm{df}=2,26 ; 0.5>P>0.25)$. However, the difference between cloacal and ambient temperatures for June, August, and September compared to November-December adults showed a highly significant difference $(t=9.253 * * * ; d f=33)$. Ambient temperature averaged lower in winter; hence, to remain active the lizards must elevate their body temperatures farther above ambient temperatures than at mid-year. This is accomplished in December by increased basking and by limiting activity to mid-day.

\section{Comparison of the Two Altitudes}

In analyzing Bogert's data on Sceloporus in Mexico, Brattstrom (1965) showed a significant negative relationship between $\overline{\mathrm{T}}_{h}$ and altitude. Rand (1964) found a similar trend for six species of 


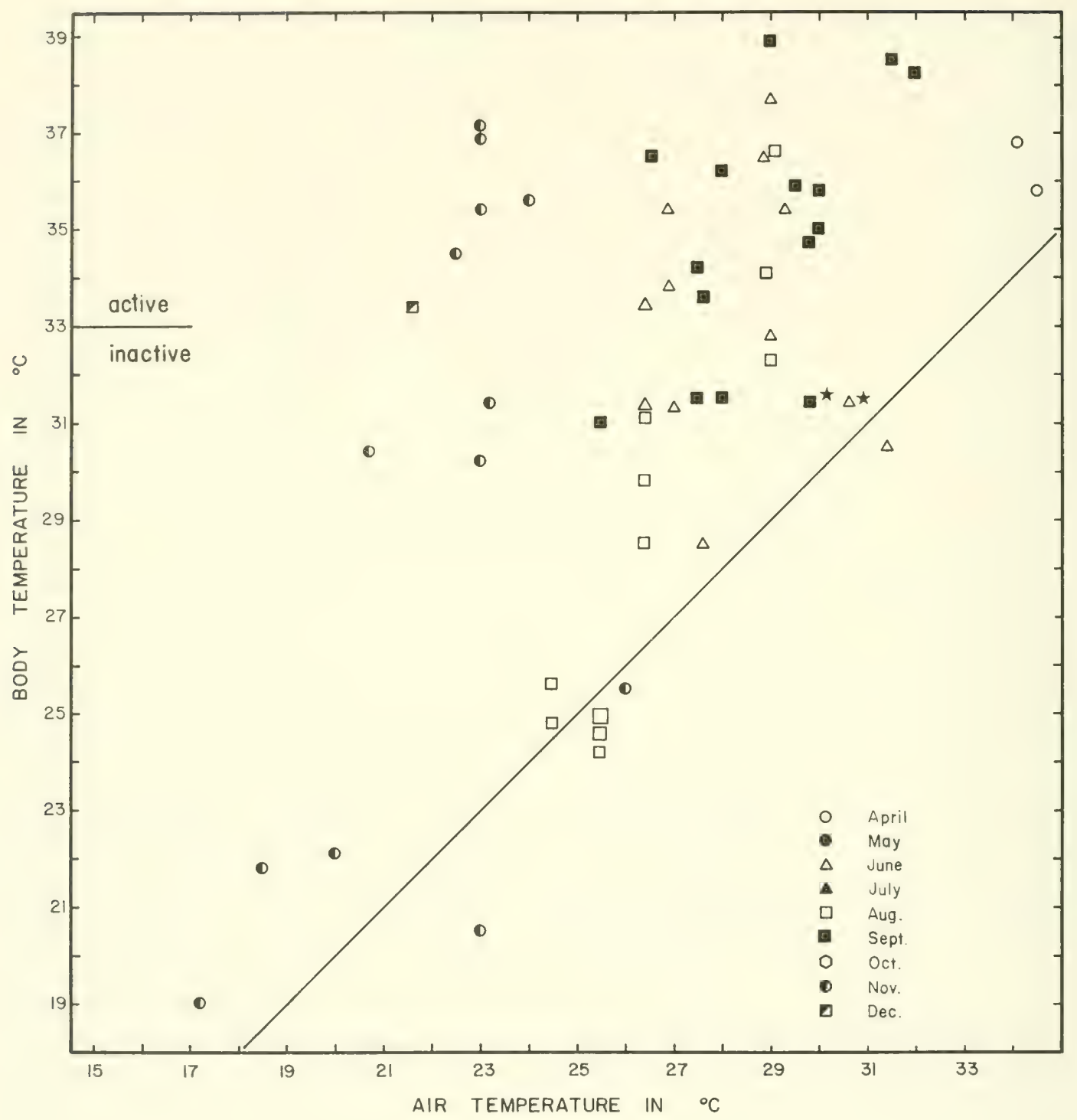

Fig. 30. Relationship between body temperature and air temperature of low altitude A. tuberculata. Except for two individuals identified by a solid star, lizards with a body temperature below $31.0^{\circ} \mathrm{C}$ were inactive and extracted from crevices or were basking beside or just inside the entrance to crevices. Symbols as in Fig. 28.

anoles in Puerto Rico. Analysis of literature data for nine anole populations ranging from $350 \mathrm{~m}$ to $1810 \mathrm{~m}$ in altitude by Clark and Kroll (1974) did not show a significant negative simple regression, but eight of their values were below the mean for 28 $\mathrm{T}_{h}$ 's from altitudes below $350 \mathrm{~m}$. A significant negative partial regression coefficient was deter- mined when the data were further analyzed by multiple linear regression for the effects of light, latitude, and altitude. Pearson and Bradford (1976) reported a preferred body temperature of $32-34^{\circ} \mathrm{C}$ for Liolacmus multiformis in Peru at $4300 \mathrm{~m}$ as well as in an individual subsequently transported to $1000 \mathrm{~m}$. 
Altitudinal comparisons of the $T_{h}$ for active individuals in June, September, and November (hatchlings only) are not significantly different $(t=0.013, \quad \mathrm{df}=25, P>0.9 ; \quad t=1.099, \quad \mathrm{~d} f=28$, $0.4>P>0.2 ; t=2.028, \mathrm{df}=12,0.1>P>0.05$ respectively). The November hatchling comparison perhaps would have been significantly different if the sample size for the low altitude had been larger. My one record of a basking adult male at high altitude in November is $35.8^{\circ} \mathrm{C}$ compared to an average of $35.8^{\circ} \mathrm{C}$ for five active adults at low altitude. The $\overline{\mathrm{T}}_{b}$ of adults in November may be quite similar at the two altitudes; however, the adults at the higher altitude (in contrast to lowland adults) were not actively foraging even at mid-day.

Monthly or seasonal comparisons of similar age groups between altitudes for the difference in $\overline{\mathrm{T}}_{h}$ and ambient temperatures are significant (Table 15). The high altitude populations tend to maintain a $\bar{T}_{b}$ close to that of low altitude populations and because air temperatures are lower, they raise their body temperatures a greater amount above ambient than the low altitude populations.

Clark and Kroll (1974) hypothesized concerning anoles that

in dispersal up a tropical mountain, use of solar radiation is maximized by occupation of more open habitats (probably with greater proficiency in basking) plus activity throughout 12 months.

They cite as evidence studies by Rand (1964) and Clark (1974) for species of tropical anoles occupying both lowland and montane altitudes which "suggest that the critical change accompanying greater elevation is occupancy of more open habi-

Table 15. t-test comparisons of differences in $\bar{T}_{b}$ and air temperature between high and low altitude $A$. tuberculata.

\begin{tabular}{llr}
\hline & \multicolumn{1}{c}{$t$} & df \\
& & \\
June & $2.943^{* * *}$ & 25 \\
July high, August low & $5.238^{* * * *}$ & 18 \\
September & $4.495^{* * *}$ & 28 \\
November high hatchlings, & & \\
$\quad$ low adults & $0.124 \cdot P>0.9$ & 14 \\
November hatchlings & $2.381^{*}$ & 12 \\
\hline
\end{tabular}

tats with their increased insolation."

Montane A. tuberculata are most frequently found in open situations which provide numerous basking sites. Similarly, lowland lizards are found in fairly open situations along stream edges, but there may also be considerable ground cover, particularly during the monsoons. As previously noted, lowland lizards are not active during midday in the hot season and even retreat into crevices, whereas montane lizards are active throughout the day but may retire to shaded areas or face the sun to present a minimal body surface during the hottest part of the day. A. tuberculata does not need to maximize the use of solar radiation with increased altitude, at least within the limits of this study. As the species is found to $4600^{+} \mathrm{m}$, it may exhibit increased utilization of solar radiation at even higher altitudes.

Ruibal and Philibosian (1970) found that one species of anole (A. oculatus) occupied the entire island of Dominica in the Lesser Antilles and occurred in a variety of habitats and diverse environments including an altitudinal range from sea level up to about $1000 \mathrm{~m}$. The lizard did not seem to prefer any specific body temperature regardless of the habitat in which it was found. It exhibited thermoregulatory behavior only at high altitude or in direct sunlight at sea level. The authors concluded that eurythermy in A. oculatus accompanies and perhaps contributes to eurytopy of the species. In his study of Uta stansburiana, Tinkle (1967) found that it remained active all day after summer rain despite a drop of $10^{\circ} \mathrm{C}$ or more of the ambient and $\overline{\mathrm{T}}_{b}$ for the season. My study of Agama tuberculata shows that its occurrence over a wide range of thermal environments is achieved mainly by behavioral thermoregulation as the species is not eurythermic. However, during the early monsoons, with decreased insolation, the montane populations remained active despite a drop in the $\overline{\mathrm{T}}_{h}$, suggesting some eurythermy. Other temperate species which have been found to vary their preferred $\bar{T}_{b}$ are Sceloporus orcutti (Mayhew, 1963) and S. undulatus (Ballinger et al., 1969).

The tropical Anolis limifrons shows a higher $\overline{\mathrm{T}}_{h}$ in the wet season compared to the dry season (Ballinger et al., 1970). The lower dry season $\bar{T}_{b}$ was presumably adaptive in conserving water or minimizing water loss. The lizard frequently basked 
during the early morning in the dry season but rarely during the wet season. Lowland $A$. tuberculata did not raise their body temperatures during the monsoon and did not exhibit any obvious change in the amount of basking compared to the dry season. Montane A. tuberculata showed a temporary decrease in $\bar{T}_{b}$ during the beginning of the monsoons and were frequently observed bask- ing under an overcast sky. The ambient temperatures were relatively low so that the lizards needed to spend more time basking in order to attain their preferred temperature. Anolis limifrons is a tropical forest species with a lower preferred temperature than Agama tuberculata which is a temperate rock-inhabiting heliotherm with a relatively high preferred body temperature.

\section{REPRODUCTION}

High altitude.-I started sampling lizards in early April 1973. Two of the four adult females collected then had developing follicles (Fig. 31). Ovulation peaked during the latter part of May and early June. In 1974, females with oviducal eggs were collected until early July with a peak in late May. Egg-laying commenced in mid-June. Females with enlarged corpora lutea were collected until early July but some females probably did not lay their clutches until mid-July. All females collected in late July had laid their eggs. Corpora lutea regress rapidly in A. tuberculata and in some individuals could not be accurately counted in late July and early August. This is in distinct contrast to Telford's (1969) findings concerning the Japanese lacertid, Takydromus tachydromoides in which the corpora albicantia apparently persist for the lifetime of the female.

Fali Kapadia collected lizards for me from Julymid-September 1973 and did not observe any hatchlings during that time. In mid-September, I noted two hatchlings which were perhaps less than 2 weeks old. Considering the earliest date of egglaying to be mid-June and appearance of hatchlings as the first of September, the incubation period approximates 75 days. Hatchlings at the study site continued to appear through October. The size of some young captured in late November suggests hatching dates a little earlier that same month.

On 17 June I observed a large adult female (124 $\mathrm{mm}$ SVL) laying her clutch of eggs at 3:00 pm under partially overcast skies. The site she selected was $25 \mathrm{~cm}$ below a small trail on a southwestfacing slope. The damp soil was interspersed with numerous rocks up to $10 \mathrm{~cm}$ in length. The area surrounding the site had approximately a $50 \%$ cover of forbs but was mostly bare adjacent to the burrow.
Several eggs had already been deposited when I arrived. The female continued laying as I observed from a distance of $5 \mathrm{~m}$. She straddled the entrance to the tunnel with her head pointing downhill and her tail curved to the left. Eggs were laid at intervals of $1 / 2$ minute to 2 minutes. After laying several eggs, she turned around and pushed them into the tunnel with rapid poking movements of her snout. She also scratched loose dirt into the tunnel with her forelegs and then packed it into the tunnel with her snout. After covering her clutch of 12 eggs and scratching some rocks and soil over the entrance to the tunnel, she ran $25 \mathrm{~m}$ up the slope and over the crest to the area which she usually frequented, on the northeast-facing slope just below the ridge.

The tunnel in which the eggs had been laid was $7 \mathrm{~cm}$ wide by $5 \mathrm{~cm}$ high at the entrance and $12 \mathrm{~cm}$ long. The eggs had been tightly packed with soil. The entrance to the tunnel was difficult to distinguish from its surroundings and would have been impossible to detect after a rain. Apparently the female took considerable care in selecting the nest site. Her normal range of activity did not include the nest site and had physical conditions considerably different from it. Locating the nest between the sparse vegetation of the southwest-facing slope insured maximum insolation during the relatively cool weather of the monsoons.

The entire clutch weighed $19.6 \mathrm{~g}$ and eggs ranged in length from $20.8-23.3 \mathrm{~mm}(\bar{x}=21.8 \mathrm{~mm})$. Over a quarter of the female's weight $(27 \%)$ was devoted to this reproductive effort. An attempt was made to determine the duration of incubation but the entire clutch was lost to a fungus infection. Gravid females from both high and low altitude were confined in order to collect more data regarding reproduction but none of the females laid their 


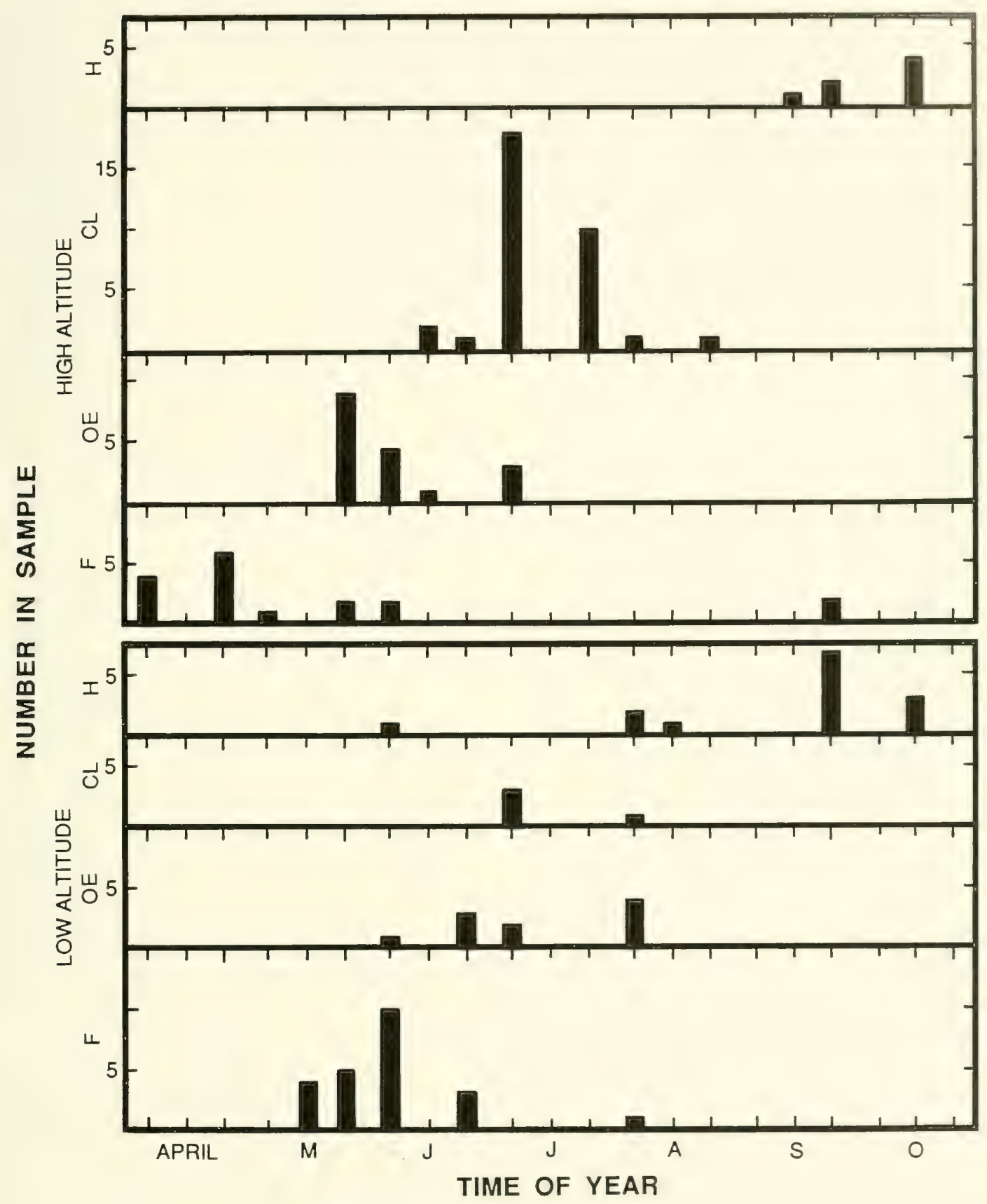

Fig. 31. Reproductive status of female A. tuberculata and appearance of hatchlings at high and low altitude. $\mathrm{F}=$ follicles, $\mathrm{OE}=$ oviducal eggs, $\mathrm{CL}=$ corpora lutea, $\mathrm{H}=$ hatchlings. 
eggs for over a month. They laid eggs only after being taken out of the cages and placed in cloth sacks overnight. Gravid females apparently require suitable environmental cues in order to lay their eggs. The cloth sacks perhaps allowed a more natural digging sensation than did the hard, smooth bottom of the cages.

Clutch size can be determined by counts of developing follicles, oviducal eggs, or corpora lutea. The latter provide an accurate count only for the first month after oviposition. The size of clutch is positively correlated with the SVL of females (Fig. 32). Females in their first reproductive season likely lay 5-6 eggs whereas females in their third or later reproductive season likely lay 9-13 eggs. Koul and Duda (1977) reported $4-7$ oviducal eggs in females from Kashmir but did not indicate the size of individuals. The average size of the clutches inclusive of all types of counts was $8.9 \pm 0.4$ eggs, $n=32$. I did not collect any adult lizards in late fall

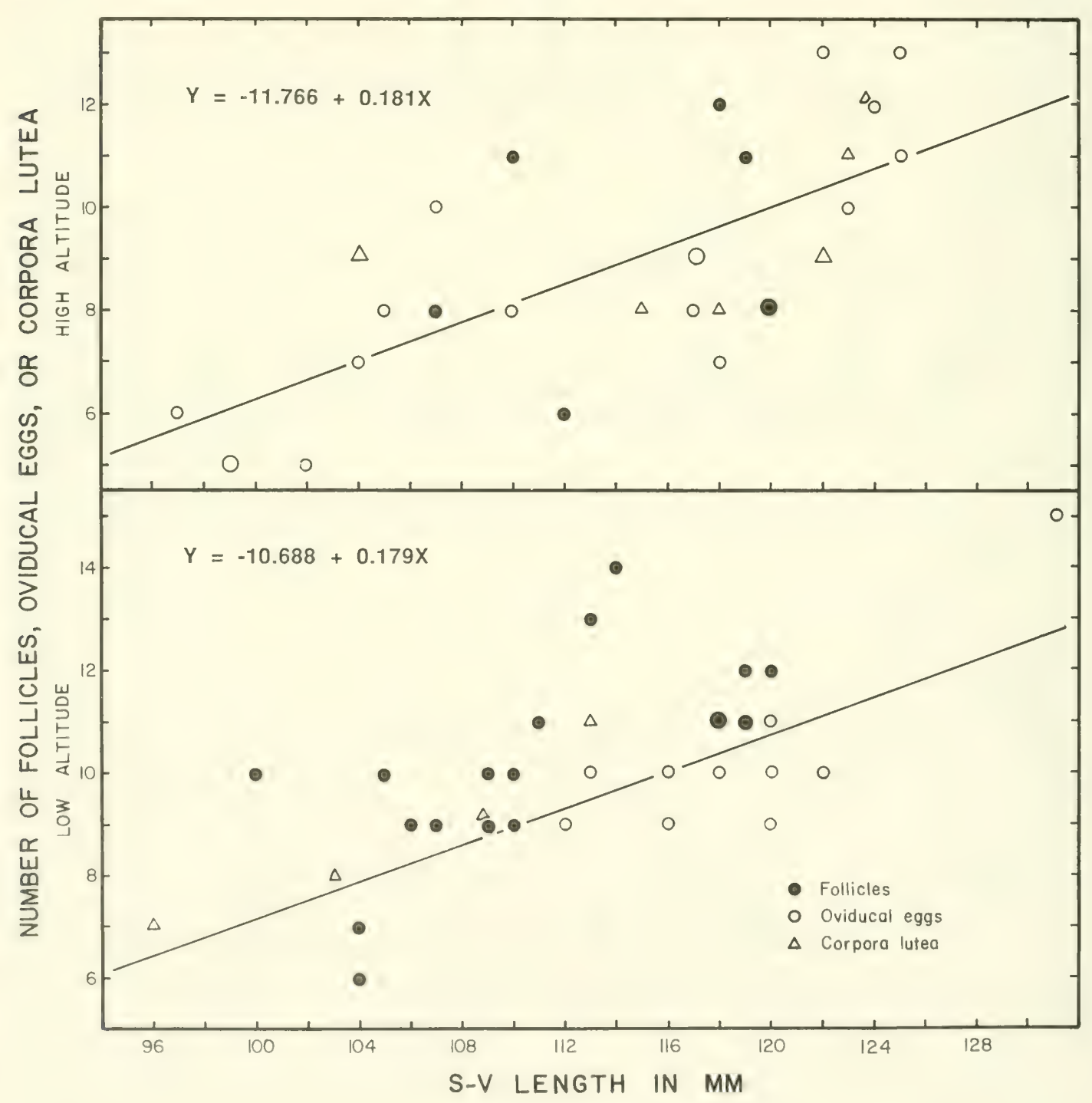

Fị. 32. Relationship between number of follicles, oviducal eggs, and corpora lutea and SVL of high and low altitude $A$. tuberculata. Large symbols show two records. 
so was unable to confirm gonadal recrudescence prior to hibernation as has been reported for female A. tuberculata (Koul and Duda, 1977) in Kashmir and male A. caucasica (Yadgarov, 1974) in the USSR.

The size of inguinal fat bodies changes dramatically during the year. In April among females the size of fat bodies ( $\bar{x}=2.09 \%$, range $1.25-3.38 \%$ of total body weight) tends to be largest for individuals who are not maturing follicles or have follicles which are just starting to mature (Fig. 33). Fat bodies rapidly decrease in size, to less than $1 / 4$ their original size ( $\bar{x}=0.48 \%$, range $0.10-0.96 \%$ of total body weight) as the follicles mature. There is a highly significant difference $\left(U=66^{* * *}\right)$ between the late April and late May samples when compared by the Wilcoxon two-sample test. After oviposition, the size of fat bodies again increased to pre-reproductive levels by September.

The degree to which the vas deferens was enlarged was judged to be a better index of sexual activity of males than variations in the size of testis. During April-August, the vasa deferentia were slightly enlarged (compared to immature males); from April-early June, coinciding with the time when females had developing follicles, they were extremely prominent.

Adult males also showed fluctuations in the size of fat bodies April-August (Fig. 34). During late May, the fat bodies averaged $0.21 \%$ (range 0.00 $0.70 \%$ ) of the total body weight. By the middle of the monsoons (late July) the fat bodies had increased in weight by 4.69 times to an average of $0.99 \% \pm$ 0.14 of the total body weight (range $0.24-1.75 \%$ ). There is an overall trend of increasing size of fat bodies April-August with little correlation to the state of the vas deferens.

Low altitude.- Sampling lizards at low latitude began in mid-May 1973. Of four adult females collected, none had enlarging follicles (Fig. 31). Females containing enlarging follicles were found from late May-early August. Females with oviducal eggs were obtained from early June-early August. However, Bhatnagar (1968) found females in the Dun Valley with oviducal eggs from April-October. In my study, oviposition (as indicated by presence of corpora lutea) started in late June and continued through early August. One hatchling was seen in early June 1974, suggesting that copulation likely took place in late March or early April. Bhatnagar (1968) did not state when small hatchlings were observed but $I$ infer from his data that they probably appeared May-November. Fali Kapadia noted numerous hatchlings in mid-August being swept along by the swift water in an irrigation canal after a heavy monsoon rain. The next period of observations were in late September when seven hatchlings were seen. Small hatchlings were also seen in mid-October.

On the basis of my data it is difficult to judge the usual length of the incubation period and attempts to incubate clutches of eggs were unsuccessful. A clutch of 10 eggs laid by a captive female was successfully incubated by Bhatnagar (1968) "under a table lamp of 25 watts ... [for] 31 days" at Dehra Dun.

In spite of the more prolonged breeding season, I did not find any evidence of females laying more than 1 clutch of eggs. Individuals which were maturing follicles in June-August did not have visible corpora lutea. Possibly a few large females breed a second time in one season if they lay their first clutch in late April or early May. Inguinal fat bodies are very small after oviposition so that fat reserves necessary to mature follicles need to be built up before a second clutch can be matured. There may be sufficient time before October for fat storage; if so, one should find some adult females in non-reproductive condition during June-August. I did not find any such females.

There is a marked correlation between clutch size and SVL of females (Fig. 32) with a significant difference between the elevations of the regression lines of females with developing follicles compared with those with oviducal eggs $(0.05>P>0.01)$. Probably some follicles are resorbed prior to ovulation. Females in their first reproductive season (to $110 \mathrm{~mm} \mathrm{SVL}$ ) typically lay 6-9 eggs whereas females in subsequent years lay 9-15 eggs. The average size of clutches (indicated by oviducal and corpora lutea counts) was $9.9 \pm 0.5$ : $n=14$.

The size of inguinal fat bodies may exceed $3 \%$ of the total body weight in late May for adult females prior to initiating follicle development or until follicles are $<6 \mathrm{~mm}$ diameter (Fig. 33). By the time the oviducal eggs have matured or shortly after oviposition (late June-early August) these fat 


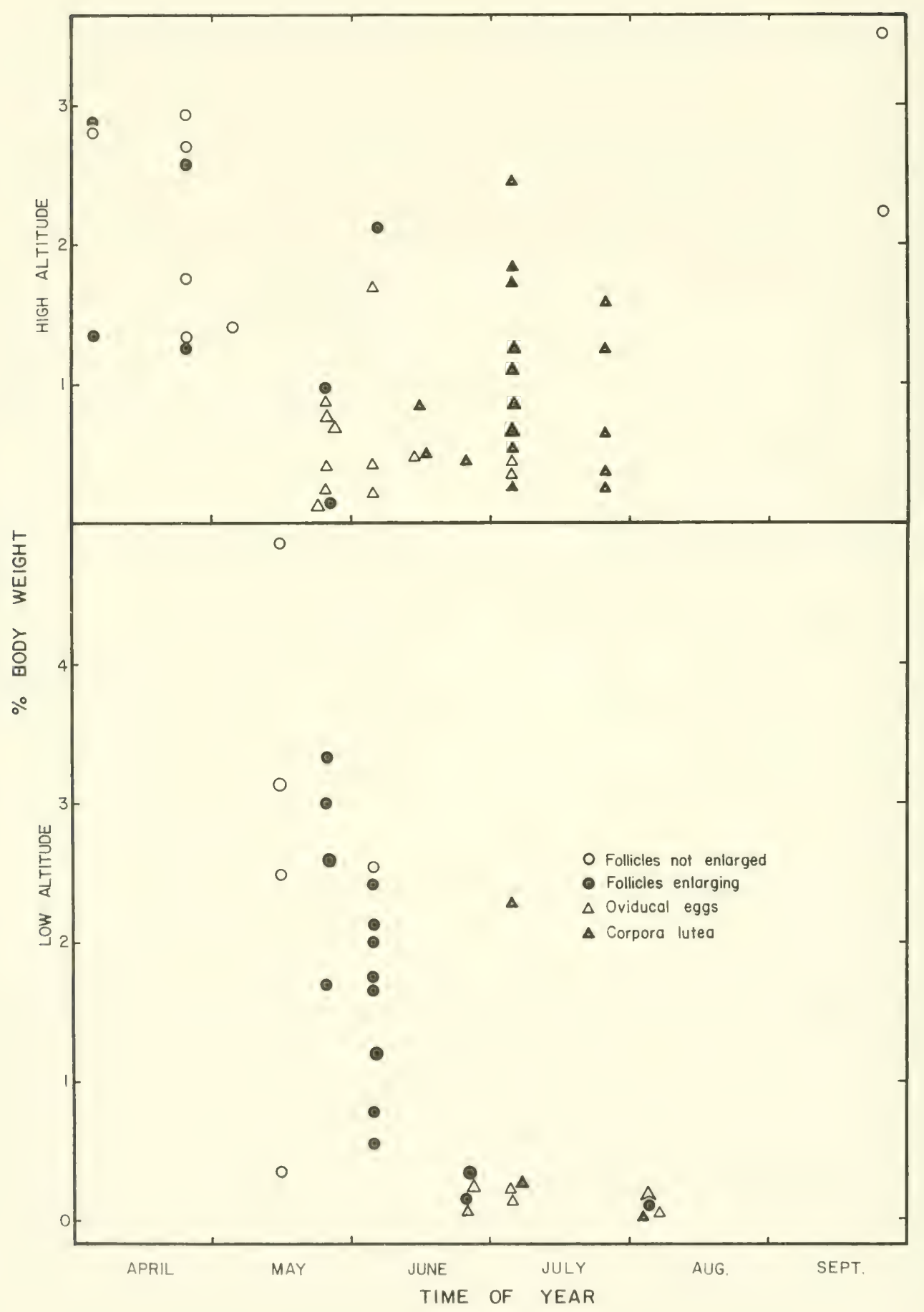

Fig. 33. Relationship between size of inguinal fat bodies and reproductive status and time of year for high and low altitude female $A$. tuberculata. Size of fat body as \% of body weight. Large symbols show three records, medium symbols two records, small symbols one record. 


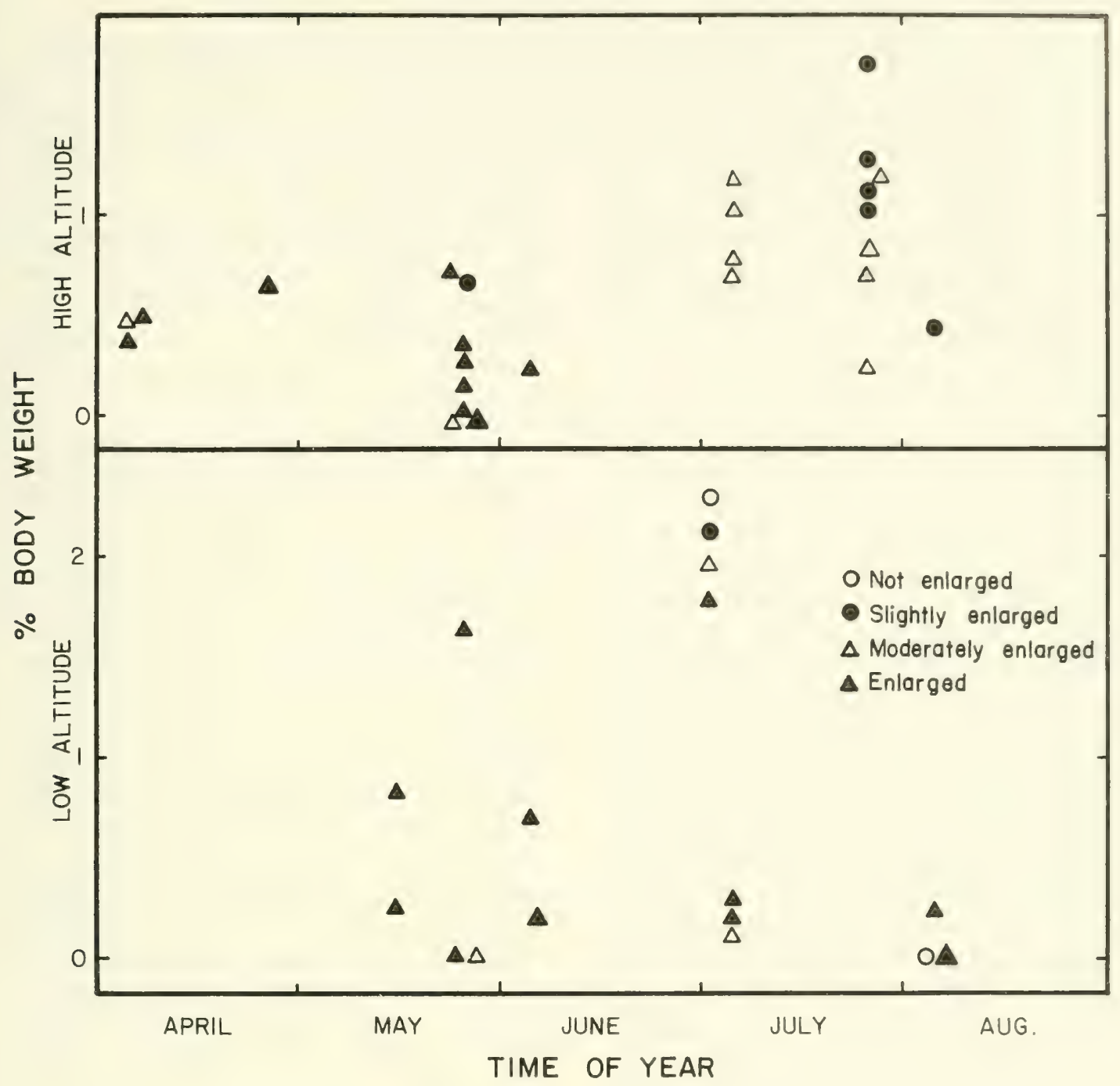

Fig. 34. Relationship between size of inguinal fat bodies and reproductive status and time of year for high and low altitude male A. tuberculata. Size of fat body as \% of body weight. Symbols as in Fig. 33.

bodies have regressed to $0.05-0.25 \%$ of the body weight. There appears to be little correlation in adult males between the size of fat bodies and reproductive status (Fig. 34). However, the wide variation in size during July gives way to a uniformly small size in August.

\section{Comparison of the Two Altitudes and Discussion}

At $2165 \mathrm{~m}$ the breeding season is much shorter than at $690 \mathrm{~m}$ and various phases of egg maturation are more sharply separated. At high altitude, all the females had ovulated before any had laid their clutches, whereas at low altitude, in early August one female still had maturing follicles even though females with corpora lutea were being collected as much as 1 month earlier. Bhatnagar's (1968) data indicate that ovulation takes place from March to October at low altitude: I found it to be limited to 2 months (mid-May-mid-July) at high altitude. At a slightly lower altitude (1833 m) in Kashmir, Koul and Duda (1977) found female A. tuberculata with oviducal eggs during a comparable period (late 
May-late July). An occasional female may be delayed. Parshad (1914) collected a female with "eggs quite ready for laying" on 22 August at Simla at an altitude of approximately $2500 \mathrm{~m}$. In my study, vasa deferentia of males at high altitude started to regress in late May or June but at low altitude were still enlarged into August.

A similar shortening of the reproductive season with increasing altitude has been reported for the lacertid Lacerta muralis in France (Saint Girons and Duguy, 1970), the iguanid Sceloporus occidentalis (Goldberg, 1974; Jameson and Allison, 1976), and the teiid Cnemidophorus inornatus (Stevens, 1983). Latitudinal differences in the geographical range of a species may also have a similar effect on the duration of breeding activity or the number of clutches laid. Pianka and Parker (1972) found reduced testes in males of northern populations of Callisaurus draconoides during late July and August whereas males of more southerly populations had enlarged testes through mid-August. Cnemidophortus tigris in Colorado lays one clutch between May and August whereas in Texas two clutches are laid between April and midAugust (McCoy and Hoddenbach, 1966). Similarly, northern populations of Crotaphytus collaris (Ferguson, 1976; Hipp, 1977) and Sceloportis scalaris (Ortega and Barbault, 1986) lay fewer clutches than the more southern populations.

The mean size of clutches of $A$. tuberculata tends to be larger at low latitude (9.9 eggs vs. 8.9 eggs) but the difference is not significant $(t=1.382$; $\mathrm{df}=44 ; 0.2>P>0.1)$. A decrease in fertility with increasing altitude has also been reported for Lacerta strigata (Melkumyan, 1983a, 1983b). There is no significant difference between the two altitudes in the rate of increase of clutch size with SVL $(t=0.045 ; \mathrm{df}=42 ; P>0.9)$. There also is no significant difference between the two altitudes in the clutch size for comparable SVL $(t=1.624$; $\mathrm{df}=43$; $0.2>P>0.1$ ). However, the regression lines (Fig. 32 ) indicate that lowland females tend to lay slightly larger clutches for a comparable SVL.

The positive relationship between body size and clutch size has been observed for many species (Fitch, 1970; Vitt, 1977) including Sceloporus occidentalis (Goldberg, 1974; Jameson and Allison, 1976), S. undulatus (Tinkle and Ballinger, 1972), S. scalaris (Ortega and Barbault, 1986), Eumeces fasciatus (Fitch, 1954), Cnemidophorus inornatus (Stevens, 1983), and Takydromus tachydromoides (Telford, 1969). Tinkle and Ballinger (1972) found that Texas populations of $S$. undulatus show a higher production of eggs/clutch/body size than do the more northern populations in Ohio, South Carolina, and Colorado. Although producing fewer eggs, the Colorado lizards produce eggs nearly twice as large as those of the Texas lizards. Tinkle and Ballinger suggested that an upper limit for clutch volume is imposed by body size but the volume can be divided among many small eggs or a few large ones.

Goldberg (1974) found a significant correlation between number of eggs laid and female body size for lowland Sceloporus occidentalis but not for montane populations. Tinkle and Ballinger (1972) found a similar trend in S. undulatus: decreased correlation between clutch size and female body size in northern populations compared with more southern populations. For A. tuberculata, both lowland and montane correlation coefficients between clutch size and female body size were highly significant $(r=0.810 * * ; \mathrm{df}=14 ;$ and $r=0.700 * *$; $\mathrm{df}=32$ respectively). However, there was no significant difference between the correlation coefficients $(t=0.809 ; 0.5>P>0.4)$.

My finding of larger fat reserves among female A. tuberculata prior to vitellogenesis compared with males has also been paralleled in studies of Uta stansburiana (Hahn and Tinkle, 1965). Sceloporus jarrovi (Goldberg, 1972), S. occidentalis (Goldberg, 1974), S. grammicus (Ortega, 1986), and Takydromus tachydromoides (Telford, 1970). Hahn and Tinkle (1965) presented experimental evidence of the role of fat bodies in the formation of the first clutch of eggs in Uta stansburiana. Cyclic variations in the fat levels of male lizards (with lowest levels during the breeding season) is possibly a reflection of the energy demands on the males due to territorial defence and courtship activity (Jameson, 1974). I do not have data to determine the case for A.tuberculata.

Size of fat bodies exhibited much greater fluctuations in the lowland population compared to the montane population. Subsequent to egg laying, fat bodies in the montane population were larger than at the lower elevation. Goldberg (1974) reported similar results for Scelopor us occidentalis at 1548 
$\mathrm{m}$ and $150 \mathrm{~m}$ in California and suggested that a larger amount of fat in the montane population was adaptive for survival during the long hibernation period. In addition to a role in winter nutrition, fat stores in male lizards have been postulated to have a role in survival in early spring when food supplies were low for Sceloporus grammicus (Guillette and Casas-Andreu, 1981) and Cnemidophorus sexlineatus (Etheridge et al., 1986). Jameson and Allison (1976) attributed larger amounts of body fat in adult female $S$. occidentalis at $2200 \mathrm{~m}$ to their capacity to lay larger clutches of eggs as compared to lizards found at $1500 \mathrm{~m}$. Stevens (1983) also noted that larger clutch sizes were characteristic of higher elevation populations of Cnemidophorus inornatus. On the other hand, montane populations of A. tuberculata in this study were found to lay slightly smaller clutches than lowland populations; the larger fat reserves may be in preparation for the longer hibernation period at higher altitudes. I was unable to compare total weight of clutches/female or SVL between montane and lowland populations.

\section{DISPLAY BEHAVIOR}

Lizard displays have been reported for more than 100 years. Monks (1881) observed head nods and spreading of the dewlap in Anolis carolinensis. Noble and his associates were the first to study the stereotyped courtship of lizards (Noble and Teal, 1930; Noble and Bradley, 1933; Noble, 1934). Fitch (1940) described the bowing behavior of Sceloporus occidentalis in the context of reproductive and territorial behavior. The social behavior of Ctenosaurapectinata was observed by Evans (1951) who described head and body movements as well as body coloration and position in relation to an intruder and resident.

Detailed qualitative descriptions of the display of $A$. carolinensis were made by Greenberg and Noble (1944) but a more objective analysis of lizard display was made possible by the use of time-motion analysis of filmed displays (Carpenter, 1961a; Carpenter and Grubitz, 1961; Hunsaker, 1962). As studies in display analysis progressed, it became apparent that the pattern and cadence of movements was species-specific (Carpenter, 1982). As a result of Carpenter and others, iguanid displays are well known for Urosaurus (Carpenter and Grubitz, 1961), Sceloporus undulatus (Carpenter, 1962a), Urosantus, Uta, and Streptosaurus (Carpenter, 1962b), Dipsosaurus (Carpenter, 1961b), various species of Uta (Ferguson, 1971), Callisaurus, Cophosaurus, and Holbrookia (Clarke, 1965), Anolis nebulosus (Jenssen, 1971), and the spinosus group of Sceloporus (Bussjaeger, 1971). Comparable information on agamids is almost entirely lacking.

Even though the push-up display appears to be species-specific, there still may be inter- and intr- apopulation variation in the display. McKinny (1971) and Ferguson (1971) observed two types of intrapopulational variation in Uta stansburianavariation in the number of units per display and in the manner in which the units were performed. Ferguson used interpopulation display differences in explaining the evolution and geographic distribution of U. stansburiana. Jenssen (1971) noted that the lengths of display between individual Anolis nebulosus differ considerably, yet each individual had its own consistent display.

Harris (1964) described four categories of head movements for Agama agama in Nigeria. 1) The head nod "consists of a rapid raising and lowering of the head alone; no other part of the body is moved." He suggested that a function of nodding was to indicate each lizard's presence to others in the same group. 2) In the head bob,

the head and chest are raised up and down mainly by the forelimbs, but the head may also be lifted even higher by neck muscles. The bob is performed in a slow, deliberate manner, and usually terminates with the head held up in an alert attitude ... the gular fold is not lowered.

Only the male gives the head bob-usually at the beginning of courtship. 3) The challenge display is more intense than the head bob. The head is moved up and down in a manner similar to that of the head bob but the gular fold is lowered. The display usually ends with the head lowered. Challenge displays have a territorial function and are performed only to members of the same sex. 4) In threat display, the head movement is slow and 
deliberate but similar to challenge display, differing in a) lifting the body up off the ground on all four limbs and b) a "striking change to the fear colour phase." Threat display has been observed among females (a similar posture but without the head movements or color change). Threat display is associated with fighting behavior.

I have observed head nodding in A. tuberculata of all ages, including hatchlings. As with A. agama, nods in A. tuberculata are frequently given after a shift in location. Nodding is not restricted to feeding or flight behavior as some authors have suggested. I did not observe courtship behavior in $A$. tuberculata; however, they did perform head bobs (raising and lowering the head by flexing the forelimbs but not lowering the gular fold) frequently when arriving at a new location. Also, such behavior was elicited when a novel situation presented itself-such as when I maneuvered myself and camera equipment to within range for filming challenge displays. In this context, head bobbing had no reproductive function but was equivalent to what Carpenter (1962a) described as assertion displays. The bobs appeared to function as a territorial declaration. Challenge display in $A$. tuberculata is similar to that reported for A. agama. I was able to elicit challenge displays from freeranging females by presenting a tethered male. Prior to fighting, A. tuberculata challenged vigorously and occasionally opened its mouth slightly. However, it did not raise itself off the ground on all limbs or change color in a distinct threat display as is the case for A. agama.

I studied the challenge display of A.tuberculata by presenting a tethered male to free-ranging resident males in the field. The behavior of the tethered male was typically submissive. Regardless of the size of the resident male, the intruding male usually flattened itself against the substrate and kept its head against the ground. Occasionally, its initial response was a sequence of weak bobs before flattening its body on the substrate. If attacked, it remained relatively motionless and even allowed the resident male to clamber upon its back. On occasion, it tried to escape. If the attack was judged to be too ferocious. I removed the tethered male.

\section{Categories Used in Analysis}

I have used the 8 categories suggested by Carpenter (1962a) in analyzing the challenge display.

Site.-In most instances, the rock lizard gave its display from an elevated site (usually a prominent rock) within its territory. At times, displays were performed on vertical faces of rocks above the intruder. If the terrain was flat, the resident displayed on the level of the intruder or placed its forelegs on a small rock to elevate the anterior part of its body.

Position.-Challenge-displaying lizards held their bodies essentially parallel to the substrate except when performing the push-up. Lizards were in any position between horizontal and vertical. The head was generally pointed up when the lizard was on a vertical surface.

The resident lizard usually positioned its body laterally toward the intruder. Sidlehopping approach ensured that a maximum view of the body was presented to the intruder at all times. Occasionally, the resident tilted its body towards the intruder which also maximized its apparent body size. Fighting lizards assumed the face-off position (Carpenter, 1962a). I believe that damaged tails of rock lizards are usually a result of these encounters rather than narrow escapes from predators.

Posture.--Lizards in the challenge display accentuated their size by slight to moderate lateral compression of the body - particularly the thoracic region. The lowered dewlap exposed large black blotches. If the resident was facing the intruder, the dark markings on its chest were visible when performing push-ups. The hind legs usually sprawled laterally with the pelvic region against the substrate. If the resident was above the intruder on a vertical surface, it twisted the anterior half of its body to effect a more lateral presentation of the head and dewlap.

Movement type and parts moved.-The dominant movement in challenge display was a push-up brought about by a series of extensions and flexions of the forelegs. The head and shoulders were held rigid and pivoted about a point in the lumbar or sacral region. At the end of the push-up there was a rapid downward jerk of the head. A series of push-ups, head jerks, and pauses made up 
the entire display.

Units of movement.-Carpenter (1962a) and Ferguson (1971) defined a unit as beginning with a lowering or raising of the body and ending with a return of the body to the starting position. Clarke (1965) also considered the pause at the end of the movement to be a part of the unit. I have used Clarke's definition for analysis in this study.

A generalized display-action-pattern (DAP) graph for A. tuberculata is shown in Fig. 35. A unit consists of raising the head in 2 stages, lowering the head in 2 stages ending in a brief head jerk, and finally a pause. For analysis I arbitrarily divided the display into 8 subunits. Some lizards omitted various subunits - called type B display if subunits 5 and 6 were omitted; type $C$ if subunits 2 and 3 were omitted; and type D if subunits 2, 3, 5, and 6 were omitted. There was variation between individuals at a given locality in the duration of the unit as well as the pattern and timing of the subunits.

Sequence of movements. - The order of units and the total number performed in succession constitute the sequence of movements. Six lizards (three each at high and low altitude) gave exclusively type A displays. The same number at high and low altitude have exclusively type B displays. Several lizards performed more than one type of push-up. Four individuals (one at high altitude and three at low latitude) performed types A and B. At high altitude, one individual included types A, B, and $\mathrm{D}$ and another individual performed types $\mathrm{B}$ C, and D (Fig. 36). I suspect that further studies will show the low altitude populations to have a complexity of display types and combinations comparable with those of the high altitude lizards. One individual at low altitude performed all four types of units but I was unable to obtain a film of its display. It is probable that few individuals have only one type of display.

Cadence.-Films were used to determine the duration of each unit and subunit. The means for the four types of units at high and low altitude were compared by the Student-Newman-Keuls test. Type A unit at high altitude $(\bar{X}=3.70 \mathrm{sec}$; range 1.89 $5.33 \mathrm{sec} ; n=14$ ) was significantly longer than type A unit at low altitude $(\bar{X}=3.00 \mathrm{sec}: 1.75-5.67 \mathrm{sec}$ : $n=14)$. At high altitude, types $\mathrm{B}(\bar{x}=1.74 \mathrm{sec} ; 1.22-$ $2.89 \mathrm{sec} ; n=31), \mathrm{C}(\bar{X}=2.33 \mathrm{sec} ; 1.72-3.51 \mathrm{sec}:$ $n=9)$, and $\mathrm{D}(\bar{x}=1.84 \mathrm{sec} ; 1.11-3.67 \mathrm{sec} ; n=8)$ were not significantly different from each other or from type B ( $\bar{x}=2.11 \mathrm{sec} ; 1.58-3.00 \mathrm{sec} ; n=16)$ at low altitude. Types B, C, and D were significantly shorter in duration than type A at high or low altitude. It is not surprising that types $\mathrm{B}$ and $\mathrm{C}$ are significantly shorter than type A as 2 subunits have been omitted. However, it is unexpected that type $\mathrm{D}$ is no shorter that type $\mathrm{B}$ at high altitude, although it has 4 subunits omitted. The rock lizard performed from 1 to 8 units in sequence, the most frequent being $3-5$.

\section{HOME RANGE AND TERRITORY}

An individual animal may wander continuously throughout its life, but individuals of most species restrict their activities to definite areas. Burt (1943) defined home range as "the area traversed by the individual in its normal activities of food gathering, mating, and caring for young." The home range may be shifted from time to time or may be permanent. Defended portions of the home range are called territories. In many cases such as that of Uta stansburiana (Tinkle, 1967), home range and territory are synonymous. In other species, the territory may not coincide exactly with the home range or may be maintained only during the breeding season.

A widely used measure of home range or territory is the area enclosed by outlying points of occurrence (convex polygon). The observations may be trap records or direct sightings. A freeranging animal probably visits many outlying points, consequently areas based on only a few outlying points are minimal. Jennrich and Turner (1969) proposed correction factors to calculate an unbiased estimate of home range based on varying numbers of outlying observations. This estimate, however, does not take into consideration differential utilization of the home range or territory.

\section{Movement and BeHavior}

Agama tuberculata exhibited shifts in the home range during the year and from 1 year to the next (Table 16). Lizards at low altitude showed a greater 


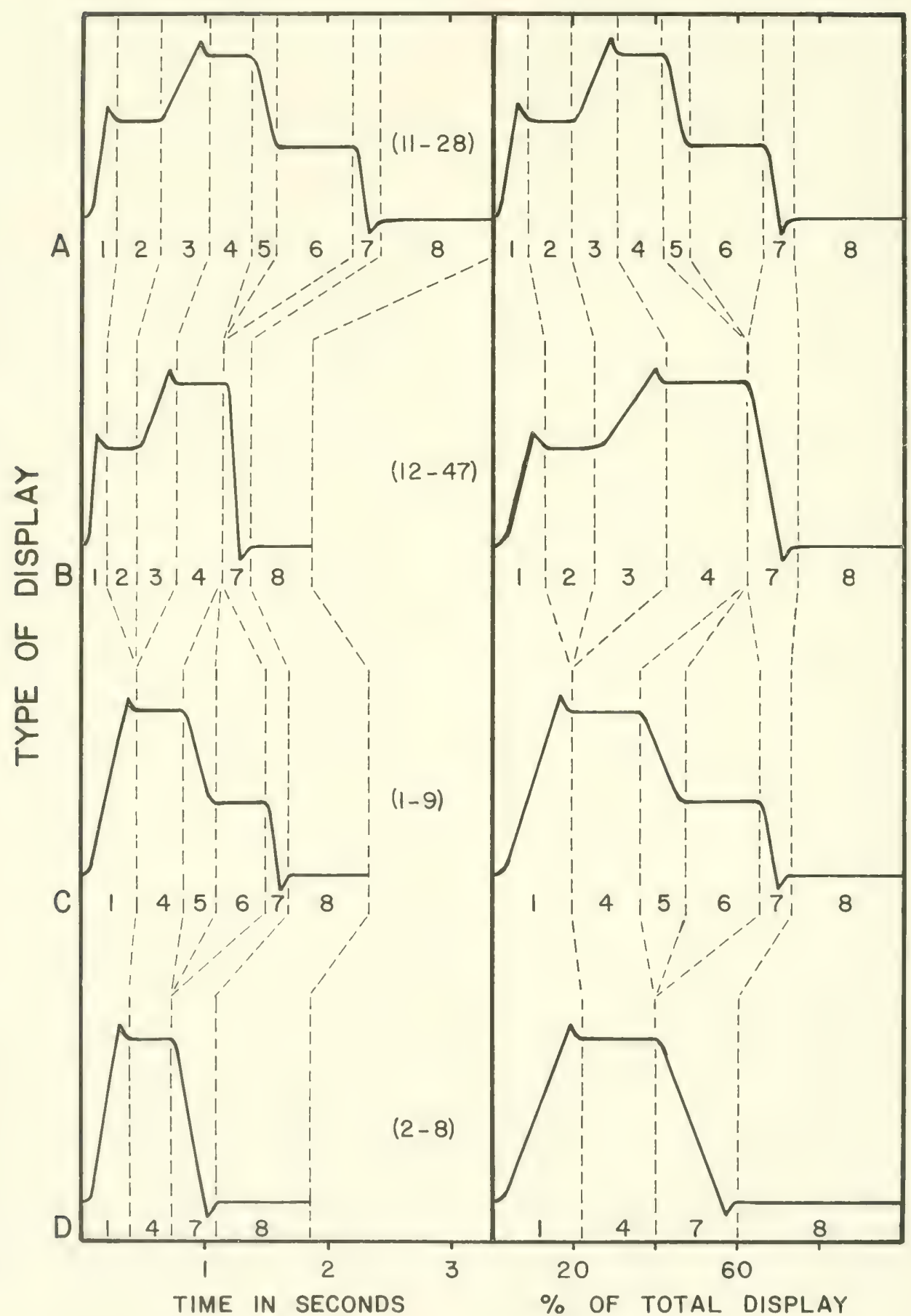

Fiig. 35. DAP graphs for challenge displays of A. fuberculata showing the four types and the subunits used in the display analysis. Types A and B are the averages for high and low altitude lizards. Types C and D were analyzed only for high altitude lizards. The first number in ( ) indicates how many lizards gave that type of display, the second number denotes the total number of units analyzed. 


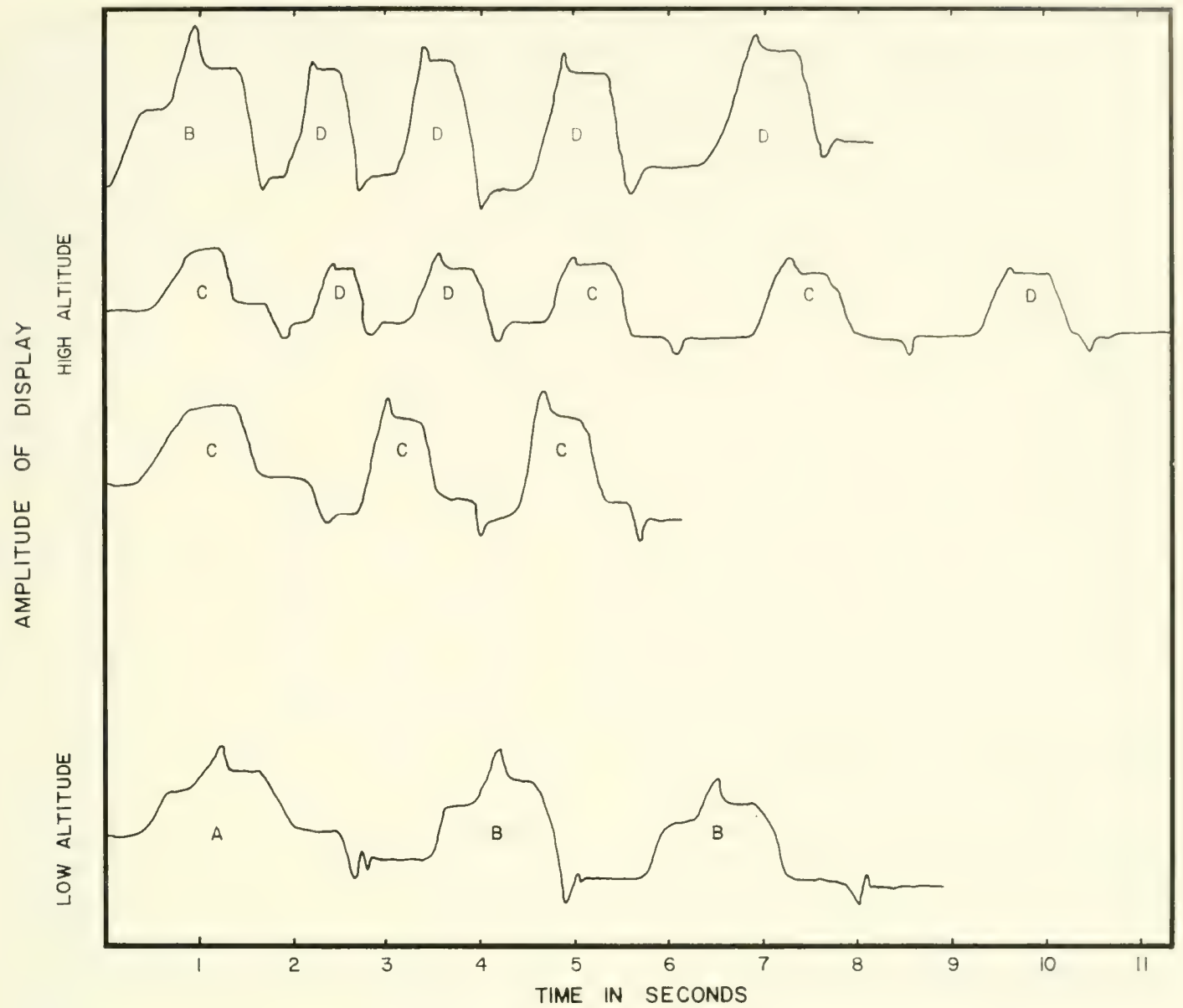

Fig. 36. Challenge display for selected A. tuberculata. Successive units in any given sequence may not be the same type. Variation in amplitude between sequences is due to inter- and intra-individual variation as well as variation in camera/lizard distance.

tendency to shift, perhaps due to their greater density than at high altitude. In addition, all lizards on the breakwater at low altitude shifted to the hillside in November where I found many of them in or near crevices used for hibernation. The many shifts at low altitude in 1974 are largely due to intensive human activity.

Movements of individual rock lizards were determined by direct observation. These diurnal lizards are relatively easy to detect as they spend most of their time basking on prominent observation sites. Territories of adult males generally have little overlap; see Waltner (1978) for details on individuals. Apparent cases of extensive overlap are due to replacement or differential use of territories. One male at high altitude in 1973 immigrated during September but stayed only for 11 days. Two other males at high altitude in 1973 showed extensive overlap but in reality spent most of their time in discrete areas. Adult males which left the study area were soon replaced.

Territorial behavior of males was most prominent after leaving the communal roosting site in the morning and prior to retiring to it for the night. At both study sites up to 10 individuals of all sexes and sizes were observed to emerge from a crevice. After a short inactive period, the males became pugnacious and dispersed to their respective terri- 
Table 16. Number of A.tuberculata on the study sites compared to number which shifted their territories (adult male's only) or home ranges (all others onto, within, or off of the study sites during 1973 and 1974. A. F=Total individuals on area; $\mathbf{B}, \mathbf{G}=$ Inmigrated or hatched; $\mathbf{C}, \mathbf{H}=$ Shifted home range or territory; $\mathbf{D}=$ Emigrated or died before 29 November: $\mathbf{E}=$ Shifted home range or territory between 1973 and 1974; $\mathbf{I}=$ Emigrated or died; ancludes December; ${ }^{b}$ marked in 1973: ' ${ }^{c}$ wo marked in 1973; "five marked in 1973.

\begin{tabular}{|c|c|c|c|c|c|c|c|c|c|}
\hline & \multicolumn{5}{|c|}{1973} & \multicolumn{4}{|c|}{1974} \\
\hline & A & B & C & D & $\mathbf{E}$ & F & G & $\mathbf{H}$ & I \\
\hline \multicolumn{10}{|l|}{ High altitude } \\
\hline Adult $\sigma$ & 7 & 2 & 2 & 2 & 1 & 6 & 1 & 0 & 1 \\
\hline Adult $\bigcirc$ & 8 & 1 & 2 & 3 & 2 & 12 & 1 & 1 & 4 \\
\hline Subadult & 6 & 2 & 3 & 0 & 1 & 3 & $1^{b}$ & 0 & 2 \\
\hline Juvenile & 10 & 1 & 1 & 3 & 1 & 22 & 15 & 3 & 5 \\
\hline Hatchling & 27 & 27 & 3 & $10^{\mathrm{a}}$ & 5 & 0 & 0 & 0 & 0 \\
\hline \multicolumn{10}{|l|}{ Low altitude } \\
\hline Adult $\sigma$ & 14 & 7 & 5 & 4 & 4 & 10 & $2^{b}$ & 3 & 4 \\
\hline Adult $Q$ & 14 & 6 & 6 & 5 & 3 & 15 & $6^{c}$ & 2 & 7 \\
\hline Subadult & 14 & 11 & 3 & 5 & 3 & $8-10$ & $8^{d}$ & 2 & $5-7$ \\
\hline Juvenile & 8 & 6 & 2 & 6 & 2 & 9 & 8 & 4 & 6 \\
\hline Hatchling & 16 & 16 & 2 & $11^{\mathrm{a}}$ & 3 & 1 & 1 & 1 & 0 \\
\hline
\end{tabular}

tories. In the late afternoon adult males returning to the roosting site occasionally chased each other. During the day, adult males visited outlying posts of their territories. On the edge of the Polo Grounds at Mussoorie an adult male regularly patrolled his territory along a rock wall throughout the day.

Home ranges of hatchlings, juveniles, subadults, and adult females showed extensive overlap. The latter did not maintain territories thereby making it possible for several to reside within an adult male's territory. However, females did maintain a dominance hierarchy similar to that reported by Harris (1964) for A. agama in Nigeria. Female rock lizards were pugnacious to each other if approached to within a certain minimum distance. The largest females were the most intolerant.

\section{Size of Territory and Home Range}

The size of the territory or home range varies considerably (Tables 17, 18) but is not associated with differences in altitude. The smallest and largest areas were recorded on the hillside and breakwater respectively at low altitude. Small territories and home ranges at low altitude were associated with increased availability of refuges from predators and amount of ground cover and relatively high population density.
Table 17. Average size of territory (adult males only) or home range (all others) in $\mathrm{m}^{2}$ of high altitude $A$. tuberculata. Adjusted areas were computed by using correction factors of Turner, et al. (1969). A=Convex polygon; $\mathbf{B}=$ Adjusted area; $\mathbf{C}=$ My estimate. ( ) $=$ =sample size.

\begin{tabular}{|c|c|c|c|c|}
\hline & & A & B & C \\
\hline Adult $\sigma$ & $\begin{array}{r}1973 \\
1974 \\
\bar{x}\end{array}$ & $\begin{array}{rr}63.8 & (8) \\
132.3 & (5) \\
90.1 & (13)\end{array}$ & $\begin{array}{l}563.5 \\
789.7 \\
650.5\end{array}$ & $\begin{array}{l}114 \\
180 \\
140\end{array}$ \\
\hline Adult Q & $\begin{array}{r}1973 \\
1974 \\
\bar{x}\end{array}$ & $\begin{array}{rr}63.1 & (6) \\
41.3 & (10) \\
49.4 & (16)\end{array}$ & $\begin{array}{l}553.7 \\
302.9 \\
396.9\end{array}$ & $\begin{array}{l}88 \\
71 \\
77\end{array}$ \\
\hline Subadult & $\begin{array}{r}1973 \\
1974 \\
\bar{x}\end{array}$ & $\begin{array}{ll}84.3 & (5) \\
36.2 & (2) \\
70.5 & (7)\end{array}$ & $\begin{array}{l}608.5 \\
373.6 \\
541.4\end{array}$ & $\begin{array}{r}121 \\
64 \\
105\end{array}$ \\
\hline Juvenile & $\begin{array}{r}1973 \\
1974 \\
\bar{x}\end{array}$ & $\begin{array}{rr}16.3 & (8) \\
34.8 & (15) \\
58.4 & (23)\end{array}$ & $\begin{array}{l}185.6 \\
277.9 \\
245.8\end{array}$ & $\begin{array}{l}40 \\
57 \\
51\end{array}$ \\
\hline Hatchling & $\begin{array}{r}1973 \\
1974 \\
\bar{x}\end{array}$ & $\begin{array}{cr}18.0 & (18) \\
- & (0) \\
18.0 & (18)\end{array}$ & $\begin{array}{c}296.2 \\
- \\
296.2\end{array}$ & $\frac{42}{42}$ \\
\hline
\end{tabular}


Table 18. Average size of territory (adult males only) or home range (all others) in $\mathrm{m}^{2}$ of low altitude $A$. nuberculatc. Adjusted areas were computed by using correction factors of Tumer, et al. (1969). A=Convex polygon; $B=$ Adjusted area; $\mathbf{C}=$ My estimate. ()$=$ sample size.

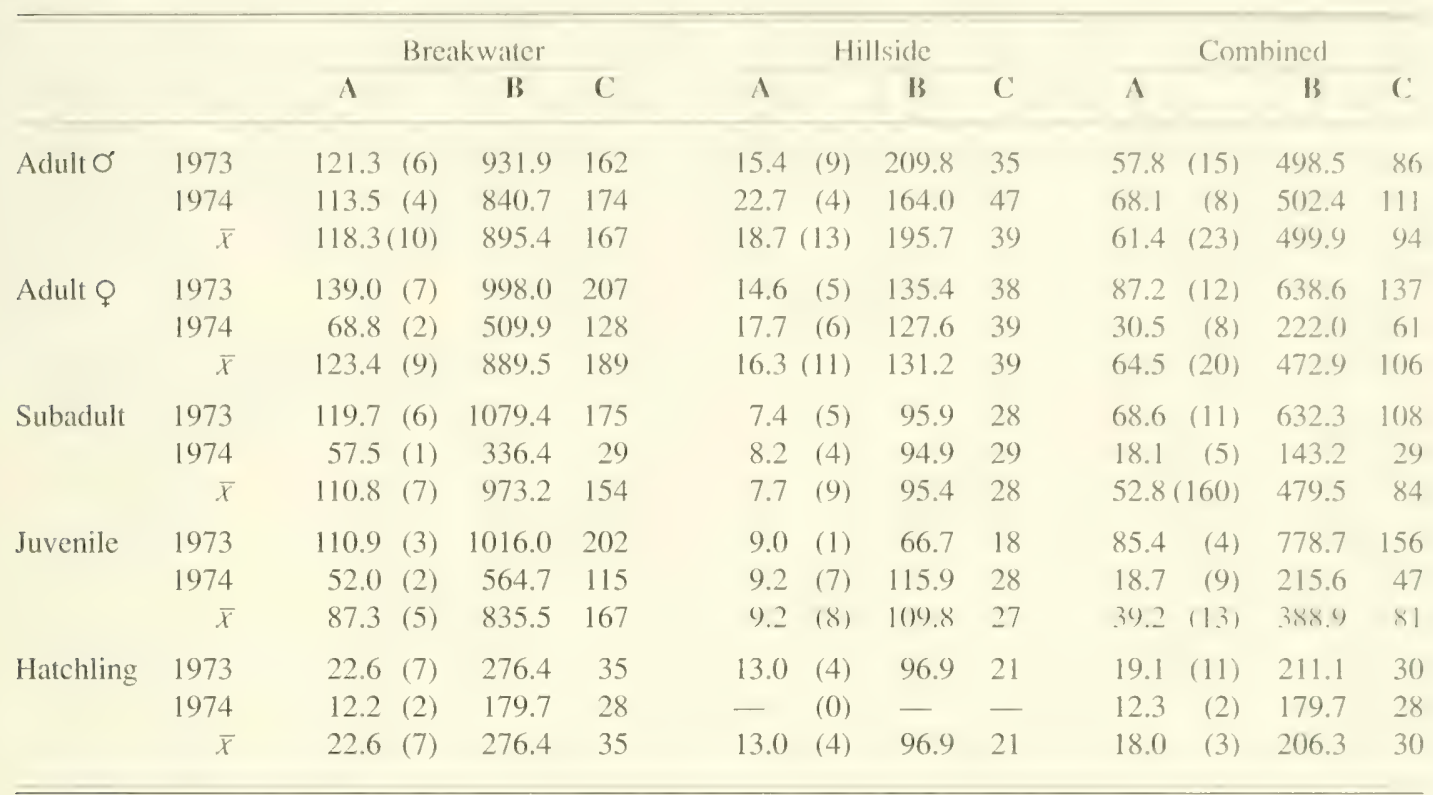

The technique employed in calculating the territory or home range dramatically affects its estimation (Tables 17, 18). For reasons previously stated, the convex polygon technique often underestimated the territory. However, when adjusted by correction factors proposed by Jennrich and Turner (1969) the estimates seem obviously too large to be reconciled with actual field observations, a situation also noted by Rose (1982) and Christian and Waldschmidt (1984). The method I finally settled upon for a representative estimate involved drawing an irregular figure around all points where an individual had been observed. The placement of this boundary took into consideration the suitability of the terrain and known behavior of the individual. hence I believe this estimate to be the most accurate; see Waltner (1978) for details on individuals.

Regardless of which method is used to estimate home range and territory, an individual does not utilize all regions equally (Adams and Davis, 1969). Rock lizards prefer prominent rocks for observation posts. They forage close to these and have readily accessible refuges. The route from one post to another is relatively fixed even though it may be circuitous. If a convex polygon is drawn to enclose outlying observations, areas of varying size may be included which are seldom, if ever, utilized. In some instances, these areas may lack obvious habitat requirements but in other cases an area is avoided for more subtle reasons.

The average size of territories based on my subjective estimate for adult males at high altitude was $140 \mathrm{~m}^{2}$ (Table 17). Home ranges averaged 77 $\mathrm{m}^{2}$ for females, $105 \mathrm{~m}^{2}$ for subadults, $51 \mathrm{~m}^{2}$ for juveniles, and $42 \mathrm{~m}^{2}$ for hatchlings. During 1973 at low altitude, the average territory for adult males was $86 \mathrm{~m}^{2}$ (Table 18). Home ranges averaged 137 $\mathrm{m}^{2}$ for adult females, $108 \mathrm{~m}^{2}$ for subadults, $156 \mathrm{~m}^{2}$ for juveniles, and $30 \mathrm{~m}^{2}$ for hatchlings. Human activity during 1974 at low altitude greatly modified the normal activity of lizards.

Compared to A. tuberculata, Harris (1964) found A. agama in Nigeria to have smaller territories (55$74 \mathrm{~m}^{2}$ ) which shrank (to $19 \mathrm{~m}^{2}$ ) under extreme territorial pressure and expanded (to $121 \mathrm{~m}^{2}$ ) in newly colonized areas. Tinkle (1969) stated that for Uta stansburiana density was probably important in determining size of home ranges but it did not always explain yearly trends. My data for high altitude show that size of territories for males 
increased in 1974 while their numbers remained constant. On the other hand, home range size for adult females decreased in 1974 with their increased numbers. Territories of adult males could expand considerably without increasing their degree of overlap. Juveniles almost doubled their numbers in 1974 but also increased the average size of their home ranges. Density is of secondary importance in determining the size of the area to which $A$. tuberculata limits itself at high altitude. At low altitude however, density is negatively correlated with size of territory or home range. Areas of activity were much larger on the breakwater which had only two roosting sites compared to the hillside which had a smaller total area as well as more roosting sites and a correspondingly higher density.

\section{BIOMASS AND NUMBERS}

\section{Biomass}

Several assumptions were made for calculating biomass: 1) SVL of non-adults for different months approximated the regression line in Figs. 14-17.2) Weight of non-adults was a function of SVL as presented in Fig. 10.3) There was no sexual dimorphism in individual biomass for non-adults. 4) Adult males show negligible changes in biomass throughout the year but adult females increased their biomass while maturing eggs and lost biomass at the time of laying. In 1973 during June-October, the biomass/ha at low altitude was 1.7-2.3 times that of high altitude (Tables 19,20) and comparable ratios were also observed for June and July 1974. Biomass increased markedly at the low altitude site after the monsoons through a combination of growth, recruitment of hatchlings, and recruitment of older age classes by immigration. Harris (1964) did not calculate biomass but estimated density of 346 individuals/ha for A. agama on a well-established site away from buildings. Densities of $A$. tuberculata at low altitude after the monsoons were somewhat lower.

\section{Estimate OF Numbers}

The number of lizards was not constant at either study site (Tables 21,22). Monthly cohorts declined after marking due to mortality and emigration. Occasionally, lizards reappeared after absences of more than a year. An extreme example was an adult male marked at high altitude on the first day of observations (7 June) in 1973 but not observed again until 14 June 1974. Finally, I captured him just below the study site on 1 August. The composition of the population changes dramatically during the year. At high altitude in particular, the total numbers remained constant from OctoberNovember, yet during that interval most subadults and adults had gone into hibernation and many new hatchlings appeared.

A direct count of all the hatchlings was not possible. However, if the instantaneous mortality rate (i) of any cohort (size $\mathrm{N}$ ) is known, it is possible to calculate the initial size of the cohort $\left(\mathrm{N}_{0}\right)$ at some previous time $(t)$ by the formula $\mathrm{N}_{t}=\mathrm{N}_{0} e^{t t}$ (Krebs, 1972). Estimates of the total number of hatchlings at high and low altitude are given in Table 23. At high altitude on 30 November, three hatchlings remained of six marked on 14 October. This finite mortality rate of 0.50 for the 47 day period gives an instantaneous mortality rate $(i)$ of -0.69 . The average age of new hatchlings observed on a given date was estimated to be $1 / 2$ of the interval from the previous marking period except for hatchlings observed on 20 September whose average age was assumed to be $1 / 2$ their estimated maximum age. For low altitude, $66 \%$ mortality was observed for periods of 24 and 33 days yielding an $i$ of -1.10 and making possible two different estimates of the total number of hatchlings. At high altitude, the total number of hatchlings was estimated to be 34 (27 observed including one immigrant). Sixteen hatchlings (including two immigrants) were observed at low altitude compared to a total estimate of 37-59 hatchlings.

In the previous section I concluded that egglaying at high altitude was probably from midJune-mid-July and at low altitude from MayOctober. Seven adult females at high altitude during 1973 laid an estimated 62 eggs (Table 24). As three of those females were observed for only a few days, the reproductive effort may have been as low as 38 eggs. In 1974, the reproductive effort increased to 75 eggs due to maturation of subadults and a low 
Table 19. Biomass (in g) estimated from numbers of $A$. luberculata observed on a monthly basis at high and low altitude in 1973. ( ) =sample size.

\begin{tabular}{|c|c|c|c|c|c|c|c|}
\hline & April & May & June & September & October & November & December \\
\hline \multicolumn{8}{|l|}{ High altitude } \\
\hline Adult $\sigma$ & - & - & $323.5(5)$ & $452.9(7)$ & 323.5 (5) & ) $129.4(2)$ & - \\
\hline Adult $Q$ & - & - & $401.8(7)$ & $263.0(5)$ & $263.0(5)$ & $52.6(1)$ & $52.6(1)$ \\
\hline Subadult & - & - & $112.0(4)$ & $204.0(6)$ & $210.0(6)$ & $74.0(2)$ & - \\
\hline Juvenile & - & - & $73.8(9)$ & $120.0(8)$ & $136.0(8)$ & $95.0(5)$ & $46.0(2)$ \\
\hline Hatchling & - & - & - & $5.1(3)$ & $16.0(8)$ & $59.4(22)$ & $54.0(18)$ \\
\hline Total biomass & - & - & 911.1 & 1045.0 & 948.5 & 410.4 & 152.6 \\
\hline Total individuals & - & - & 25 & 29 & 32 & 32 & 21 \\
\hline Biomass/ha & - & 一 & 4874.4 & 5590.8 & 5074.5 & 2195.6 & 816.4 \\
\hline Individuals/ha & - & - & 134 & 155 & 171 & 171 & 112 \\
\hline \multicolumn{8}{|l|}{ Low altitude } \\
\hline Adult $\sigma$ & $117.2(2)$ & $410.2(7)$ & $410.2(7)$ & $586.0(10)$ & $586.0(10)$ & $527.4(9)$ & 175.8 (3) \\
\hline Adult $Q$ & $145.2(3)$ & $387.2(8)$ & $449.1(9)$ & $435.6(9)$ & $484.0(10)$ & $290.4(6)$ & $145.2(3)$ \\
\hline Subadult & $74.0(2)$ & $152.0(4)$ & $156.0(4)$ & $376.0(8)$ & $414.0(9)$ & $423.0(9)$ & 153.0 \\
\hline Juvenile & $22.0(2)$ & $78.0(6)$ & $77.5(5)$ & 96.0 (4) & 84.0 (3) & - & $63.0(2)$ \\
\hline Hatchling & - & - & $9.9(9)$ & $25.0(10)$ & $18.6(6)$ & $26.6(7)$ & $21.5(5)$ \\
\hline Total biomass & 358.4 & 1027.4 & 1102.7 & 1518.5 & 1586.6 & 1267.4 & 558.5 \\
\hline Total individuals & 9 & 25 & 34 & 41 & 38 & 31 & 16 \\
\hline Biomass/ha & 2684.4 & 7695.2 & 8259.2 & 11374.3 & 11883.6 & 9492.8 & 4183.2 \\
\hline Individuals/ha & 67 & 187 & 255 & 307 & 285 & 232 & 120 \\
\hline
\end{tabular}

mortality of adults. Similarly, at low altitude, the reproductive effort of 91 eggs in 1973 rose to 108 eggs in 1974. Here, however, human disturbance resulted in more frequent shifts of home range and the temporary appearance of individuals so that the actual egg production in 1974 may have been as low as 75 eggs.

\section{SuRVIVORSHIP}

Survivorship of eggs at high altitude in 1973 was $55 \%\left({ }^{34} / 62\right)$ and at low altitude was $41-65 \%$ $\left({ }^{37} / 9 k\right.$ and $\left.59 / 91\right)$. If females which were observed on the study areas for only a few days during the egglaying season did not lay eggs on the study site, survivorship of eggs at high altitude rises to $92 \%$ $\left({ }^{34} / 37\right)$ and at low altitude rises to $51-79 \%\left({ }^{37} / 73\right.$ and $59 / 75$ ). Lower survivorship at low altitude is not unexpected. Suitable egg-laying sites along the river bank were generally subject to intermittent flooding during the monsoons.

Survivorship from June 1973 to June 1974 increased with age (Fig. 37). Another way to examine survivorship is to determine how long each individual was present on the study area (Fig. 38). Again, increased survivorship with age is evident. A. tuberculata is an example of a Type III survivorship curve (Pearl, 1928) where few individuals survive the early stages of life but for those that do, life expectancy is relatively long. In this study estimates of survivorship of lizards at low altitude has little significance. Construction activities uncovered at least one clutch and undoubtedly buried others under piles of debris. Survival of subadults and adults was probably underestimated. Undoubtedly some individuals emigrated as disturbance to the study site by humans increased.

\section{Reproductive and Life History Strategy}

In discussing certain tropical lizard populations in Costa Rica, Fitch (1973) distinguished four types of reproductive and life history strategies. Type 1 populations have a stable age structure due to year round reproduction at a constant level. Type 2 populations have a fluctuating age structure due 
Table 20. Biomass (in g) estimated from numbers of A. tuberculata observed on a monthly basis at high and low altitude in 1974. ( )=sample size.

\begin{tabular}{|c|c|c|c|c|c|}
\hline & March & May & June & July & August \\
\hline \multicolumn{6}{|l|}{ High altitude } \\
\hline Adult $\sigma$ & - & $323.5 \quad(5)$ & $388.2 \quad(6)$ & $323.5 \quad(5)$ & - \\
\hline Adult $Q$ & - & $631.2(12)$ & $516.6(9)$ & $458.1 \quad(9)$ & - \\
\hline Subadult & - & 26.0 (1) & $56.0 \quad(2)$ & 60.0 & - \\
\hline Juvenile & - & $105.0(15)$ & $164.0(20)$ & $160.0(16)$ & - \\
\hline Hatchling & - & - & - & - & - \\
\hline Total biomass & - & 1085.7 & 1124.8 & 1001.6 & - \\
\hline Total individuals & - & 33 & 37 & 32 & - \\
\hline Biomass/ha & - & 5808.5 & 6017.7 & 5358.6 & - \\
\hline Individuals/ha & - & 177 & 198 & 171 & - \\
\hline \multicolumn{6}{|l|}{ Low altitude } \\
\hline Adult $\sigma$ & $468.8 \quad(8)$ & - & $527.4 \quad(9)$ & $410.2 \quad(7)$ & 351.6 \\
\hline Adult $\bigcirc$ & $435.6 \quad(9)$ & - & $598.8(12)$ & $512.0(10)$ & 338.8 \\
\hline Subadult & $74.0 \quad(2)$ & - & 273.0 & 205.0 & 132.0 \\
\hline Juvenile & 11.0 & - & 108.5 & $162.0 \quad(9)$ & 63.0 \\
\hline Hatchling & - & - & $1.1 \quad(1)$ & 1.7 (1) & 2.0 \\
\hline Total biomass & 989.4 & - & 1508.8 & 1290.9 & 887.4 \\
\hline Total individuals & 20 & - & 36 & 32 & 20 \\
\hline Biomass/ha & 7410.6 & - & 11300.9 & 9668.8 & 6646.6 \\
\hline Individuals/ha & 150 & - & 270 & 240 & 150 \\
\hline
\end{tabular}

to changing year round reproduction. Type 3 populations are found in areas with dry seasons and restrict their reproduction to the wetter months. The population at the beginning of the breeding season consists mostly of adults but is heterogeneous with immatures of all sizes and adults towards the end of the breeding season. Type 4 populations have several discrete age groups due to a short breeding season and delayed maturity. A few species fit type 4 in Costa Rica but this type is most characteristic of species ranging farther into the temperate zone. Agama tuberculata fits the type 4 pattern, having delayed maturity and a restricted breeding season. At low altitude it exists in a subtropical climate but experiences an increasingly temperate climate as it penetrates the Himalayas.

In reviewing reproductive strategies of lizards, Tinkle et al. (1970) concluded that they

are clearly divided into two categories: early-maturing, multiple brooded vs. latematuring, single brooded. Delayed maturity appears to be more frequent in temperate than in tropical environments,

an observation also made by Vitt (1977). Agama tuberculata fits this pattern by delaying maturity till 2 or 3 years old and laying a single clutch per year.

\section{SUMMARY}

High $(2165 \mathrm{~m})$ and low $(690 \mathrm{~m})$ altitude populations of the common rock lizard, Agama tuberculata, in the western Himalayas were studied between 15 March 1973 and 5 August 1974. Individual identification was by means of toe clipping and combinations of two spots of enamel paint on the head after initial capture by noosing or, rarely, by hand. Of 77 individuals observed 858 times at high altitude, 60 were marked and observed 796 times. Of 82 individuals observed 991 times at low altitude, 72 were marked and observed 959 times. Additional data were obtained from 158 
Table 21. Numbers of high altitude A. tuberculata observed during 1973-74. A given cohort progresses to the lower right (of five new adult males captured in June 1973 five were recaptured in September, four in Oetober, etc.). $\mathrm{RC}=$ recaptures from 1973; “20 September; " 14 October; ${ }^{\mathrm{C}} 30$ November.

$\begin{array}{ccccc} & & & & 1974 \\ \text { June Sept. Oct. Nov. Dec. } \\ 29-30 & 10\end{array} \quad$ May June July

$\begin{array}{ccccccc}\text { Adult } \sigma & \text { Total } & 5 & 7 & 5 & 2 & 0 \\ & \text { New } & 5 & 2 & 0 & 0 & 0 \\ & & 5 & 1 & 0 & 0 \\ & & & 4 & 1 & 0 \\ & & & & 1 & 0\end{array}$

$\begin{array}{cccc}\text { Total } & 5 & 6 & 5 \\ \text { New } & 1 & 0 & 0 \\ \text { RC } & 4 & 1 & 0 \\ & & 1 & 0 \\ & & 4 & 0 \\ & & 1 \\ & & 4\end{array}$

$\begin{array}{ccccccc}\text { Adult } & \text { Total } & 7 & 5 & 5 & 1 & 1 \\ \text { New } & 7 & 1 & 0 & 0 & 0 \\ & & 4 & 1 & 0 & 0 \\ & & & 4 & 0 & 0 \\ & & & & 1 & 0\end{array}$

$\begin{array}{rrrr}\text { Total } & 12 & 9 & 9 \\ \text { New } & 1 & 0 & 0 \\ \text { RC } & 11 & 0 & 0 \\ & & 1 & 0 \\ & & 8 & 0 \\ & & & 1 \\ & & & 8\end{array}$

\begin{tabular}{|c|c|c|c|c|c|c|c|c|c|c|}
\hline \multirow[t]{7}{*}{ Subadult } & Total & 4 & 6 & 6 & 2 & 0 & Total & 1 & 2 & 2 \\
\hline & New & 4 & 2 & 0 & 0 & 0 & New & 0 & 0 & 0 \\
\hline & & & 4 & 2 & 0 & 0 & $\mathrm{RC}$ & 1 & 1 & 1 \\
\hline & & & & 4 & 1 & 0 & & & 0 & 0 \\
\hline & & & & & 1 & 0 & & & 1 & 1 \\
\hline & & & & & & 0 & & & & 0 \\
\hline & & & & & & & & & & 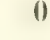 \\
\hline \multirow{7}{*}{ Juvenile } & Total & 9 & 8 & 8 & 5 & 2 & Total & 15 & 20 & 16 \\
\hline & New & 9 & 1 & 0 & 0 & 0 & New & 10 & 6 & 1 \\
\hline & & & 7 & 1 & 0 & 0 & $\mathrm{RC}$ & 5 & 0 & 0 \\
\hline & & & & 7 & 0 & 0 & & & 9 & 3 \\
\hline & & & & & 5 & 0 & & & 5 & 0 \\
\hline & & & & & & 2 & & & & 8 \\
\hline & & & & & & & & & & 4 \\
\hline \multirow[t]{6}{*}{ Hatchling } & Total & 0 & $3^{\mathrm{a}}$ & $8^{b}$ & $22^{c}$ & 18 & Total & 0 & 0 & 0 \\
\hline & New & & 1 & 6 & 17 & 1 & & & & \\
\hline & & & 2 & 1 & 3 & 13 & & & & \\
\hline & & & & 1 & 1 & 3 & & & & \\
\hline & & & & & 1 & 0 & & & & \\
\hline & & & & & & 1 & & & & \\
\hline \multicolumn{2}{|c|}{ Total on Area } & 25 & 29 & 65 & 65 & 21 & & 33 & 37 & 32 \\
\hline
\end{tabular}

lizards collected at high altitude and 83 at low altitude. Supplementary notes were taken on lizards observed outside the principal study areas.

Fissures in rocks are an essential component of the rock lizard's habitat. Cracks in walls and spaces under eaves and between slate slabs on roofs pro- vide similar refuges near human habitations at least during the activity season. The apparent predilection for riparian habitat at low altitude is due to the abundance of cracks and fissures in the exposed rocks along streams.

Compared with females, males have grayer 
Table 22. Numbers of low altitude A, tuberculata observed during 1973-74. A given cohort progresses to the lower right (see Table 16). RC=recaptures from 1973.

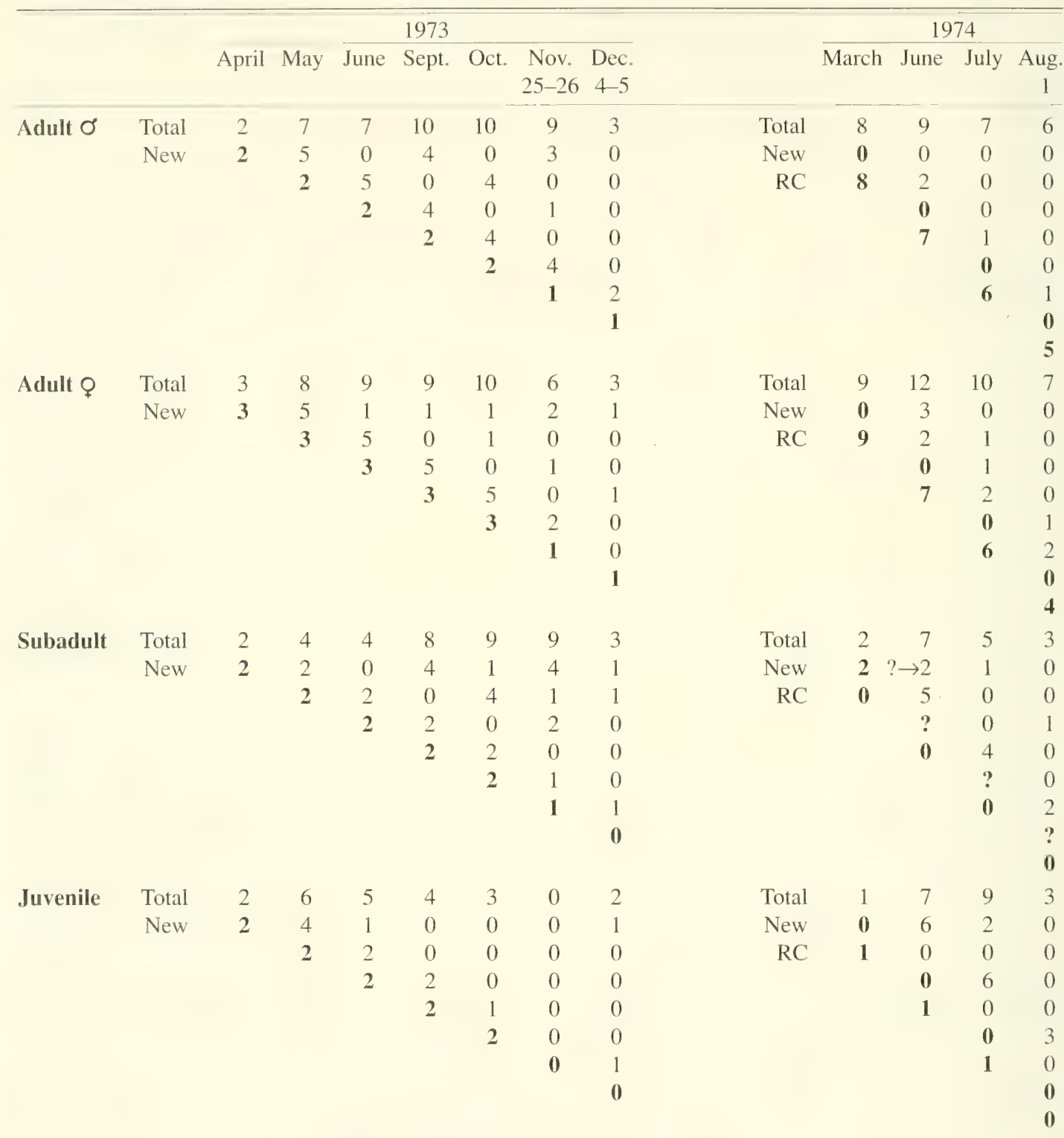

Sept. Sept. Oct. Nov. Dec.

\begin{tabular}{rlllllllllllllll}
\multirow{3}{*}{ Hatchling } & Total & 0 & 0 & 9 & 10 & 6 & 7 & 5 & Total & 0 & 1 & 1 & 1 \\
& New & 0 & 0 & 3 & 3 & 0 & 3 & 1 & New & $\mathbf{0}$ & 1 & 1 & 0 \\
& & & & $\mathbf{6}$ & 2 & 1 & 0 & 0 & & & $\mathbf{0}$ & 1 & 0 \\
& & & & $\mathbf{5}$ & 1 & 0 & 0 & & & & & $\mathbf{0}$ & 1 \\
0
\end{tabular}

April May June Sept. Oct. Nov. Dec.

March June July Aug. 
Table 23. Estimates of total number of hatchling $A$. tuberculata at high and low altitude in 1973. N, computed by $\mathrm{N}_{t}=\mathrm{N}_{0} e^{i t}$ (Krebs, 1972), starting population size. $\mathrm{N}_{t}=$ population at time $t . t=$ time (period of time being considered expressesd as a fraction of time-period used to calculate $i$, $i=$ instantaneous mortality rate $=\log _{c}$, (finite survival rate).

High altitude.- based on 47 day period from 14 Oct.30 Nov. Finite mortality rate $=0.50$; therefore, $\bar{x}=-0.69$.

\begin{tabular}{lrrr} 
Capture date & N, & \multicolumn{1}{c}{$t$} & $N_{0}$ \\
20 September & 1 & $7 / 47$ & 1 \\
20 September & 2 & $10.5 / 47$ & 2 \\
14 October & 6 & $12 / 47$ & 7 \\
30 November & 17 & $23.5 / 47$ & 24 \\
& & Total & 34
\end{tabular}

Low altitude.-based on 24 day period from 21 Sept.5 Oct. Finite mortality rate $=0.67$; therefore, $\bar{x}=-1.10$

\begin{tabular}{lrrr} 
Capture date & N & \multicolumn{1}{c}{$t$} & $N_{0}$ \\
12 September & 3 & $7 / 24$ & 4 \\
12 September & 6 & $44.5 / 24$ & 46 \\
21 September & 3 & $4.5 / 24$ & 4 \\
25 November & 2 & $20.5 / 24$ & 5 \\
& & Total & 59
\end{tabular}

Low altitude.- based on 33 day period from 12 Sept.5 Oct. Finite mortality rate $=0.67$, therefore $\bar{x}=-1.10$

\begin{tabular}{lrrr}
\hline Capture date & $N_{t}$ & $t$ & $N_{0}$ \\
\hline 12 September & 3 & $7 / 33$ & 4 \\
12 September & 6 & $44.5 / 33$ & 26 \\
21 September & 3 & $4.5 / 33$ & 3 \\
25 November & 2 & $20.5 / 33$ & 4 \\
& & Total & 37
\end{tabular}

heads with a larger black gular patch; dark slate back with more conspicuous dorsal cream colored or orangish spots; a more intense orange wash to the chest and belly with larger and more numerous blue spots. Hatchlings and immatures are cryptically marked dorsally and have a reticulated gular pattern.

Males have a significantly longer SVL than females with the degree of difference between the sexes being less at high altitude. However, differences in SVL within each sex at the two altitudes are not significant. At a given altitude. length of the tail relative to SV L is not significantly different for immatures compared with adults but there is a definite trend towards a lower ratio for adults compared to immatures at high altitude. However, lizards at low altitude grow proportionately longer tails compared to a given SVL than the high altitude population. Comparisons of toe length and ratios of SVL to weight also show the high altitude population to be bulkier than the low altitude population.

The rate of growth declines with increasing age in both populations. At high altitude, lizards reach sexual maturity in their second full season of activity (22-24 months); however, females probably do not lay their first clutch until the following season (30-32 months). At low altitude. some individuals may reach sexual maturity at the end of their first full season of activity (16-18 months) but most probably do not make contributions to natality until the following year (20-23 months). Growth rates at the two altitudes are the same. Low altitude populations reach sexual maturity at an earlier age because of a longer activity season and earlier date of hatching.

The proportion of plant material in the lizard's diet increases with age and in the non-monsoon months. Seasonality of food items such as Viburnum berries, Orthoptera, Coleoptera (especially coccinellids), snails, millipedes, and spiders is due to their increased activity or abundance at different months. Increasing herbivory among older individuals may reduce competition and also may help satisfy increased caloric requirements due to larger body size. Smallest lizards have the largest relative volume of food in their stomachs per gram of body weight. The tendency to eat less food during the monsoons, particularly at high altitude. is probably due to increased time spent in thermoregulatory behavior. Diet of hatchlings (particularly at high altitude) tends to be negatively correlated with older lizards regardless of the time of year or altitude. Hatchlings at low altitude appear earlier and have a wider choice of prey items.

Upon emerging from communal roosts and basking for a short period, lizards disperse to their respective areas of activity. Activity during the day is most intense at mid-morning and mid-afternoon. During the monsoon, with decreased amounts of insolation, activity during mid-day is much greater 
Table 24. Reproductive effort of A. tuberculata at high and low altitude from June 1973-June 1974. ${ }^{\text {a estimated }}$ from Fig. 21; bactual counts of enlarging follicles or oviducal eggs; ' observed only 1 or 2 days; dexcludes individuals observed only 1 or 2 days.

\begin{tabular}{|c|c|c|c|c|c|c|c|}
\hline \multicolumn{4}{|c|}{ High Altitude } & \multicolumn{4}{|c|}{ Low Altitude } \\
\hline \multicolumn{2}{|c|}{1973} & \multicolumn{2}{|c|}{1974} & \multicolumn{2}{|c|}{1973} & \multicolumn{2}{|c|}{1974} \\
\hline SVL & Clutch size $^{a}$ & SVL & Clutch size & SVL & Clutch size & SVL & Clutch size \\
\hline 118 & 10 & 117 & 9 & 118 & 10 & 118 & $10^{\mathrm{b}}$ \\
\hline $117^{\mathrm{c}}$ & 9 & 116 & 9 & 117 & 10 & 116 & $10^{\mathrm{b}}$ \\
\hline 114 & 9 & 115 & 9 & $114^{c}$ & 10 & $115^{\mathrm{c}}$ & 10 \\
\hline 113 & 9 & 112 & 9 & 107 & 8 & 111 & 9 \\
\hline $112^{c}$ & 8 & 109 & 8 & 106 & 8 & 110 & $9^{b}$ \\
\hline \multirow[t]{7}{*}{$103^{c}$} & 7 & 104 & 7 & $103^{c}$ & 8 & $105^{\mathrm{c}}$ & 8 \\
\hline & & 104 & 7 & 100 & 7 & 105 & 8 \\
\hline & & 103 & 7 & 97 & 7 & $104^{c}$ & 8 \\
\hline & & & & 96 & 6 & 104 & $6^{b}$ \\
\hline & & & & 96 & 6 & 100 & 7 \\
\hline & & & & & & 98 & 7 \\
\hline & & & & & & $97^{c}$ & 7 \\
\hline Total & 62 & & 75 & & 91 & & 108 \\
\hline Total $^{\mathrm{d}}$ & 38 & & 75 & & 73 & & 75 \\
\hline
\end{tabular}

than during the hot season. Except for hatchlings, basking activity increases sharply in October and November, because adults forage little, or not at all. The duration of activity during the day is also sharply curtailed. The time between emerging from and retiring to roosting crevices is longer for the low altitude lizards. However, during the hot season, and to more limited extent during the monsoons, they are inactive for a longer mid-day period than those at high altitude.

The $\overline{\mathrm{T}}_{h}$ for active lizards at high and low altitude are 33.1 and $34.6^{\circ} \mathrm{C}$ respectively. During the beginning of the monsoon, the $\overline{\mathrm{T}}_{b}$ of the montane population showed a temporary drop, correlated with decreased insolation. Lizards at high altitude raise their body temperatures above ambient to a significantly greater degree than at low altitude. Because of increased cloud cover during the monsoons, lizards engage in increased amounts of basking behavior. As winter approaches, adults and immatures of both populations increase their amount of basking behavior thereby maintaining body temperatures near the pre-monsoon level. High altitude lizards are found in open habitat affording ample opportunity for thermoregulatory behavior.
Most ovulation takes place during the latter part of May and early June at high altitude with egglaying from mid-June until mid-July. Hatchlings appear from early September until late October or early November. Clutch size varies from 5-6 eggs for the first reproductive effort to 9-13 eggs for older females. The breeding season is prolonged at low altitude. From this and other studies, ovulation is judged to occur from April to October with hatchlings appearing from May to November. Clutch size varies from 6-9 eggs for the first reproductive effort to $9-15$ eggs in subsequent years. I found no direct evidence of a second reproductive effort by females. Females at low altitude tend to lay slightly larger clutches than at high altitude for a comparable SVL. Fat bodies of montane lizards are larger ( $\%$ body weight) at all times of the year compared to lowland populations. Large fat bodies facilitate a longer period of hibernation at high altitude. Hatchlings have little or no fat bodies in early December and actively forage throughout the day.

One unit of the display-action-pattern (DAP) for challenge display consists of raising the head in two stages, lowering it in two stages ending in a brief head jerk, and a final pause. Individual lizards 


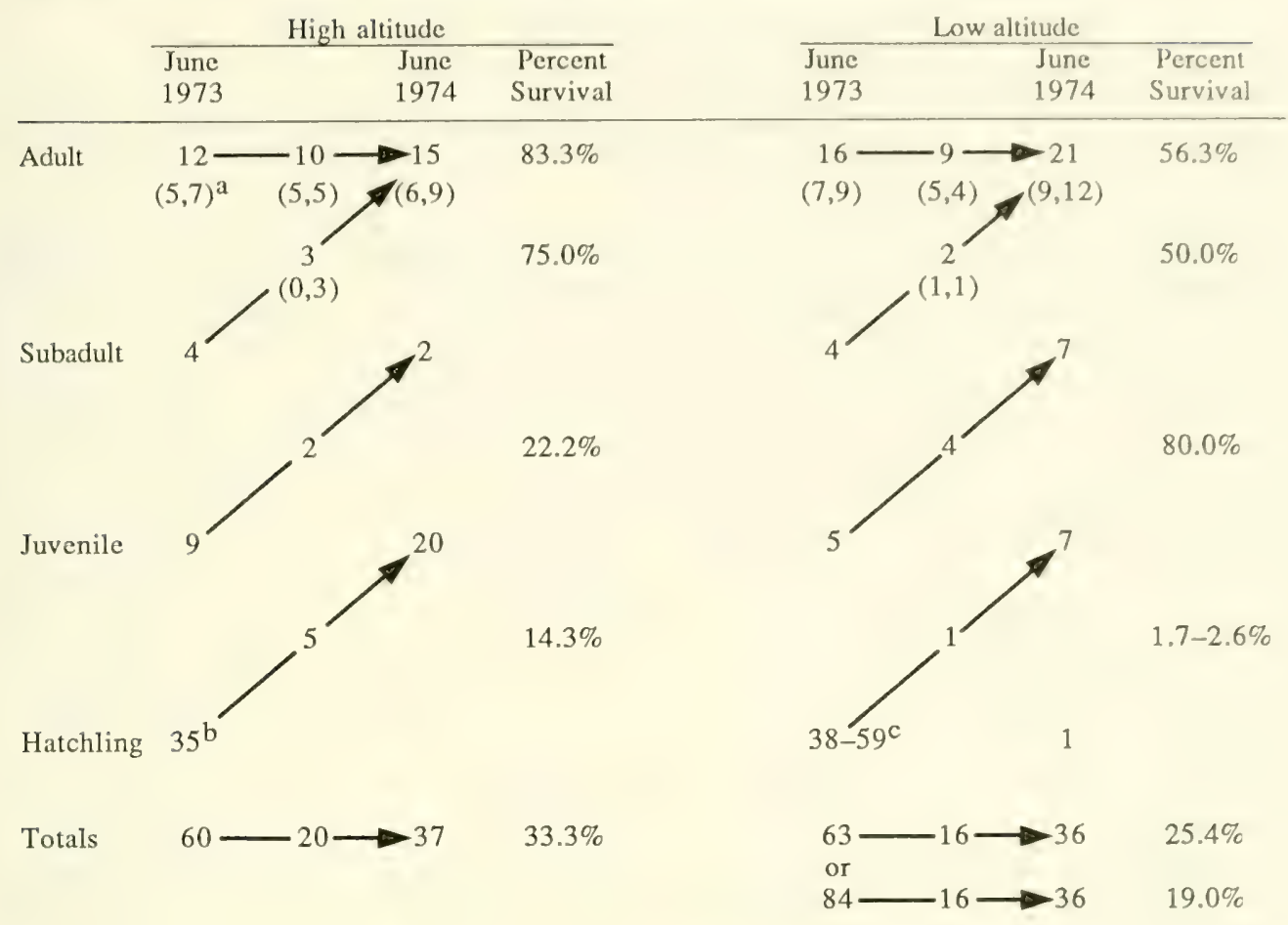

Fig. 37. Percent survivorship of high and low altitude A. tuberculata marked during 1973. Sample size in ( ); a(males, females); ${ }^{b}$ total number estimated to have hatched from late August to early November; ${ }^{c}$ total number estimated to have hatched from mid-June to late September.

varied in the duration of a unit as well as the omission of or timing of subunits.

Territories of adult male rock lizards typically include more than one adult female. As many as ten lizards of all ages disperse from a communal roosting site which may be up to $30 \mathrm{~m}$ from the respective areas of activity. Increased density is not necessarily correlated with a decreased territory or home range.
Survivorship of eggs laid by resident females at high altitude in 1973 was estimated at $94.4 \%$ and at low altitude was $50.7-78.7 \%$. Placement of clutches along the river bank by the latter group probably contributes to their lower survivorship. Populations of A. tuberculata are characterized by declining mortality rates as individuals mature. The reproductive strategy is one of delayed maturity till 2 or 3 years old and laying a single clutch per year. 


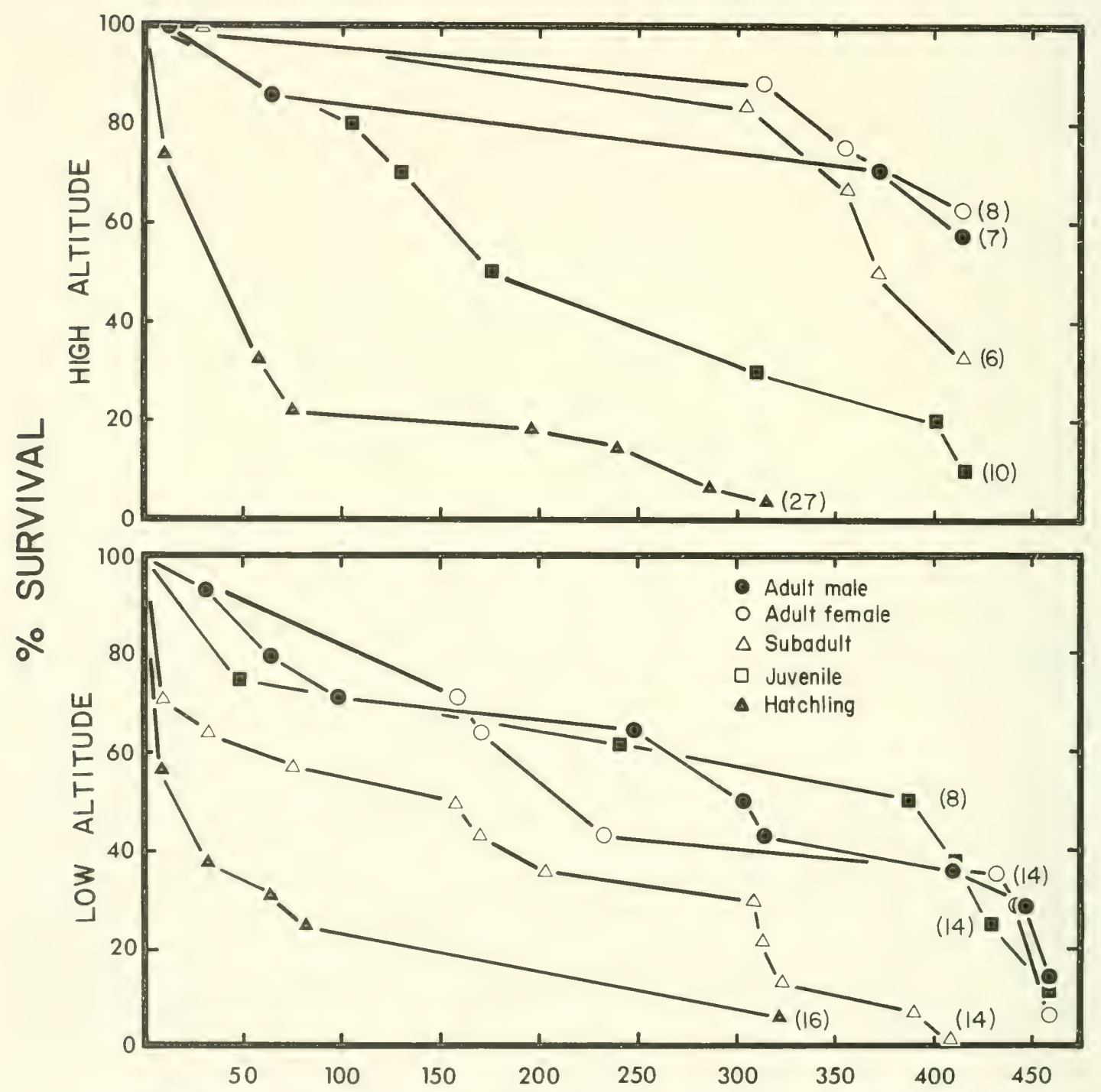

NUMBER OF DAYS AFTER FIRST OBSERVATION

Fig. 38. Survivorship (in days) of high and low altitude A. tuberculata marked during 1973. ( )=sample size. 


\section{LITERA'TURE CITED}

Acharji, M. N.. and M. B. Kripalani. 1952. On a collection of Reptilia and Batrachia from the Kangra and Kulu Valleys, W. Himalayas. Rec. Indian Mus. 49(2):175-184.

Adams, L., AND S. D. Davis. 1969. The internal anatomy of home range. Jour. Mamm. 48(4):529-536.

BALlinger, R. E. 1979. Intraspecific variation in demography and life history of the lizard, Sceloporus jarrovi, along an altitudinal gradient in southeastern Arizona. Ecology 60(5):901-909.

Ballinger, R. E., and R. A. Ballinger. 1979. Food resource utilization during periods of low and high food availability in Sceloporus jarrovi (Sauria, Iguanidae). Southwestern Nat. 24(2):347-364.

Ballinger, R. E.. J. Hawker, and O.J.Sexton. 1969. The effect of photoperiod acclimation on the thermoregulation of the lizard, Sceloporus undulatus. Jour. Expt. Zool. 171(1):43-47.

Ballinger, R. E., K. R. Marion, and O. J. Sexton, 1970. Thermal ecology of the lizard Anolis limifrons with comparative notes on three additional Panamanian anoles. Ecology 51(2):246-254.

Berezhnol, O. A. 1980. Daily activity of Agama sanguinolenta (Reptilia, Sauria) in the southeastern TurkmenSSR, USSR. Vestn Zool. 0(3):71-33. Abstr. only In: Biol. Abstr. 71(9):58430.

Bhatnagar, R. K. 1967. Studies on biology and ecology of common rock lizard (Agama tuberculata Gray)(Reptilia: Agamidae) in the Doon. Cheetal 10(1):39-46.

Bhatangar, R. K. 1968. Studies on biology and ecology of common rock lizard (Agama tuberculata Gray)(Reptilia: Agamidae) in the Doon. Cheetal 10(2):27-37.

Bostic, C. C. 1966. Food and feeding behavior of the teiid lizard, Cnemidophorus hyperythrus beldingi. Herpetologica 22(1):23-31.

Boulenger, G. A. 1890. The Fauna of British India including Ceylon and Burma. Reptilia and Batrachia. Taylor and Francis, London. 541 pp.

Brattstrom, B. H. 1965. Body temperature of reptiles. Am. Midl. Nat. 73(2):376-422.

Brownlee, K. A. 1960. Statistical Theory and Methodology in Science and Engineering. John Wiley and Sons, Inc., New York. 590 pp.

Burt, W. H. 1943. Territoriality and home range concepts as applied to mammals. Jour. Mamm. 24(3):346352.

Bussjaeger, L. J. 1971. Ph.D Dissertation. Phylogenetic significance of the comparative ethology of the spinosus group of Sceloports (Iguanidae). Univ. of Oklahoma. 187 pp.
Capel-Williams, G., and D. Pratin. 1978. The diel of adult and juvenile Agama bibroni (Reptilia: Lacertae) and a study of the jaw mechanism in the two age groups. Jour. Zool. (London) 185(3):3(1)-318.

Carpenter, C. C. 1961 a. Patterns of social behavior of Merriam's canyon lizard (Sceloporus m. meriamiIguanidae). Southwestern Nat. 6(3-4):138-148.

Carpenter. C. C. 1961 b. Patterns of social hehavior in the desert iguana, Dipsosamms dorsalis. Copeia 1961(4):396-405.

Carpenter, C. C. 1962a. Patterns of behavior in two Oklahoma lizards. Am. Midl. Nat. 67(1):132-151.

Carpenter, C. C. 1962b. A comparison of the pattems of display of Urosaurus, Uia, and Streptosaurus. Herpetologica 18(3):145-152.

Carpenter, C. C. 1982. The aggressive displays of iguanine lizards. In: Iguanas of the world. Bunghardt. G.M. and A.S. Rand (eds.) Noyes Publ., New York.

Carpenter, C. C.. and G. Grubitz. III. 1961. Time-motion study of a lizard. Ecology 42(1):199-200.

Champion, H. G.. and S. K. Seth. 1968. A Revised Survey of the Forest Types of India. Govt. of India. Delhi. 404 pp.

Christian, K. A.. And S. Waldschmidt. 1984. The relationship between lizard home range and body size: a reanalysis of the data. Herpetologica 40(1):68-75.

Clark, D.R. 1974. Temperature responses of three Costa Rican lizards (Anolis). Carib. Jour. Sci. 13(3-4):199206.

Clark, D. R., and J. C. Kroll. 1974. Thermal ecology of anoline lizards; temperate versus tropical strategies. Southwestern Nat. 19(1):9-19.

Clarke, R. F. 1965. An ethological study of the iguanid lizard genera Callisaurus, Cophosaurus, and Holbrookia. Emporia State Res. Stud. 13(4):1-66.

Dakshini, K. M. M. 1965. A study of the vegetation of Mothronwala swamp forest. Jour. Indian Bot. Soc. $44(4): 411-428$.

Das, S. M., AND P. L. DudA. 1964. The functional anatomy of the urogenital organs of Agama tuberculata Gray, (The common lizard of Kashmir.) Kash. Sci. 1(1-2)1964:53-64.

DoDsworth. P. T. L. 1913. On the habits of the rock lizard (Agama tuberculata). Jour. Bombay Nat. Hist. Soc. 22(2):404-405.

DuDA, P. L. 1962. Hyoid arch skeleton of Agama tuberculata (Gray). Proc. All-Indian Congr. Zool. 1962(1966): 179-184.

DudA, P. L. 1965a. On the cranial osteology of Agama tuberculata (Gray) with a note on the comparative study of skull in the family Agamidae. Vestn. ceskosl., zool. Spolec. 29:156-174. 
DudA, P. L. 1965b. Studies on the functional morphology of Agama tuberculata Gray. (The common lizard of Kashmir) Part II. The post-cranial skeleton. Kash. Sci. 2(1965):40-57.

DudA, P. L., AND O. Kaul. 1976. Subtunic Leydig cells in the testis of Agama tuberculata (Gray). Brit. Jour. Herpetol. 5(6):539-541.

Dudgeon, W., And L. A. Kenoyer. 1925. The ecology of Tehri Garhwal: a contribution to the ecology of the Western Himalaya. Jour. Indian Bot. Soc. 4(7-8):233285.

Etheridge, K., L. C. Wit, J. C. Sellers, and S. E. TRAuTH. 1986. Seasonal changes in reproductive condition and energy stores in Cnemidophorus sexlineatus. Jour. Herpetol. 20(4):554-559.

Evans, L.T. 1951. Field study of the social behavior of the black lizard Ctenosaurapectinata.Am. Mus. Nov. 1493:1-26.

FERGUSON, G. W. 1971. Variation and evolution of the push-up displays of the side-blotched lizard genus Uta (Iguanidae). Syst. Zool. 20(1):79-101.

Ferguson, G. W. 1976. Color change and reproductive cycling in female collared lizards (Crotaphytus collaris). Copeia 1976:491-494.

Fitch, H. S. 1940. A field study of the growth and behavior of the fence lizard. Univ. California Publ. Zool. 44(2):151-172.

Fitch, H. S. 1949. Study of snake populations in central California. Am. Midl. Nat. 41(3):513-519.

Frrch, H. S. 1954. Life history and ecology of the fivelined skink, Eumeces fasciatus. Univ. Kansas Pub. Mus. Nat. Hist. 8(1):1-156.

Fitch, H. S. 1970. Reproductive cycles in lizards and snakes. Univ. Kansas Mus. Nat. Hist. Misc. Pub. 52:1-247.

Fitch, H. S. 1973. Population structure and survivorship in some Costa Rican lizards. Univ. Kansas Mus. Nat. Hist. Occ. Pap. 18:1-41.

Fleming, JR, R. L. 1967. Ph.D Dissertation. The birds of Mussoorie, U.P., India-a distributional and ecological study. Michigan State Univ. 246 pp.

Fuentes, E. R., And F. M. JaKsic. 1979. Activity temperatures of eight Liolaemus (Iguanidae) species in central Chile. Copeia 1979(3):546-548.

GoldBerg, S. R. 1972. Seasonal weight and cytological changes in the fat bodies and liver of the iguanid lizard Sceloporus jarrovi Cope. Copeia 1970(4):227232.

Goldberg, S. R. 1974. Reproduction in mountain and lowland populations of the lizard Sceloporus occidentalis. Copeia 1974(1):176-182.

GoldBerg, S. R. 1976. Reproduction in a mountain population of the coastal whiptail lizard, Cnemidophorustigrismultiscutatus. Copeia 1976:260-266.

Greenberg. B.. And G. K. Noble. 1944. Social behavior of the American chameleon (Anolis carolinensis Voigt). Physiol. Zool. 17(4):392-439.

Gruber, U. 1981. Notes on the herpetofauna of Kashmir and Ladakh. Brit. Jour. Herpetol. 6:145-150.

Guillette, JR., L. J.. And G. Casas-Andreu. 1981. Seasonal variation in fat body weights in the Mexican high elevation lizard Sceloporus grammicus microlepidotus. Jour. Herpetol. 15(3):366-371.

Guillette, JR., L. J., And G. Casas-Andreu. 1987. The reproductive biology of the high elevation Mexican lizard Barisia imbricata. Herpetologica 43(1):29-38.

Gunther, A. 1860. Contributions to a knowledge of the reptiles of the Himalaya mountains. Proc. Zool. Soc. London 1860: 148-175.

GuptA, R. K. 1967. Seasonal Flowers of the Indian Summer Resorts: Mussoorie hills. Navayug Traders, New Delhi. 287 pp.

Hahn, W. E., And D. W. Tinkle. 1965. Fat body cycling and experimental evidence for its adaptive significance to ovarian follicle development in the lizard Uta stansburiana. Jour. Expt. Zool. 158(1):79-86.

Hardwicke, T., And J. E. Gray. 1827. A synopsis of the species of saurian reptiles, collected in India by Major-General Hardwicke. Zool. Jour: 3:213-229.

HARris, V. A. 1964. The Life of the Rainbow Lizard. Hutchinson Tropical Monographs. Hutchinson and Co., Ltd., London. 174 pp.

Hertz, P. E. 1981. Adaptation to altitude in two West Indian anoles (Reptilia: Iguanidae): field thermal biology and physiological ecology. Jour. Zool. (London) 195:25-37.

Hertz, P. E., And R. B. Huey. 1981. Compensations for altitudinal changes in the thermal environment by some Anolis lizards on Hispaniola. Ecology 62(3):515-521.

Heulin, B. 1985. Maturité sexuelle et âge à la première reproduction dans une population de plaine de Lacerta vivipara. Canadian Jour. Zool. 63:1773-1777.

Hipp, T. G. 1977. M.A. Thesis. Reproductive cycle and correlated hematological characteristics in Crotaphytus collaris in west central Texas. Angelo State Univ., San Angelo, Texas.

Huey, R. B.. And E. R. PiankA. 1977. Seasonal variation in thermoregulatory behavior and body temperature of diurnal Kalahari lizards. Ecology 58(5):10661075 .

HunSAKER II, D. 1962. Ethological isolating mechanisms in the Sceloportus torquatus group of lizards. Evolution 16(1):62-74.

J ACKSON. D. R.. AND S. R. TELFORD, 1975. Food habits and predatory role of the Japanese lacertid Takydromus tachydromoides. Copeia 1975(2):343-351.

JAMESON, JR., E. W. 1974. Fat and breeding cycles in a montane population of Sceloporus graciosus. Jour. Herpetol. 8(4):311-322. 
JAMESON, JR., E. W., ANd A. Alilison. 1976. Fat and breeding cycles in two montane populations of Sceloporus occidentalis (Reptilia, Lacertilia, Iguanidac). Jour. Herpetol. 10(3):211-220.

JAMESON, JR., E. W., A. A. HEusner, AND D. LEM. $198($ ). Seasonal, sexual and altitudinal variations in stomach content and ingested fat in Sceloporus occidentalis. Jour. Herpetol. 14(3):255-262.

JENnRICH, R. I., AND F. B. TuRnER. 1969. Measurement of non-circular home range. Jour. Theoret. Biol. 22(2):227-237.

Jenssen, T. A. 1971. Display analysis of Anolis nebulosis (Sauria, Iguanidae). Copeia 1971(2):197-209.

Johnson, D. R. 1966. Diet and estimated energy assimilation of three Colorado lizards. Am. MidI. Nat. 76(2):504-509.

Koul, O., And P. L. DudA. 1977. Ovarian cycle in high altitude lizards from Kashmir. Copeia 1977(4):751754.

KozlowskA, M. 1971. Differences in the reproductive biology of mountain and lowland common frogs, Rana temporaria L. Acta Biologica Crac. 14(1):1732.

Krebs, C. J. 1972. Ecology: The Experimental Analysis of Distribution and Abundance. Harper and Row, Inc., New York. 694 pp.

Krishnan, M. S. 1960. Geology of India and Burma. 4th ed. Higginbothams Lid., Madras, 604 pp.

LEgris, P. 1963. La Végetation de l'Inde: Ecologie et Flore. Inst. fr. Pondichery, Trav. Sec. sci, tech. 6:1596.

LINDSEY, C. C. 1966. Body sizes of poikilotherm vertebrates at different latitudes. Evolution 20(4):456465.

MAYhew, W. W. 1963. Temperature preferences of Sceloporus orcutti. Herpetologica 18(4):217-233.

Mayhew, W. W. 1964. Photoperiodic responses in three species of the lizard genus Uma. Herpetologica 20(2):95-113.

McCoy, C. J., And G. A. Hoddenbach. 1966. Geographic variation in ovarian cycles and clutch size in Cnemidophorustigris (Teiidae). Science 154:1671-1672.

McKinny, C. O. 1971. Individual and intrapopulational variation in the push-up display of Uta stansburiana. Copeia 1971(1):159-160.

Melkumyan. L. S. 1983a. Information about the increase of duration of life and the decrease of fertility of striped lizard (Lacerta strigata) with its transition from plain to highlands. Uchenye Zap, erevan. gos. Univ. 1983 (2):17 I-172. Title only in Zool. Record $120(17)$.

Melkumyan, L. S. 1983b. Fecundity decrease in the lizard Lacerta strigata occurring while the passage of the species from plain to the high mountains. Ékologiya, Sverdlovsk 14(3):90-92. Title only in
Zool. Record 120(17).

Minton, S. A. 1966. A contribution to the herpetology of West Pakistan. Bull. Am. Mus. Nat. Hist. 134(2):1 184.

Monks, S. P. 1881. A partial biography of the green lizard. Am. Nat. 15(1):96-99.

Mount, R. H. 1963. The natural history of the red-lailed skink, Eumeces egregius Baird. Am. Midl. Nat. $70(2): 356-385$

Noble, G. K. 1934. Experimenting with courtship in lizards. Nat. Hist. 34( 1):3-15

Noble, G. K., and H. TEale. 1930. The courtship of some iguanid and teiid lizards. Copeia 1930(2):54-56

Noble, G. K., And H. T. Bradley. 1933. The mating behavior of lizards: its bearing on the theory of sexual selection. Ann. New York Acad. Sci. 35(1):25-100)

Ortega, A. 1986. Fat body cycles in a montane population of Sceloporus grammicus. Jour. Herpetol 20(1):104-108

Ortega, A., And R. Barbault. 1986. Reproduction in the high elevation Mexican lizard Sceloporus scalaris Jour. Herpetol. 20(1):111-114.

PARSHAD, B. 1914. Lizards of the Simla Hill states. Rec. Indian Mus, 10(4):367-369.

Paulissen, M. A. 1987. Optimal foraging and intraspecific diet differences in the lizard Cnemidophorus sexlineatus. Oecologia 71:439-446.

PEARL, R. 1928. The Rate of Living. Knopf, New York. $185 \mathrm{pp}$.

PEARSON, O. P. 1954. Habits of the lizard Liolaemus multiformis multiformis at high altitudes in southern Peru. Copeia 1954(2):111-116.

Pearson. O. P.. and D. F. Bradford. 1976. Thermoregulation of lizards and toads at high altitudes in Peru. Copeia 1976(1):155-170.

Péfaur, J. E., And W. E. Duellian. 1980. Community structure in high Andean herpetofaunas. Trans. Kansas Acad. Sci. 83(2):45-65

PIANKA, E. R. 1969. Sympatry of desert lizards (Ctenotus) in Western Australia. Ecology 50(6):1012-1030.

PIANKA, E. R. 1970. Comparative autecology of the lizard Cnemidophorus tigris in different parts of its range. Ecology 51(4):703-720.

Pianka, E. R., And W. S. Parker. 1972. Ecology of the iguanid lizard Callisamus draconoides. Copeia 1972(3):493-508.

Pough, F. H. 1973. Lizard energetics and diet. Ecology 54(4):837-844.

PuRI, G. S. 1960. Indian Forest Ecology. Vols. I-II. Oxford Book and Stationery Co., New Delhi. 710 pp.

RaINA, M. K., ANd P. L. DUdA. 1967. A pulmo-portal vein. an abnormality in Agama tuberculata (Gray). Herpetologica 23(1):64.

RAND, A. S. 1964. Ecological distribution in anoline lizards of Puerto Rico. Ecology 45(4):745-752. 
RAY, C. 1960. The application of Bergmann's and Allen's rules to poikilotherms. Jour. Morph. 106(1):85-108.

Rose, B. 1982. Lizard home ranges: methodology and functions. Jour. Herpetol. 16(3):253-269.

Ruby, D. E., And A. E. Dunham. 1984. A population analysis of the ovoviviparous lizard Sceloporus jarrovi in the Pinaleño mountains of southeastern Arizona. Herpetologica 40(4):425-436.

Ruibal, R., ANd F. Philibosin. 1970. Eurythermy and niche expansion in lizards. Copeia 1974(4):645-653.

Saint Girons, H., And R. Duguy. 1970. Le cycle sexuel de Lacerta muralis L. en plaine et en montagne. Bull. Mus. Nat. D'Hist. Natur. 42(4):609-625.

Schoener, T. W. 1971. Theory of feeding strategies. In: R.F. Johnston, P.W. Frank, and C.D. Michner (eds.), Ann. Review Ecology and Syst. 2:369-404. Ann. Rev. Inc., Palo Alto, California.

Schoener, T. W., and G. C. Gorman. 1968. Some niche differences in three Lesser Antillean lizards of the genus Anolis. Evolution 49(5):819-830.

SChweInfurth, U. 1957. Die horizontale und vertikale Verbreitung der Vegetation in Himalaya. Bonner geographische Abhandlungen 20:1-372.

Smith, M. A. 1935. The Fauna of British India. Reptilia and Amphibia. Vol. 2. Sauria. Taylor and Francis, Ltd., London. 440 pp.

Sokal, R. R., And F. J. Rohlf. 1969. Biometry. W.H. Freeman and Co., San Francisco. 776 pp.

SoKol, O. M. 1967. Herbivory in lizards. Evolution 21(1):192-194.

Stevens, T. P. 1983. Reproduction in an upper elevation population of Cnemidophorus inornatus (Reptilia, Teiidae). Southwestern Nat. 28(1):9-20.

StoliczKa, P. 1872. Notes on new or little-known Indian lizards. Jour. Asiatic Soc. Bengal 41(2):86-135.

TELFORD, S. R. 1969. The ovarian cycle, reproductive potential, and structure in a population of the Japanese lacertid Takydromus tachdromoides. Copeia 1969(3):548-567.

TElford, S. R. 1970. Seasonal fluctuations in liver and fat body weights of the Japanese lacertid Takydromus tachydromoides Schlegel. Copeia 1970(4):681-688.

TinkLe, D. W. 1967. Life and demography of the sideblotched lizard Uta stansburiana. Misc. Publ. Mus. Zool., Univ. Michigan 132:1-182.

Tinkle, D. W., And R. E. Ballinger. 1972. Sceloporus undulatus: a study of the intraspecific comparative demography of a lizard. Ecology 53(4):570-584.

Tinkle, D. W., H. M. Wilbur, and S. G. Tilley. 1970. Evolutionary strategies in lizard reproduction. Evolution 24(1):55-74.

TrOYER, K. 1984. Diet selection and digestion in Iguana iguana: The importance of age and nutrient requirements. Oecologia 61:201-207.

VITT, L. J. 1977. Observations on clutch and egg size and evidence for multiple clutches in some lizards of southwestern United States. Herpetologica 33(3):333-338.

WADIA, D. N. 1953. Geology of India. 3rd ed. Macmillan and Co., Ltd., London. 531 pp.

Waltner, R. C. 1978. Ph.D Dissertation. Comparative ecology of Agama tuberculata Gray at different altitudes in the western Himalayas. Univ. of Kansas. 272 pp.

Yadgarov, T. 1974. Ecology of the Turkestan agama from the basin of the Surkhandar'ya. Soviet Jour. Ecol. 75(4):382-383. Transl. from Ékolgiya 4:9697(1974). 
Herp

QL666.L223 W2 1991

Altitudinal ecology of Agama tubere

Harvard MCZ Library AKL1038

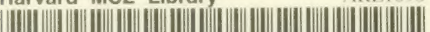

32044062405998 
69. The Eleutherodac dae). By John D. bound.

70. Sexual size differ Paper bound.

71. Late Pleistocene 8 May 1981. Pap

72. Leptodactylid fro jacent Colombia.

73. Type and figured Museum of Natur and R. W. Coldir

74. Relationships of $\mathrm{p}$ By Lawrence R. I

75. The taxonomy an Duellman and Marinus S. Hoogmoed. Pp. 1-39, 30 figures. 1 March 1984. Paper bound.

76. Variation in clutch and litter size in New World reptiles. By Henry S. Fitch. Pp. 1-76, 15 figures. 24 May 1985. Paper bound.

77. Type and figured specimens of fossil vertebrates in the collection of The University of Kansas Museum of Natural History. Part II. Fossil amphibians and reptiles. By H.-P. Schultze, L. Hunt, J. Chorn and A. M. Neuner. Pp. 1-66. 3 December 1985. Paper bound.

78. Type and figured specimens of fossil vertebrates in the collection of The University of Kansas Museum of Natural History. Part III. Fossil birds. By John F. Neas and Marion Anne Jenkinson. Pp. 1-14. 5 February 1986. Paper bound.

79. Type and figured specimens of fossil vertebrates in the collection of The University of Kansas Museum of Natural History. Part IV. Fossil mammals. By Gregg E. Ostrander, Assefa Mebrate and Robert W. Wilson. Pp. 1-83. 21 November 1986. Paper bound.

80. Phylogenetic studies of North American minnows, with emphasis on the genus Cyprinella (Teleostei: Cypriniformes). By Richard L. Mayden. Pp. 1-189, 85 figures, 4 color plates. 1 June 1989. Paper bound. ISBN: 0-89338-029-6.

81. A phylogenetic analysis and taxonomy of iguanian lizards (Reptilia: Squamata). By Darrel R. Frost and Richard Etheridge. Pp. 1-65, 24 figures, 3 appendices. 28 September 1989. Paper bound. ISBN: 0-89338-033-4.

82. Bats of Portugal: zoogeography and systematics. By Jorge M. Palmeirim. Pp. 1-53, 39 figures, 24 tables, 1 appendix. 15 March 1990. Paper bound. ISBN: 0-89338-034-2. 
